2. To: (Receiving organization)

Distribution

5. Proj./Prog./Dept./Div.:

W-320 TWRS/TCPN \# D2991.

8. Originator Remarks:

For approval and release of a new supporting document. This document has been generated to ensure retrievability of the Project $W-320$ "Construction Specification $W-320-C 7$ ".
11. Receiver Remarks:
11A. Design Basel ine Document?
[X] Yes
[] No

6. Design Authority/ Design Agent/Cog. Engr.:

JW Bailey, NHC

\section{3rom: (Originating Organization)}

9. Equip./Component No.:

10. System/Bldg./Facility: 241-C-106

12. Major Assm. Dwg. No.:

$n / a$

13. Permit/Permit Application Ho.: $\mathrm{n} / \mathrm{a}$

14. Required Response Date:

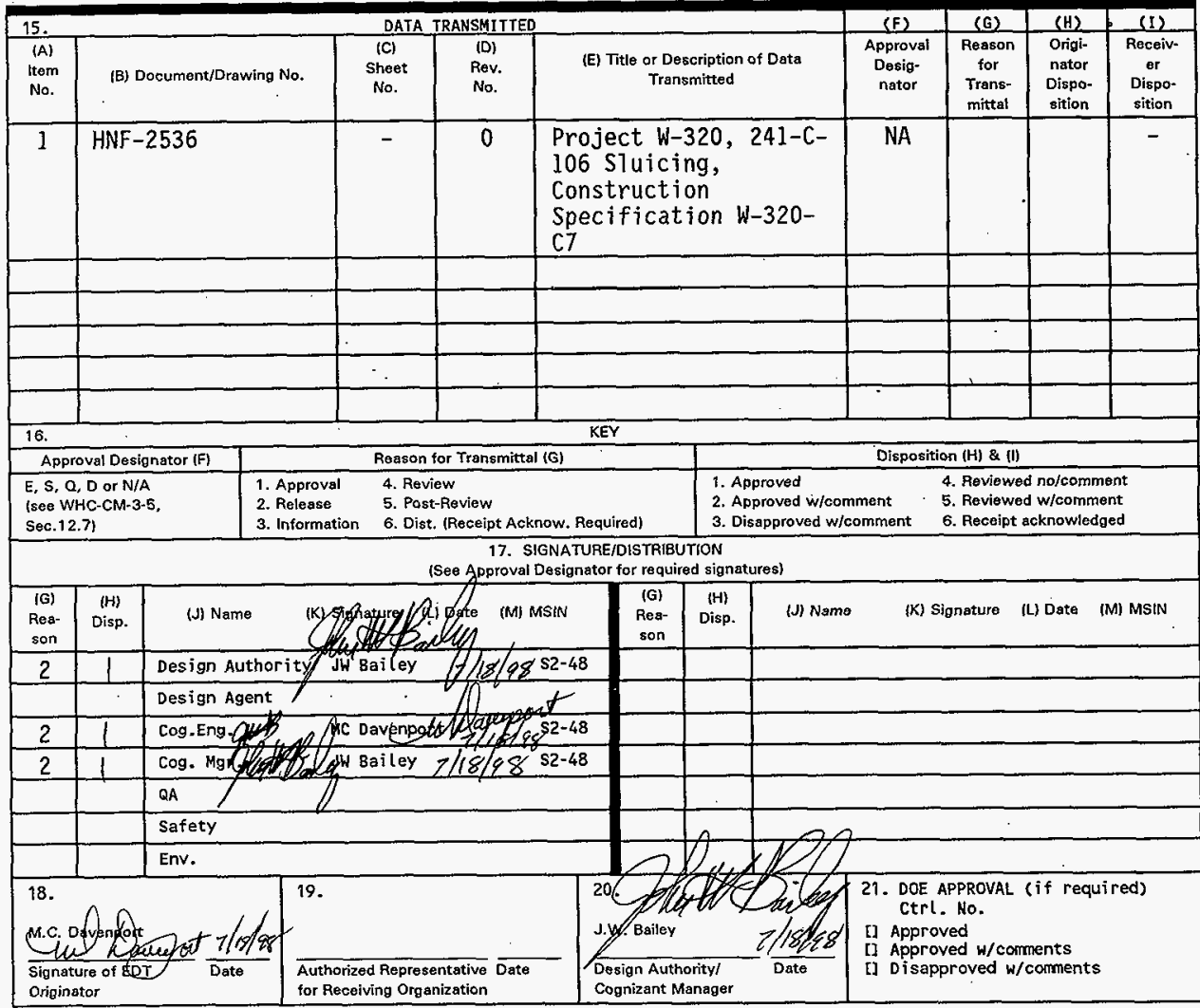




\section{Project W-320, 241-C-106 Sluicing, Construction Specification, W-320-C7}

John W. Bailey

Numatec Hanford Co., Richland, WA 99352

U.S. Department of Energy Contract DE-AC09-96RL13200

EDT/ECN: 622270

Org Code: $8 \mathrm{C} 452$

B\&R Code: EW3130010

UC: 506

Charge Code: D2991/HANA0600

Key Words: W-320, Sluicing, Tank 241-C-106, Tank 241-AY-102, WRSS, Specifications, Construction.

Abstract: This supporting document has been prepared to make the construction specifications for Project $W-320$, readily available.

TRADEMARK DISCLAIMER. Reference herein to any specific comercial product, pracess, or service by trade name, trademark, manufacturer, or otherwise, does not necessarily constitute or imply its endorsement, recommendation, or favoring by the United states Government or any agency thereof or its contractors or subcontractors.

Printed in the United States of America. To obtain copies of this document, contact: Document Control Services, P.0. Box 950, Mailstop H6-08, Richland WA 99352, Phone (509) 372-2420;

Fax (509) 376-4989.
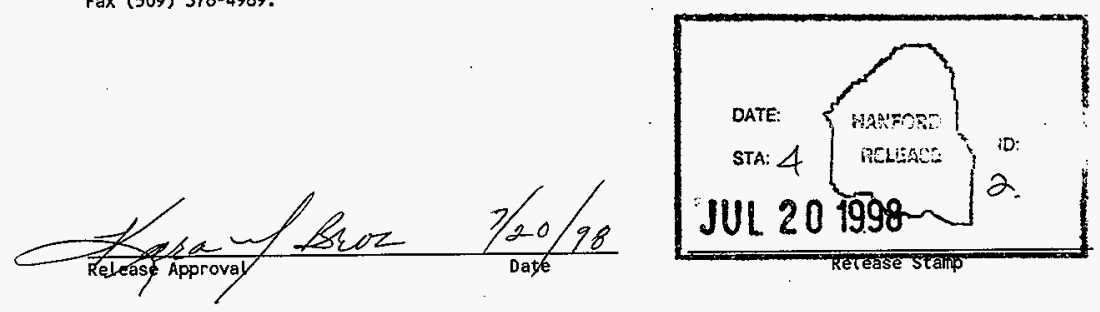

\section{Approved for Public Release}




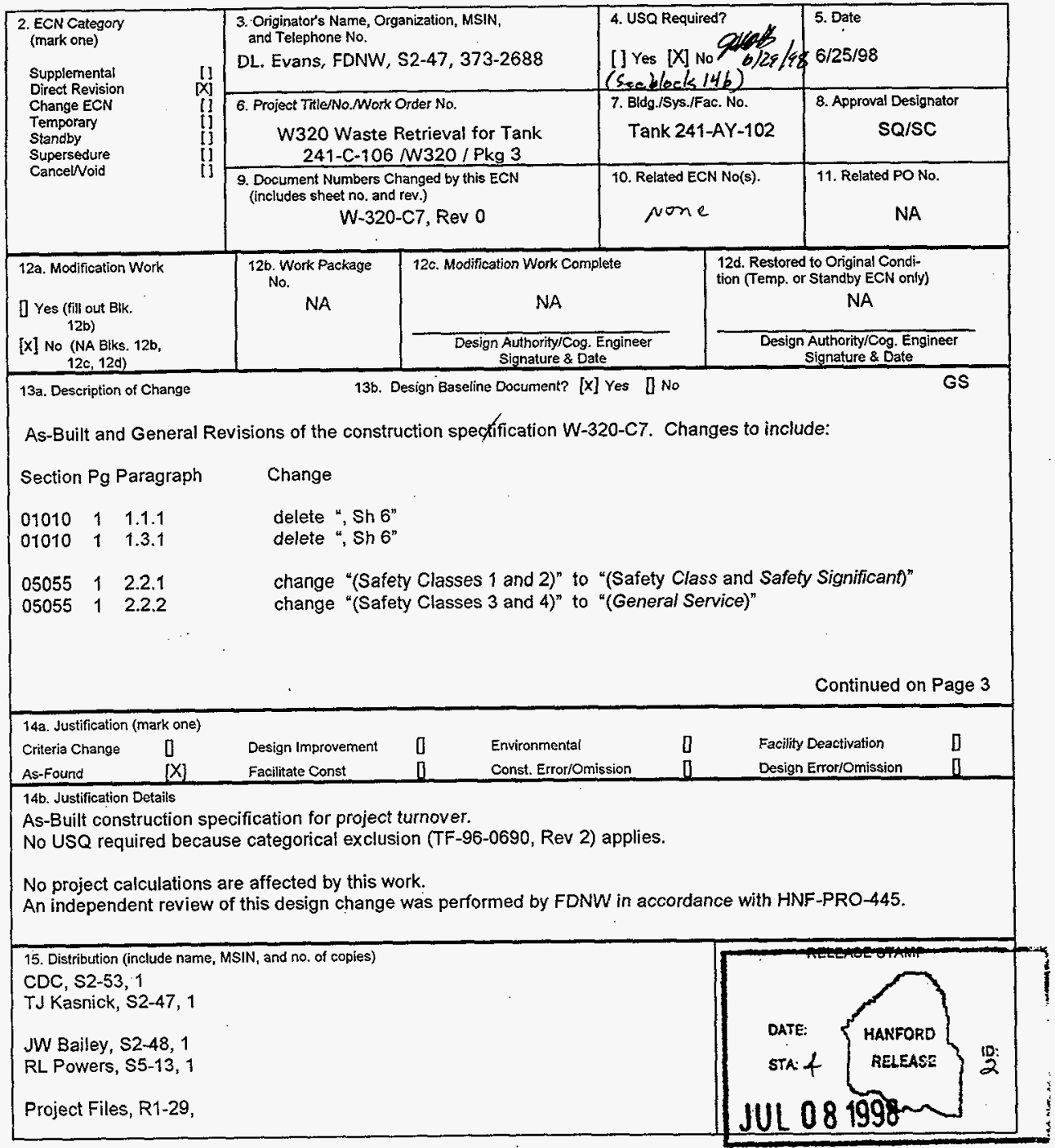




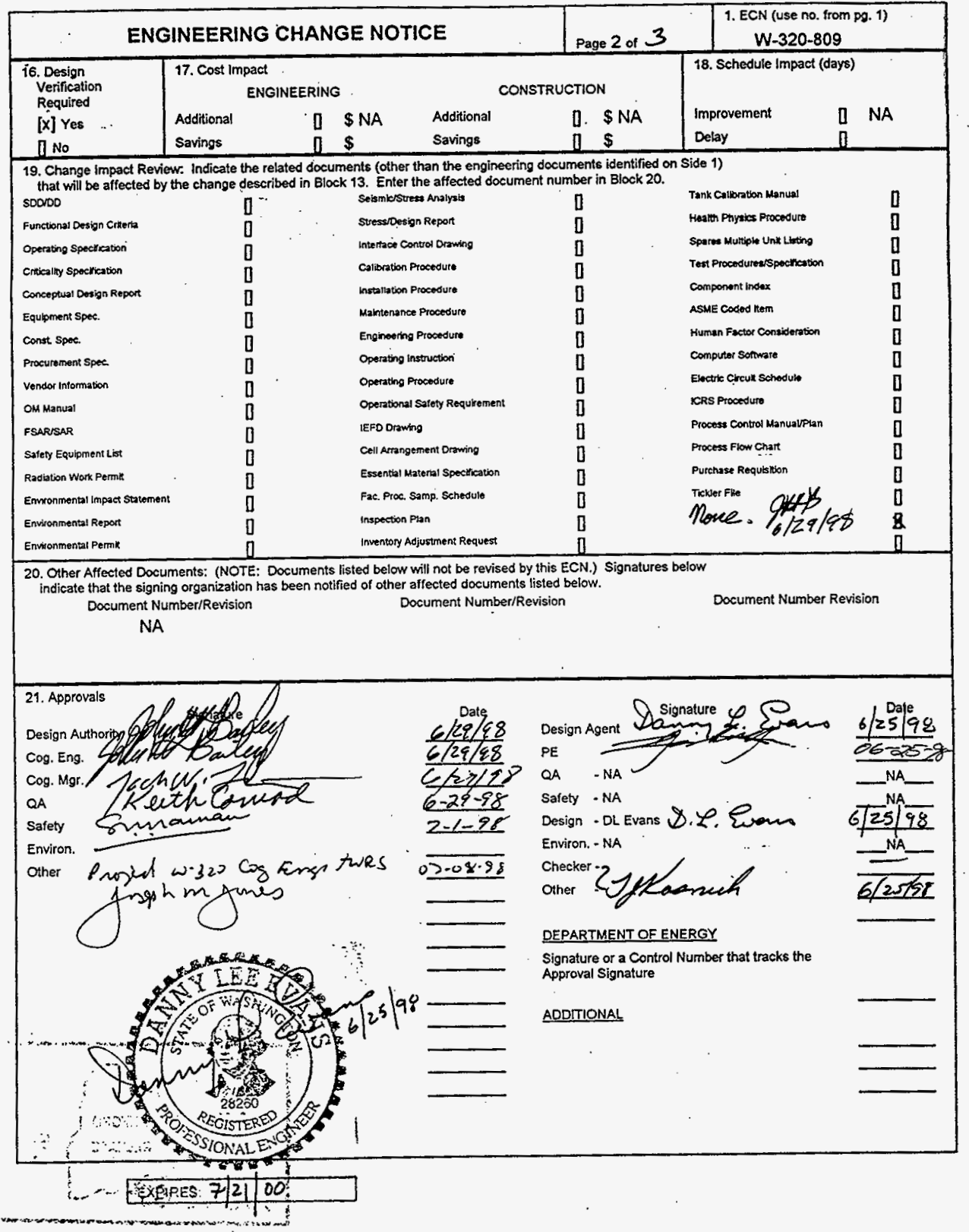

HNF-2536, Rev, 0 Page ii 


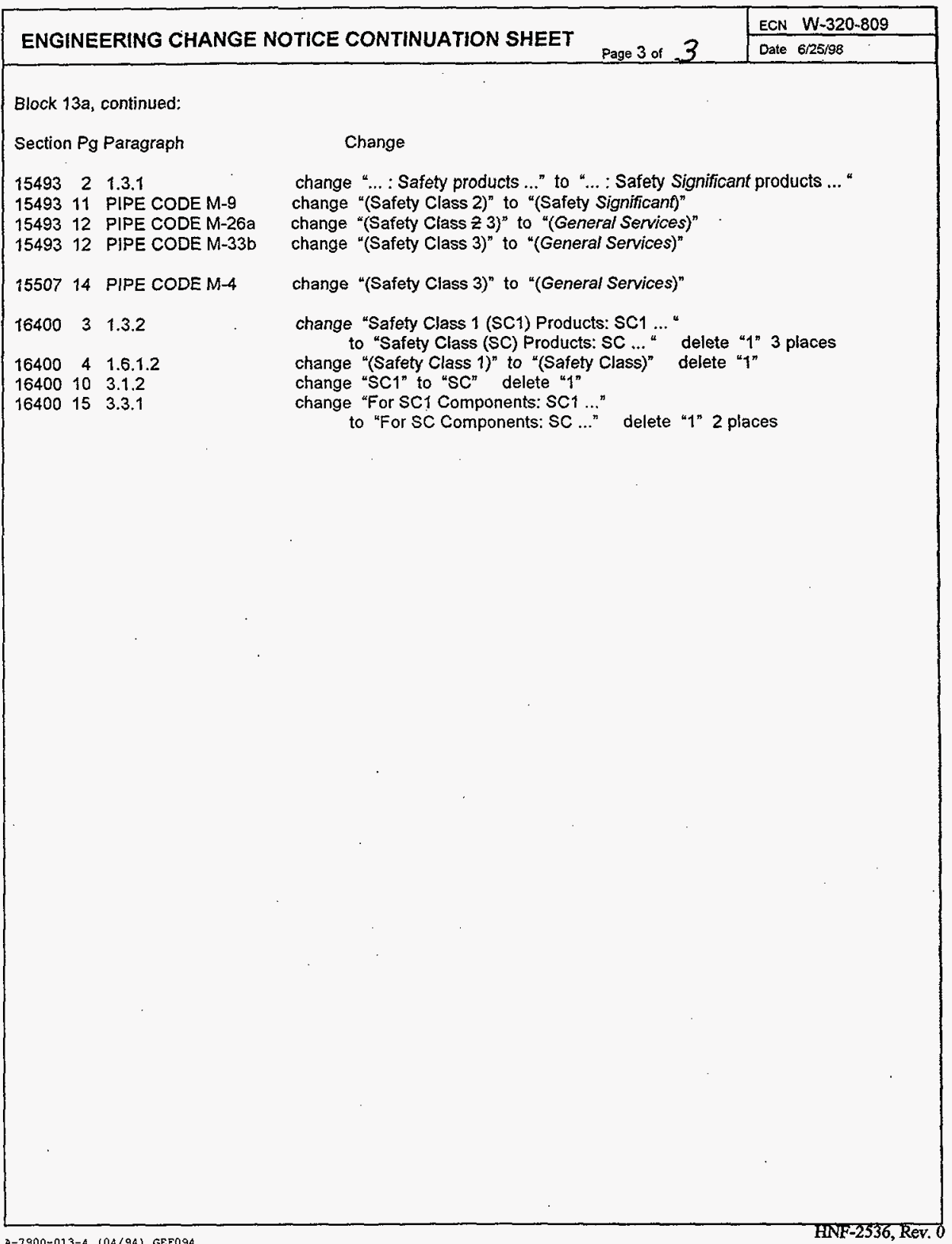




\section{AS-BUILT REV 1}

\section{TANK 241-C-106 SLUICING}

AY TANK FARK

Original Issue: $08 / 30 / 95$

\section{Prepared By}

Fluor Daniel Northwest

Rich7and, Washington

For.

Numatec Hanford Corporation

Contract 651005
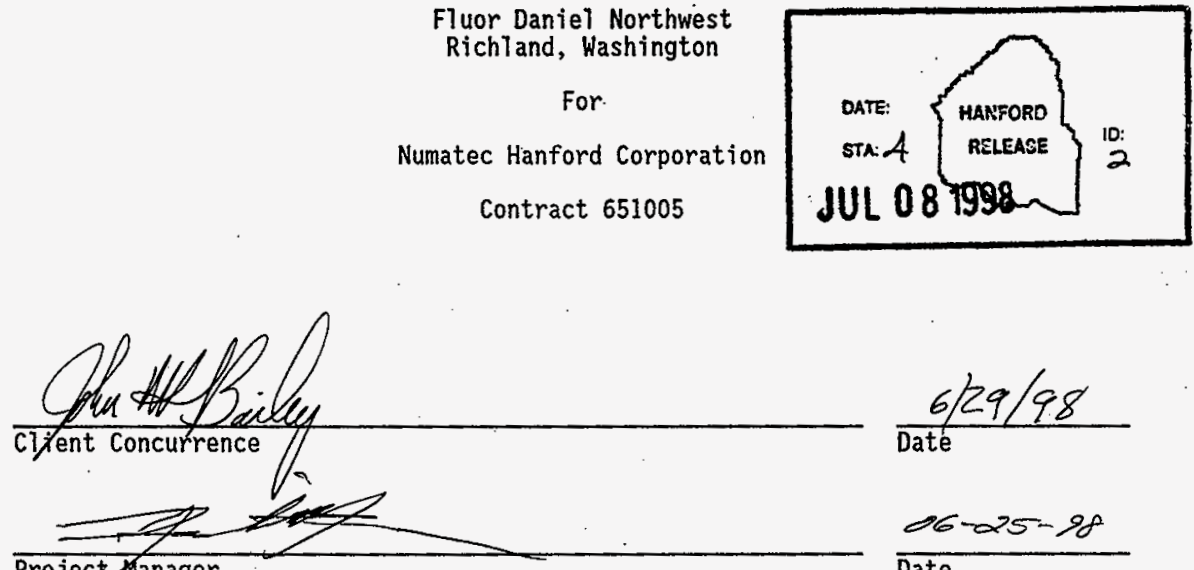

Project rianager

$\frac{-66-25-98}{\text { Date }}$
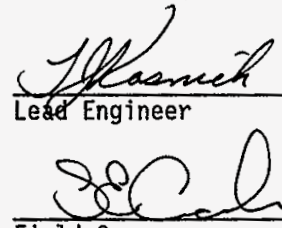

Fieid Concurrence
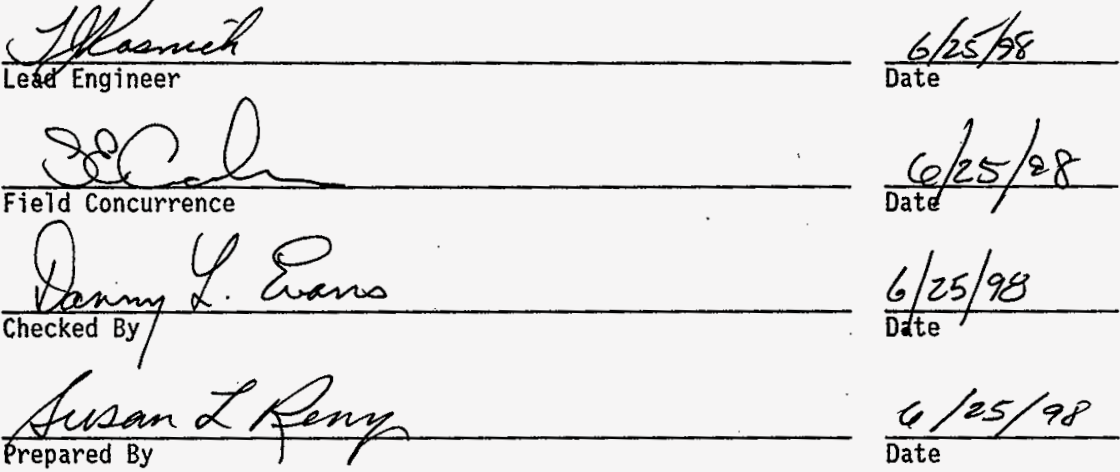

$\frac{6 / 25 / 98}{\text { Date }}$

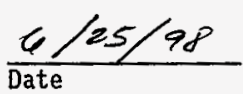

The ECNs affecting specification page attached. 


\section{RECORD OF REVISION}

(2) Title

Tank 241-C-106 Sluicing AY Tank Farm

CHANGE COHTROL RECORO

\begin{tabular}{|c|c|c|c|}
\hline \multirow{2}{*}{$\begin{array}{c}(3) \\
\text { Revision }\end{array}$} & \multirow{2}{*}{ (4) Description of Change - Replace, Add, and Delete Pages } & \multicolumn{2}{|c|}{ Authorized for Release } \\
\hline & & (5) Cog. Engr. & (6) Cog. Mgr. Date \\
\hline 0 & W-320-C7, Rev. O, EDT 606537 & $N / A$ & N/A \\
\hline 1 RS. & $\begin{array}{l}\text { W-320-C7, Rev. 1, As-Built per ECN W-320-809 } \\
\text { includes incorporation of the following ECNs: } \\
\text { H-320-113,-116,-117,-121, -123,-128, } \\
-138,-150,-166,-167,-170,-173,-197, \\
-200,-201,-203,-205,-290,-294,-335, \\
-347,-419,-441,-454,-458,-499,-525, \\
-548,-588,-597,-601,-662,-748,-809 \text {. }\end{array}$ & $\begin{array}{l}\text { DL Evans } \\
\text { D. Evans }\end{array}$ & MA Lane \\
\hline & & & \\
\hline & & & \\
\hline & & & \\
\hline & & & \\
\hline & & & \\
\hline & & & \\
\hline & & & \\
\hline & & & \\
\hline & & & \\
\hline & & & \\
\hline & & & \\
\hline & & & \\
\hline & & & \\
\hline & & & \\
\hline & & & \\
\hline & & & \\
\hline & & & \\
\hline & & & \\
\hline & & & \\
\hline & & & \\
\hline & & & \\
\hline & & & \\
\hline & & & \\
\hline & & & \\
\hline & & & \\
\hline & & & \\
\hline
\end{tabular}


The ECNs affecting specification are as follows:

ECN W-320-113

15493-5

ECN $\mathrm{W}-320-116$

15493-1, 2, 7, 9, 11, 12

ECN W-320-117

$03400-1,2,3,4,5,7$

ECN $\mathrm{H}-320-121$

$16640-5,7,8$

ECN $W-320-123$

$03300-1,2,5$

ECN $\mathrm{W}-320-128$

$13440-6,10,11,17,19$, $20,23,24$

ECN W-320-138

$05500-1,3$

ECN $W-320-150$

$16640-6$

ECN W-320-166

$13440-7,10,24$

ECN $W-320-167$

$01300-2$

$16400-7,9,10,17$

$\frac{E C N ~}{0-320-170}$

ECN W-320-173

09900-5

ECN W-320-197 $15507-6$
ECN $W-320-200$

$13440-16,17,18$

ECN W-320-201

15493-8

ECN H-320-203

15507-11

ECN W-320-205

15493-12

ECN $N-320-281$

03300-3

ECN W-320-290

$03300-2,3,7$

ECN W-320-294

15493-12

ECN W-320-335

15493-3

15507-6

ECN $\mathrm{H}-320-347$

15493-7, 9

ECN W-320-419

16400-16

ECN $\mathrm{H}-320-441$

15493-7, 9

ECN W-320-454

15493-9

ECN W-320-458

$13440-2$
ECN W-320-499

15507-6, 11

ECN $W-320-525$

16640-6

ECN W-320-548

$02200-2,3,4$

02225-2, 3, 5

09900-5

15507-15

ECN $\mathrm{H}-320-588$

$15507-4,5$

ECN W-320-597

05500-2

16640-2

ECN W-320-601

13440-3

ECN W-320-662

15493-1, 2, 3

15493-Appendix A

ECN $W-320-748$

15493-9

ECN W-320-809

$01010-1,2$

05055-1

$15493-2,11,12$

15507-14

$16400-3,4,10,15$ 


\title{
CONSTRUCTION SPECIFICATION
}

\section{TANK 241-C-106 SLUICING}

PACKAGE 3 - AY TANK FARM

\author{
Work Order ER4319
}

Prepared By

ICF Kaiser Hanford Company

Richland, Hashington

For Westinghouse Hanford Company:

Contract WHC 380393

APPROVED

ICE Rziser Hanfore Company (ICF KH)

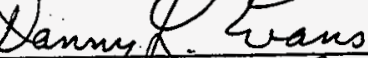

Principal LAa Enginger

Safety

cendraton
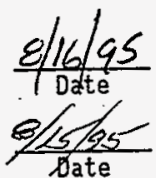

Eanclafe Fut

Environmental Engineering

$\frac{8-15.95}{\text { Date }}$

$\frac{8 / 10 / 15}{\text { Date }}$

Quality Engineering

Project Management

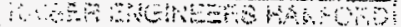
whtomen 5005 STATICNNO. 4

SEP 14 IESS

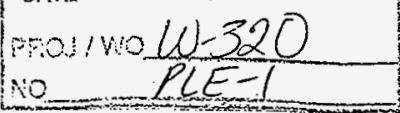

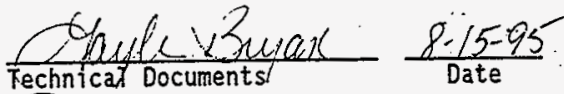

$\frac{8 / 16 / 95}{\text { Date }}$

$\frac{\text { Stage }}{\text { Date: }}$

Hestinghouse Hanford Company (WHC)

$\frac{\text { Chomas } z \text { May }}{\text { Projects Department }} \frac{8 / 22 / 95}{\text { Date }}$

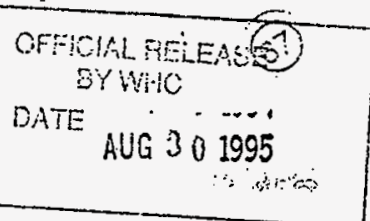




\section{CONSTRUCTION SPECIFICATION}

TANK 241-C-106 SLUICING

PACKAGE 3 - AY TANK FARM

Prepared by

ICF Kaiser Hanford Company

Richland, Washington

\section{CERTIFICATION}

I certify that the indicated sections of this specification were prepared by me or under my supervision and that I am a registered professionat engineer under the laws of the State of Washington.

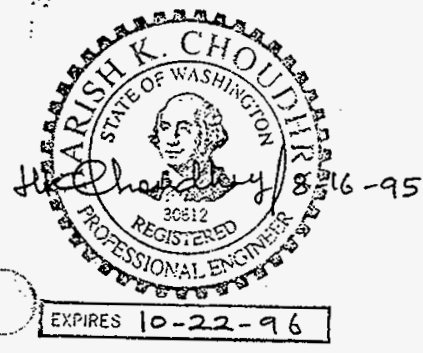

Harish K. Choudhry, PE instrumentation Section 13440

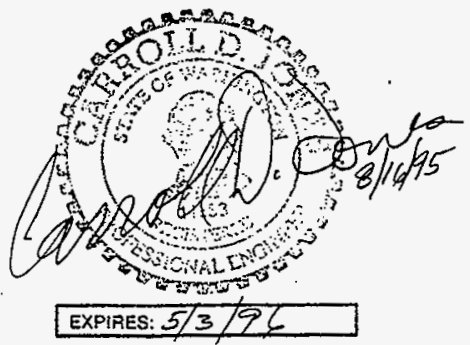

Carrol1 D. Jones, PE Mechanical Section 15493

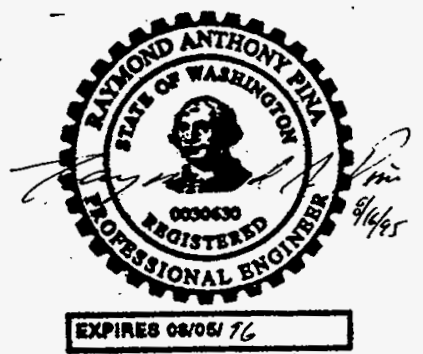

Raymond A. Pina, PE HVAC

Section 15507, 15990

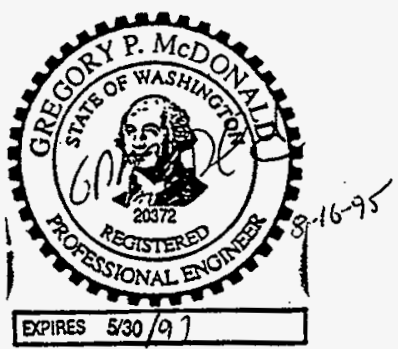

Gregory P. McDonald, PE Cathodic Protection Section 16640

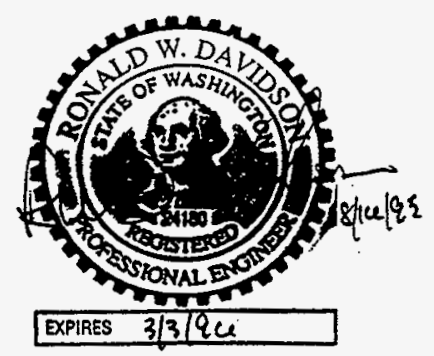

Ronald W. Davidson, PE Civil/Structural

Sections 02200, 02225 , $02831,03300,03400,05055$, $05500,09805,09900$

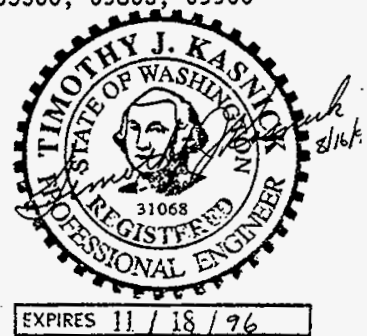

Timothy J. Kasnick, PE Electrical Section 16400 
Title and Approval Page

Certification Page

Page

$\dot{i}$

Table of Contents

Total Pages

$\begin{array}{lll}\text { DIVISION } 1-\text { GENERAL REQUIREMENTS } & \\ \text { Section } 01010 & \text { Summary of Work } & 2 \\ \text { Section } 01019 & \text { Items Furnished for Construction } & 1 \\ \text { Section } 01200 & \text { Project Meetings } & 3 \\ \text { Section } 01300 & \text { Submittals } & 3 \\ \text { Section } 01400 & \text { Quality Assurance } & 3 \\ \text { Section } 01610 & \text { Delivery, Storage, and Handling } \\ \text { Section } 01630 & \text { Product Options and Substitutions } & 3 \\ \text { Section } 01720 & \text { Project Record Documents }\end{array}$

DIVISION 2 - SITEWORK

Section 02200 Earthwork 4

Section 02225 Excavating, Backfilling and Compacting for Utilities 5

Section 02831 Chain Link Fences and Gates 3

DIVISION 3 - CONCRETE

Section 03300 Cast-In-Place Concrete $\quad 7$

Section 03400 Precast Concrete 8

DIVISION 5 - METALS

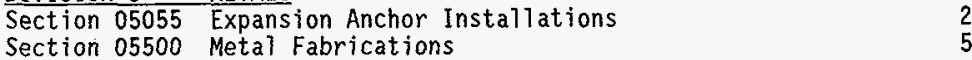

DIVISION 9 - FINISHES

Section 09805 Special Protective Coating

Section 09900 Painting

DIVISION 13 - SPECIAL CONSTRUCTION

Section 13440 Instrumentation

DIVISION 15 - MECHANICAL

Section 15493 Chemical Process Piping Systems 12

Section 15507 Contaminated Air HVAC Systems 16

Appendix A Identification of Piping Systems .2

Section 15990 Testing, Adjusting, and Balancing 2

DIVISION 16 - ELECTRICAL

Section 16400 Service and Distribution 17

Section 16640 Cathodic Protection 11 
SUMMARY OF WORK

PART 1 - GENERAL

\section{$1.1 \quad$ INTRODUCTION}

1.1.1 Project W-320, WASTE RETRIEVAL SLUICING SYSTEM (WRSS), is located as shown on Drawing $\mathrm{H}-2-818423$, Sh-6.

1.1.2 This Specification is for procurement, fabrication and installation of equipment at the "AY" Tank Farm, including some equipment just outside the "AY" Tank Farm fence, necessary to support the sluicing operation.

\subsection{STATEMENT OF WORK}

1.2.1 Scope: Work consists of furnishing 1abor, equipment, and materials to provide the means to procure materials and equipment, fabricate items, excavate and place concrete, and install equipment, piping, wiring, and structures in accordance with the Project documents.

1.2.2 Work Included: The following itemization is intended to be broad in scope, and identify major work elements only.

1.2.2.1 Excavation for process piping and electrical conduit trenches, and foundations for small structures.

1.2.2.2 Placement of concrete for foundations and equipment pads.

1.2.2.3 Procurement and installation of double walled piping, electrical conduit, and electrical and instrumentation cable.

1.2.2.4 Core drilling existing concrete.

1.2.2.5 Furnishing and installation of electrical distribution equipment.

1.2.2.6 Fabrication and installation of in-pit pipe "jumpers," including related valves, instruments and wiring.

1.2.2.7 Installation of vertical submersible pump and horizontal booster pump into tank access riser pits (Specification W-320-P17).

1.2.2.8 Installation of the concrete seismic foundation. Assembly and installation of two Seismic Shutdown Systems with Environmental (missile shield) Enciosures (Specifications W-320-P35 and P36).

1.2.2.9 Installation of electrical and cathodic protection equipment. Pulling and termination of power and control wiring at the AY-Farm.

1.2.2.10 Installation of conduit and wiring between tank-top pit devices and the operator station, electrical distribution panel, and motor starters located in the electrical equipment skid just outside the AY-Farm fence. 
1.2.2.11 Installation of Electrical Equipment Skid (Specification W-320-P33).

1.2.2.12 Furnishing and installation of Instrumentation and Controls for Operator Station located on Electrical Equipment Skid.

1.2.2.13 Procurement, assembly, and installation of pit cooling system at 241-AY-02E pit.

1.2.2.14 Performing construction tests on installed equipment, such as pressure tests on pipe, and insulation and continuity tests on wiring.

1.2.3 Work Not Included: The following work elements are part of the Project, are covered by other documents noted, and will be done by others, concurrently with work included in the Project documents.

1.2.3.1 Fabrication and installation of construction support trailers.

\subsection{DRAWINGS}

1.3.1 Drawings which show work required by the Project documents are iisted on Drawing H-2-818423, Sh-6.

PART 2 - PRODUCTS

Not Used

PART 3 - EXECUTION

Not Used

END OF SECTION 


\section{ITEMS FURNISHED FOR CONSTRUCTION}

PART 1 - GENERAL

1.1 REFERENCES: Not Used

1.2 SUBMITTALS: Not Used

1.3 GENERAL

1.3.1 Material and equipment furnished or made available for incorporation into the Work are identified in this Section. Other services and utilities provided are covered in other sections of this specification.

$1.4 \quad$ EQUIPMENT

1.4.1 Items listed below will be furnished for incorporation into the Work.

1.4.1.1 Sluice Pumps P-0621 and P-0622, procured under Specification W-320-P17. The Booster Pump includes a variable speed drive.

1.4.1.2 Pump winch, including position indication system procured under Specification $\mathrm{W}-320-\mathrm{P} 24$.

1.4.1.3 Electrical equipment skid, procured under Specification W-320-P33.

\subsubsection{Seismic Shutdown System and Enclosures, procured under} Specifications $W-320-P 35$ and P36.

1.4.2 Items noted in 1.4.1.1 through 1.4.1.4 are being procured by operating Contractor and will be delivered to Project site. Notify the Construction Engineer 5 working days before need date to arrange for delivery.

PART 2 - PRODUCTS

Not Used

PART 3 - EXECUTION

Not Used

END OF · SECTION 


\section{PROJECT MEETINGS}

\section{PART 1 - GENERAL}

1.1 REFERENCES: Not Used

1.2 SUBMITTALS: Not Used

1.3 SUMMARY

1.3.1 Representatives from ICF KH, CONTRACTOR, and major subcontractors shall participate in project meetings. Representatives from Operating Contractor and DOE may attend, as required by items to be discussed.

1.3.2 Meeting times and locations shall be mutually agreed to by CONTRACTOR and ICF KH, and will be held at the Hanford Site in Richland, Washington. Informal design reviews are an exception.

1.3.3 ICF KH will issue notices of meetings, and prepare and issue meeting minutes as promptly as possible after each meeting. Minutes will be distributed to project participants.

1.3.4 When applicable, minutes will identify action items, with assigned followup. Issues resolved will be reported, as well as closed action items.

PART 2 - PRODUCTS

Not Used

\section{PART 3 - EXECUTION}

\subsection{SITE LABOR CONFERENCE}

3.1.1 Before starting construction at the worksite, CONTRACTOR and subcontractors shal1 conduct an informational conference concerning Hanford Site labor requirements applicable to the Project. Review the General Conditions relating to labor, and present a proposed work plan with craft utilization requirements.

3.1.2 ICF KH will send a meeting notice to representatives from labor organizations, identified by CONTRACTOR as those with members who may be utilized in construction, and are to attend the conference.

\subsection{PRECONSTRUCTION CONFERENCE}

3.2.1 A conference will be scheduled and chaired by ICF KH before the start of onsite work. Authorized representatives of CONTRACTOR and major subcontractors shall attend, and ICF $\mathrm{KH}$ will advise others having an interest in the Work. 
3.2.2 The following items will be incorporated into the agenda.

3.2.2.1 Points of contact and key personnel representing Operating Contractor, Safety, Quality Assurance/Quality Control, Acceptance Inspection, and Construction Engineering.

3.2.2.2 Schedule requirements and restraints, submittals and work limitations.

3.2.2.3 Safety, construction progress meetings and their frequency, and certified payrolls.

3.2.2.4 Report requirements and their frequency.

3.2.2.5 ICF KH forms CONTRACTOR is required to use.

3.2.2.6 Quality requirements.

3.2.2.7. Major material and equipment lists.

3.2.2.8 0ther pertinent items.

$3.3 \quad$ CONSTRUCTION PROGRESS MEETINGS

3.3.1 Meetings will be held every 2 weeks, at times and locations determined at the preconstruction conference, and will be approximately 1 hour long.

3.3.2 ICF KH will chair the meetings, and request attendance of key personnel required. Authorized representatives of CONTRACTOR and pertinent subcontractors shall attend.

3.3.3 The purpose is to monitor status, and provide a forum for exchanging pertinent information related to the Work. Major topics may include the following.

3.3.3.1 Schedule, cost, and construction status.

3.3.3.2 Design and scope changes.

3.3.3.3 Submittal status, key material, and equipment delivery status.

3.3.3.4 Potential problem areas.

3.3.3.5 Inspection and testing status.

3.3.3.6 Action item status, and goals for the next meeting.

3.3.3.7 Other appropriate items.

END OF SECTION

\TWRS \SPEC\W320C7.WP5 $01200-2$

$\mathrm{H}-320-\mathrm{C7}$

As Built Rev 1 


\section{SUBMITTALS}

\section{PART 1 - GENERAL}

1.1 REFERENCES: Not Used

1.2 SUBMITTALS: Not Used (See the other sections requiring submittals)

1.3 SUBMITTAL CONDITIONS

1.3.1 Materials and equipment fabricated or installed without required approved submittals, or which differ from approved drawings or vendor data, are subject to rejection and replacement at CONTRACTOR's expense.

1.3.2 Delays arising from failure to submit required drawings and other related data described in Contract Documents, in a timely manner, will not constitute excusable delays for extensions, unless excusable under other provisions of the Contract.

1.4 SUBMITTALS REQUIRED

1.4.1 Required submittals are defined in Part 1 of the Specification Sections.

1.4.2 Submittals are divided into 2 types; those requiring approval and those not requiring approval. Included in the former are submittals of architectural material samples, where ICF KH reserves the right to make final selections. Included in the latter are documents containing vendor information necessary for operations, and information for project records.

1.4.3 Submittals are required no later than the times indicated. Those requiring ICF KH approval must be approved before further submittal related procurement, fabrication, or construction is accomplished. This also applies for ICF KH selections made from samples submitted.

1.5 SUBMITTAL REVIEWS

1.5.1 Submittals requiring approval will be reviewed to verify completeness and conformance to requirements. Appropriate dispositions will be made as specified in Part 3.

1.5.2 Allow 21 calendar days for ICF KH review and disposition of submittals. This time period will be measured from date of submittal receipt in ICF KH's office to date of return mailing.

1.5.3 Submittals not requiring approval will be reviewed to verify completeness and adequacy for their intended purposes. If acceptable, these items are filed, and finally delivered to Operating Contractor. Unacceptable items will be handled as specified in Part 3. 
1.5.4 If a submittal not requiring approval has not been returned within the Page 7 specified time period, and ICF KH has not informed CONTRACTOR that additional review time is necessary, CONTRACTOR may consider it accepted by ICF KH.

PART 2 - PRODUCTS

Not Used

PART 3 - EXECUTION

3.1 SUBMITTAL PROCEDURE

3.1.1 Transmit submittaTs using "Data Transmittal/Review," Form KEH 1838. Copies will be supplied during the Preconstruction Conference (see Section 01200).

3.1.2 Identify each submittal by submittal number, section/paragraph number and submittal title as shown on the master submittal log included with Contract Documents. The number of copies required includes 2 copies for return to CONTRACTOR. If necessary, provide additional copies required for return to CONTRACTOR.

3.1.2.1 Approvai data (for products): Mark each line item package with the specification section and paragraph numbers specifying the product.

3.1.2.2 Vendor information (for products): Mark each line item package with the specification section and paragraph numbers specifying the product, and the item name, manufacturer's name, model or part number, and ICF KH tag number (if specified).

3.1.2.3 Items that require approval: Submit 6 copies, including 1 reproducible.

3.1.2.4 Samples for selections: Submit as required by the Sections of this Specification.

3.1.2.5 Items that do not require approval: Submit 106 copies.

3.1.3 Review each submittal for completeness, compliance with Contract Documents, and proper identification before sending to ICF KH.

Submittal data shall ejther be stamped, showing the review process has taken place, or the Data Transmittal form may be stamped "Reviewed for Compliance," and signed. Submittals not stamped or signed will be returned without consideration.

3.1.4 Procedures for performing certain types of work must be submitted for approval before work is commenced. Such procedures which have previously been approved by ICF KH, for work similar to that to be accomplished on this Project, may not need to be reapproved. Forward 1 copy of previously approved procedures to ICF KH, by Data Transmittal form, and identify each by section/paragraph number, title, and either procedure number or project number for which the procedure was approved. 
Submittals will be reviewed by ICF KH and, if acceptable, retained for Page 8 record. If a previously approved procedure is not acceptable, the submittal will be returned, with requirements for resubmittal.

3.2.1 Submittals requiring approval will be stamped by ICF KH, and marked "Approved," "Approved with Exception," or "Not Approved, Revise and Resubmit." Approval of submittals does not relieve CONTRACTOR of responsibility for errors contained therein.

3.2.1.1 Approved submittals are identified by the submittal stamp, with either the "Approved" or "Approved with Exception" box checked. "Approved" signifies general concurrence of submittal conformance with project design concepts and compliance with Contract Document requirements. "Approved with Exception" signifies general concurrence, with noteworthy comments or clarifications. Approval of a specific item shall not be construed as approval of the system or assembly of which that item is a component.

3.2.1.2 A submittal which is not approved is identified as "Not Approved, Revise and Resubmit." The submittal is considered technically deficient, or incomplete, and therefore unacceptable. Resubmittal is required, hence fabrication, procurement, or performance of procedures shall not proceed.

3.2.1.3 Submittals not requiring approval that are found to be incomplete or inadequate will be returned marked "Resubmit." An explanation of the deficiencies will be included, for corrective action by CONTRACTOR.

3.3

RESUBMITTAL

3.3.1 Upon receipt of deficient submittals, make corrections noted on the transmitta 1 , and resubmit complete packages to ICF KH.

END OF SECTION 
PART 1 - GENERAL

1.1 REFERENCES: Not Used

1.2 SUBMITTALS: Not Used

1.3 THE ONSITE CONSTRUCTION CONTRACTOR'S QAP WILL BE IMPLEMENTED

1.4 INSPECTION AND WITNESS POINTS

1.4.1 Perform specified inspection and testing (see 1.4.3).

1.4.1.1 Provide and maintain an inspection system that will ensure that work performed, including that performed by subcontractors and suppliers, conforms to requirements.

1.4.1.2 Perform, or have performed, inspections and tests required to substantiate conformance to Project requirements. Such inspections shall be documented, indicating the inspector, date, item(s) inspected, and the results of inspection.

1.4.1.3 Perform, or have performed, inspections required by referenced codes and standards. Such inspections shall be documented as in 1.4 .1 .2 above.

1.4.2 The customer wi\}l perform inspections and testing identified in this specification as the customer's responsibility, including the following.

1.4.2.1 Inspection and witness points specified in 1.6.

1.4.2.2 Final acceptance inspection.

1.4.3 Inspection Points: Adhere to inspection points. Personnel shall have completed inspections of, and approved portions of, work in accordance with Project requirements, before notifying the customer for inspection/ witnessing.

1.4.3.1 Listed inspection points define the type of inspections required to be performed, and are considered a minimum inspection level for customer involvement.

1.4.3.2 Customer inspection points are defined as follows.

a. Receiving (R): Special items of fabrication, equipment, or material scheduled to be delivered to the Project site, or other designated location, which require inspection upon arrival and before installation. Notify the customer within four hours after item arrival.

b. Construction inspection $(H)$ : Required for witnessing of specific construction features, before further construction is allowed to proceed. 
c. Witness (W): Selected for inspection at the option of the customer. Work may proceed upon verbal release by the customer, or upon expiration of one hour beyond the scheduled time of witnessing.

1.4.3.3 $\mathrm{R}, \mathrm{H}$, and $\mathrm{W}$ points apply to both onsite and offsite work. Except where a longer period is specified, notify the customer at least four working hours before each point for onsite work. For offsite work, notify the customer at least three working days before each required point.

1.4.3.4 $R, H$, and $W$ points are specified in $I .6$.

1.5

\section{ELECTRICAL/ELECTRONIC PRODUCT ACCEPTABILITY}

1.5.1 Each product shall be listed for intended use in one of following and shall bear listing organization's label. In absence of label, provide documentation that verifies product listing.

a. UL Electrical Construction Materials Directory.

b. UL Electrical Appliance and Utilization Equipment Directory.

c. FM Approval Guide.

1.5.2 If product is not listed in above directories or guide, provide product which has been tested and certified by a laboratory which has been nationally recognized in accordance with 29 CFR 1910.7. Provide following.

a. OSHA documentation which demonstrates recognition.

b. Laboratory documentation that verifies testing in accordance with national code or standard.

1.5.3 If product is not listed by UL or FM and if a nationally recognized laboratory is not available, submit descriptive literature to ICF KH. Literature shall include product specification and description of intended application.

1.6 SCHEDULE OF HOLD AND WITNESS POINTS

INSPECTION POINT NO.

INSPECTION POINT DESCRIPTION

$$
\begin{aligned}
& \text { INSPECT } \\
& \text { POINT OFFSITE }
\end{aligned}
$$

ONSITE

\begin{tabular}{|c|c|c|c|}
\hline$\frac{02200}{02200-1}$ & $\frac{\text { EARTHWORK }}{\text { Approving Backfill Permits }}$ & $W$ & $x$ \\
\hline$\frac{02225}{02225-1}$ & $\frac{\text { EXCAVATING, BACKFILLING AND }}{\text { Approving Backfil1 Permits }}$ & $\frac{\text { ING FOR UTILITIES }}{W}$ & $X$ \\
\hline $\begin{array}{l}\frac{03300}{03300-1} \\
03300-2\end{array}$ & $\begin{array}{l}\text { CAST-IN-PLACE CONCRETE } \\
\text { Approving Pour Slips for Cov } \\
\text { Blocks, Seismic Shutdown Pad } \\
\text { Initial SCl Grout Placement }\end{array}$ & $\begin{array}{l}\mathrm{H} \\
\mathrm{H}\end{array}$ & $X$ \\
\hline
\end{tabular}


05055

05055-1

09805

09805-1

13440

$13440-1$

15507

15507-1

$15507-2$

15990

$15990-1$

15493

$15493-1$

15493-2

$15493-3$

$15493-4$

16400

$16400-1$

$16400-2$

16640

$16640-1$

PART 2 -

PART 3 -
EXPANSION ANCHOR INSTALLATIONS

Initial SC1 Installation

$x$

SPECIAL PROTECTIVE COATING

Initial Application on Cover

Blocks

INSTRUMENTATION

Electrical Testing

$W$

$x$

CONTAMINATED AIR HVAC SYSTEMS

X-Ray Film Reading

Leak/Pressure Testing

$$
\begin{aligned}
& x \\
& x
\end{aligned}
$$

TESTING, ADJUSTING, AND BALANCING

Functional Testing

$W$

$x$

CHEMICAL PROCESS PIPING SYSTEM

Initial Welding

$X$-Ray Film Reading

M-9 Leak/Pressure Testing

Leak/Pressure Testing

HNF-2536, Rev. 0

Page 11

SERVICE AND DISTRIBUTION

Megger Testing

Before Energizing

H

$\hat{x}$

CATHODIC PROTECTION

Functional Testing of Reference

Electrodes

PRODUCTS

Not Used

EXECUTION

Not Used

END OF SECTION 
DELIVERY, STORAGE, AND HANDLING

PART 1 - GENERAL

1.1 REFERENCES: Not Used

1.2 SUBMITTALS: Not Used

1.3 SUMMARY

1.3.1 This Section contains generally applicable requirements for delivery, inspection, marking, storage, and handling. Product unique requirements are contained in other sections.

1.4 RAILROAD DELIVERIES

1.4.1 Railroad shipments are possible into boundaries of the Hanford Site. Carload shipments may be made to Richland, Washington, over Washington Central Railroad from Burlington Northern or Union Pacific Railroads.

1.4.2 ICF KH will arrange for movement of rail cars from Richland to available spurs or sidings on the Government owned railroad system, within the Hanford Site. ICF KH is not liable for demurrage charges, or loss or damage to cars or lading, unless loss or damage is the fault of or due to negligence by ICF $\mathrm{KH}$.

1.4.3 Investigate availability of rail spurs or sidings in the Site vicinity. Use of spurs shall be coordinated with other users at the Site. Notify ICF KH at least 2 working days before scheduled arrival of carload shipments.

PART 2 - PRODUCTS

Not Used

PART 3 - EXECUTION

3.1 DELIVERY

3.1.1 Provide equipment and labor required for unloading, transporting, and handling del tvered products. For railroad deliveries, unload each car within 3 working days after arrival, unless a time extension is granted by ICF KH.

\subsection{RECEIVING INSPECTION}

3.2.1 Arrange for immediate disposal and replacement of products found to be defective, damaged beyond repair, or in otherwise unacceptable condition.

3.2.2 Dry or clean products that have become wet or have accumulated foreign substances during shipment, but have not become damaged. 
Perform additional identification marking of products when necess meet the requirements of this section, and other sections of this Specification.

\subsection{PRODUCT IDENTIFICATION AND SEGREGATION}

3.3.1 Provide identification tags or markings for products of similar appearance, or intended for similar use, procured to different specifications, or from different manufacturers.

3.3.2 Include the following information, as applicable, on tags, with markings, and preexisting labels: Manufacturer's name, product brand name, specification number, and type, grade or class. Also include additional information required by other sections of this Specification.

3.3.3 Segregate tagged or marked products, providing separate storage for each.

3.3.4 Preserve the identity of bulk and lot products (those consumed on an "as needed" basis during progress of the work) from the time of receipt at the worksite until use in construction.

3.3.4.1 Control the identification and storage of welding materials in accordance with a written filler metal control procedure, maintained at the worksite. The procedure shall specify methods for control by heat or lot number, from receipt of material through consumption during fabrication, and for disposal of contaminated and partially used material.

3.3.4.2 When pipe or tube is removed from storage and cut, clearly and permanently remark remaining pieces with either original markings or field code identification symbols, and return to storage.

3.3.4.3 Use permanent marking methods on pipe and tube, including pens with water insoluble, indelible ink, crayon, paint, or paint stick. Vibratory etching equipment may be used with the approval of ICF $\mathrm{KH}$. Marking with steel stamps is not acceptable.

3.4 STORAGE

3.4.1 Basic Storage

3.4.1.1 Store packaged products in their original, unbroken packages or containers, with seals and labels intact.

3.4.1.2 Store rolled products in an upright position.

3.4.1.3 Store products with finished surfaces in a manner to preclude surface damage by mechanical, atmospheric, or other effects.

3.4.1.4 Where contact between products could result in damage or rendering useless of 1 or both, store them far enough apart to prevent contact. If close proximity storage is necessary, provide a barrier between them. 
3.4.1.5 Keep ports, nozzles, ends, and other openings on equipment, tanks, and Page 14 lengths of pipe and tube capped or plugged during storage.

3.4.1.6 Follow manufacturer's recommendations for storage when such recommendations are given.

3.4.1.7 Remove, dispose of, and replace products with expired shelf-life dates.

\subsubsection{Indoor Storage}

3.4.2.1 Provide indoor storage for products that can be damaged by, or can deteriorate from, changes in temperature and relative humidity.

3.4.2.2 When required by other sections of this Specification, or when recommended by product manufacturers, provide environmentally controlled storage. Maintain temperature 15.5 to $21{ }^{\circ} \mathrm{C}\left(60\right.$ to $\left.70^{\circ} \mathrm{F}\right)$, relative humidity below 55\%, and provide ventilation.

3.4.3 Outdoor Storage

3.4.3.1 Provide skids, pallets, platforms, or other supports for products stored outdoors to prevent ground contact.

3.4.3.2 Provide sunshade protection for products that can be damaged by, or can deteriorate from, exposure to sunlight.

3.4.3.3 Provide weatherproof covers for products that can be damaged by, or can deteriorate from, the effects of contact with rain, snow, ice deposits, or blowing sand and debris.

3.4.3.4 Arrange stacks of stackable products so that condensation, which may accumulate during storage, will drain off.

$3.5 \quad$ HANDLING

3.5.1 Provide handiing tools and equipment, and use methods designed to prevent occurrence of the following.

3.5.1.1 Impact, rubbing, or other contact damage to ends and surfaces of cylindrical (pipe and tube) type products, or to edges, corners, and surfaces of flat (panel and sheet) type products.

3.5.1.2 Twisting, racking, or other distortion of prefabricated structures and equipment assemblies.

3.5.1.3 Tearing or puncturing of wrappings or coverings, or breaking of seals on packages or cartons. 


\section{PRODUCT OPTIONS AND SUBSTITUTIONS}

\section{PART 1 - GENERAL}

1.1 REFERENCES: Not Used

\subsection{SUBMITTALS}

1.2.1 See Section 01300 for submittal procedures.

\subsubsection{Approval Required}

1.2.2.1 Substitution Approval Request(s): Before start of construction, submit request(s) as required by 1.3 .4 and 1.3 .5 , prepared in accordance with 3.1 .

\subsubsection{Approval Not Required: None}

\subsection{SUBSTITUTIONS}

1.3.1 Products include those items identified on Drawings as well as in Part 2 of the specification sections.

1.3.2 Product options given in the specification sections represent functionally and physically equivalent items. In addition to generic type, materials, form and size, physical equivalence includes maintainability, reliability, and durability characteristics, as applicable for specific material or equipment items.

1.3.3 A substitute product may be used in place of a product or the product options identified in specification sections, without approval, if it is functionally and physically equivalent as defined above, and is not more hazardous.

1.3.4 Substitution of a product that is functionally but not physically equivalent, as defined above, or is more hazardous, requires submittal of a Substitution Approval Request.

1.3.5 Submittal of a Substitution Approval Request is also required when a product callout in the specification sections includes the phrase "or an approved substitute."

1.3.6 Total quantities of products required in specification sections shall be the same. Differences due to partial quantity substitutions are not acceptable.

1.3.7 Do not use materials and equipment removed from existing structure as substitutes for specified products, unless such use is required or allowed elsewhere in Contract Documents. 
1.4.1 Substitutions will not be considered when indicated or implied on fabricator drawings, or product data submittals, without separate Substitution Approval. Requests, when requested directly by subcontractors or suppliers, or when acceptance will require substantial revision of Contract Documents.

1.4.2 Substitute products that require a substitution approval request sha11 not be ordered or installed before the request is approved.

1:4.3 Oniy 1 Substitution Approval Request for each product will be considered. When a substitution is not accepted, provide the specified product.

1.4.4 ICF KH will review and disposition requests for substitutions within 10 working days, unless evaluation requires extensive comparison or consultation.

1.4.5 The same submittals required for original products, by 1.2 of the sections specifying them, are required for accepted substitute products.

PART 2 - PRODUCTS

Not Used

PART 3 - EXECUTION

3.1 REQUEST PREPARATION

3.1.1 Submit a separate request for each substitution, using "Substitution Approva? Request," Form KEH 1151. Copies will be supplied during the Preconstruction Conference (see Section 01200).

3.1.2 Identify products by specification section and article or paragraph numbers. Provide manufacturer's name and address, trade name of product, and model or catalog number. List fabricators and suppliers as appropriate.

3.1.3 To each Substitution Approval Request attach descriptive information for substitute and original products. The information shall consist of drawings, calculations, and data as appropriate to define operational and physical characteristics of products, and establish a basis for comparison.

3.1.4 Give an itemized comparison of proposed substitution with specified product, listing variations, with reference to specification section and article or paragraph numbers.

3.1.5 Give a quality and performance comparison between the proposed substitute and specified product.

3.1.5 Give a cost data comparison between the proposed substitute and specified product, showing the Contract sum net change. 
3.1.7 List availability of maintenance services and replacement materials. Page 17

3.1.8 State effect of the substitution on construction schedule, and changes required in other work or products. If a substitute product requires or necessitates revisions to structures, foundations, footings, services, systems, piping, electrical, etc, engineering costs shall be borne by CONTRACTOR. Submit drawings, calculations, and vendor data, clearly showing revisions to accommodate the substitution, for approval.

END OF. SECTION 


\section{PROJECT RECORD DOCUMENTS}

PART 1 - GENERAL

1.1 REFERENCES: Not Used

1.2 SUBMITTALS: Not Used

1.3 GENERAL

1:3.1 Hanford Site work requires that certain documents, defined herein, be used to record the construction process, and administration of the contract. ICF KH will assemble pertinent data for final disposition.

1.3.2 Some data required for project records shall be delivered to ICF KH during the course of construction and contract administration, while other data shall be assembled after completion of construction for delivery to ICF KH.

1.3.3 Certain information for project records is to be recorded on standard ICF KH forms. These forms are identified in the specification sections where required. Copies will be supplied during the Preconstruction Conference (see Section 01200).

1.3.4 Project Record Documents, required by the Contract, sha11 be prepared, preserved, and delivered to ICF KH. These deliverable documents are in addition to submittals required in Section 01300.

PART 2 - PRODUCTS

Not Used

PART 3 - EXECUTION

3.1 PROCEDURE

3.1.1 Identification and Marking: Mark documents that will become project records before use for construction. Upon completion, identify documents by title or number.

3.1.1.1 Notes or markings added by hand shall be legible, utilizing permanent nonsmearing marking media, such as ink or felt tip markers, in contrasting color.

3.1.1.2 Mark items to record actual construction, including changes to dimensions and details, manufacturer's name, catalog number, and substitute products.

3.1.2 Availability: Keep copies of Project Record Documents in the field office, and make available to ICF KH during progress of the Work. 
3.1.3 Storage: Store 1 set in the field office, apart from documents used in Page 19 construction, and maintain in clean, dry, and legible condition.

3.1.4 Delivery: Record delivery of documents by retaining copies of letters of transmittal itemizing delivered items, and reports delivered during the course of work. Retain until construction completion. An alternate means, acceptable to ICF KH, may be used.

\subsection{ACTIVITY AND ADMINISTRATIVE DOCUMENTS}

3.2.1 Deliver or retain in accordance with the following.

3.2.2 Certified Payrolls: Each week deliver certified payrolls as required by General Conditions, Section 108 to ICF KH and keep copies in the field office until Contract completion. Progress payments will not be processed unless certified payrolls for work periods have been received by ICF $\mathrm{KH}$.

3.2.3 Daily Force and Equipment Reports: Before noon each day, deliver 1 copy of a detailed daily force report, covering labor and supervision of CONTRACTOR and subcontractors for previous day. Report shal7 include a general description of work performed, and list major items of equipment onsite.

3.2.4 Weekly Manpower Reports: Prepare weekly manpower reports and deliver, before 10 am on Monday, for previous week, during performance of contract. Forms will be furnished by ICF KH.

3.2.5 Subcontracting Plan Reports: Deliver reports documenting conformance with Subcontracting Plan, as required by General Conditions, Section 89.

3.2.6 Backfill Permit: Retain backfill permits approved for work required in Division 2.

3.2.7 Soil Compaction Procedure: Retain Forms KEH 0382 completed for work required in Division 2 .

3.2.8 Pour Slips: After obtaining ICF KH approval of concrete pour slips required in Division 3 , deliver copies to ICF KH, and retain CONTRACTOR copies until contract closeout. After closeout deliver them to ICF KH.

3.2.9 Trip Tickets: Deliver copies to ICF KH with each truck load of concrete required in Division 3 , and retain CONTRACTOR copies until Contract closeout. After closeout, deliver them to ICF KH.

3.3 CONSTRUCTION, QUALITY ASSURANCE, AND SUPPORTING DOCUMENTS

3.3.1 Deliver in accordance with the following, when called for in specification sections.

3.3.2 Quality Assurance Programs: 1 copy of each supplier's Quality Assurance Program, 15 days before start of fabrication. 
3.3.3 Drawings: 3 copies of weld (bond) identification drawings, 5 days Page 20 before start of fabrication.

3.3.4 Expansion Anchor Installation Reports: I copy within 5 days after completion.

3.3.5 NDE Records: 1 copy of weld (bond) NDE records within 5 days after NDE completion. These records may be either signed NDE record forms, or signed fabrication drawings with each weld (bond) bearing the inspector's stamp.

3.3.6 Material Properties Test Records: 1 copy of test results prior to delivery of material. These records are for acceptance tests of bulk materials and of lots or heats of preformed stock materials and parts.

3.3.7 Flushing Records: 1 copy of records verifying acceptable completion of flushing, before testing.

3.3.8 Leak/Pressure Testing Records: 1 copy of records verifying acceptable completion of leak and pressure testing, within 5 days after completion.

3.3.9 Disinfecting Records: 1 copy of records verifying acceptable completion of sanitary water line disinfecting, 5 days after completion.

3.3.10 Electrical Testing: 1 copy of records verifying acceptable completion of electrical insulation, continuity, and grounding tests, within 5 days after completion.

3.3.11 Operational Testing: 1 copy of records of component or subsystem operational testing, within 15 days before the start of acceptance testing.

3.3.12 Completed Acceptance Test Procedure (Test Results): 1 copy of Acceptance Test Procedure, with test resuTts and other required information entered, within 5 days after completion.

3.3.13 Completed Certificate of Compliance: l copy of completed Certificate of Compliance, based on the above completed acceptance test procedure, along with that procedure.

\subsection{PRODUCT SAMPLES AND MANUFACTURER'S INSTRUCTIONS}

3.4.1 In addition to submittals required in Section 01300, and requirements of this Section, information received by CONTRACTOR (from suppliers) that documents products used, and how they were installed, shall be delivered to ICF KH as Project Records. 


\section{EARTHWORK}

PART 1 - GENERAL

\section{$1.1 \quad$ REFERENCES}

1.1.1 The following documents, including others referenced therein, form part of this Section to the extent designated herein.

1.1.1.1 Washington State Department of Transportation (WSDOT)
M 41-10-94
Road, Bridge, and Municipal
Construction

M 41-01-93

Construction Manua]

1.2 SUBMITTALS: Not Used

1.3 QUALITY ASSURANCE

1.3.1 Deliverable Documentation: The following documents and records, required by this Section, shall be delivered to Construction Document Control in accordance with Section 01720.

Document

Excavation Permit

Backfill Permit

Soil Compaction Procedure

Soil Compaction Test Results 
HNF-2536, Rev. 0

2.1.3 Stabilization: Crushed rock, with a maximum fragment size of 3/4-inch. Page 22 for walkways, and under 2 inches for other areas:

PART 3 - EXECUTION

3.1 EXCAVATION

3.1.1 Obtain an excavation permit before performing excavation. Excavation permits will be provided by the Operating Contractor.

3.1.2 If cultural properties (eg, bones, artifacts) are encountered during excavation, stop work. The Hanford Cultural Resources Laboratory will assess the significance of the find.

3.1.3 Locate and expose underground utilities by hand tools. Use of heavy equipment and machinery is restricted within 5 feet of suspected underground utilities, and requires approval by the Construction Engineer.

3.1.4 Wherever slopes of excavations will intersect existing underground lines or structures such as building foundations, underground piping, electrical ducts or direct buried electrical lines, install shoring or other means of support to prevent overstressing existing structure or underground 1 ines or to prevent interrupting service to existing buildings.

3.1.5 Footings and Foundations

3.1.5.1 Make excavations for footings to depth shown on the Drawings or additional depth necessary to provide undisturbed surface to receive footing. Make excavations to proper width with allowances made for forms and bracing. Make bottom of excavations compact, Jeve 1, true, and free of loose material.

3.1.5.2 If over-excavation occurs where footings are designed to be placed on undisturbed earth, correct at time of placing concrete by extending concrete down to undisturbed earth, or by placement of backfill, compacted as specified in 3.2.1.2b, Method C.

3.1.6 In Situ Soils

3.1.6.1 Salvage in situ stabilization material and reuse for backfilling and compacting. Contact the Construction Engineer for acceptability of backfill material, if required.

3.1.6.2 Conduct in-place density tests on in situ soils, using nuclear density gage, during excavation. Results of tests will be used for testing compaction of backfill and to ensure that the density of backfill material placed over the tank dome is equal to or less than the density assumed in the tank safety and structural analyses.

3.1.6.3 Excavated material containing concentrations of radioactive materials that can be detected by portable survey instruments normally used for performing radiation surveys is considered contaminated, and shall be 
sampled and analyzed for content. Contact the Construction Engineer forPage 23 disposal or reuse within approved contamination level limits set by the Operating Contractor.

\section{1 .7 Where-stabilization is pequired, finish subgrate-3-inches-betow}

elevations shown on the orawings.

\subsection{PLACEMENT}

3.2.1 Fill and Backfill

3.2.1.1 General:

a. Backfill Permit: Obtain signatures required on the backfill permit for each element to be filled or backfilled. Hork not started within 5 calendar days from the time a permit is approved shall not be started until a new permit has been approved. A continuing job that has not had backfill installed within the past 5 calendar days will require a new backfil1 permit.

b. Remove debris and organic matter from the area to be filled or backfilled.

c. Use only specified materials for fill or backfill. Keep materials free of frozen particles, lumps, organic matter, and trash.

d. Do not place fill or backfill on frozen ground.

e. Filling or backfilling by sluicing or flooding with water will not be permitted.

f. Bring fill or backfill up evenly on sides of walls, structures, and utility lines to avoid unbalanced loading. Written approval shall be obtained from the Construction Engineer for other procedures.

g. Do not place fill or backfill against concrete structure or foundation wall less than 14 days after completion of structure or wall unless written permission from the Design Engineer is obtained. Provide wall support, where noted on the Drawings, before filling or backfiliting.

\subsubsection{Compaction:}

a. Before placement of fill or backfill, demonstrate by physical test at the worksite, that proposed layer depths and the procedure for compaction of soils will provide compaction specified. Prepare "Soil Compaction Procedure," Form KEH-0382, in accordance with the instructions.

b. P1ace backfill in accordance with WSDOT M 41-10, Section 2-03.3(14)C and approved procedure as follows.

1) Use Method $C$ under foundations, slabs, and when backfilling around Concrete Pits. 
2) Use Method B under pavements and roads, and within 5 feet of Page 24 buildings, fences, other structures, or poles supporting electric lines or pipe.

c. Compaction control tests will be in accordance with WSDOT M 41-10, Section 2-03.3(14)D.

\subsubsection{Common:}

a. Place fill or backfill in layers not more than 12 inches thick, loose measurement.

b. Compact each layer, full width, by at least 1 pass of vibratory or rammer-type compactor, pneumatic-tired roller, loaded scraper wheel, grader wheel, or power roller.

c. Mound over top layer of backfill to depth of 1 inch for each

12 inches of trench depth to maximum mound height of 6 inches.

\subsubsection{In situ soils:}

a. Compact backfill by depositing soils in 8 inch 1ayers and compacting to density equal to in situ density determined by tests made during excavation. Maintain uniformity of compaction throughout backfill.

b. Do not use soils containing rocks larger than 3 inches in greatest dimension for compacted backfili.

3.2.2 Finish Grading and Stabilization

3.2.2.1 Rake areas disturbed by work, remove surface stones larger than 6 inches and dispose of excess material and debris at an area designated by the Construction Engineer.

3.2.2.2 Stabilize areas disturbed by work with a-3-inched couse-of crushed rock specified in 2.1.3. Finish stabilization course to elevations shown on the Drawings.

3.3 FIELD QUALITY CONTROL

3.3.1 Soil Compaction Tests: Sampling and testing of compacted fill and backfill will be performed. Frequency of testing shall be in accordance with WSDOT M 41-01, Page 9-52 and as directed by the Construction Engineer to ensure uniform compaction of backfill material.

END OF SECTION 
EXCAVATING, BACKFILLING, AND COMPACTING FOR UTILITIES

PART 1 - GENERAL

1.1 REFERENCES

1.1.1 The following documents, including others referenced therein, form part of this Section to the extent designated herein.

1.1.1.1 American Society for Testing and Materia]s (ASTM)

D $653-90$

Standard Terminology Relating to Soil, Rock, and Contained Fluids

1.1.1.2 Washington State Department of Transportation (WSDOT)

M 41-01-93

Construction Manua]

M 41-10-94

Road, Bridge, and Municipa 7

Construction

M 46-01-88 w/Revisions

Materials Branch Laboratory Manual

through 1994

1.2 SUBMITTALS: Not Used

1.3 QUALITY ASSURANCE

1.3.1 Deliverable Documentation: The following documents and records, required by this Section, shall be delivered to Construction Document Control in accordance with Section 01720.

Document

Excavation Permit

Backfill Permit

Soil Compaction Procedure

Soil Compaction Test Results
Paragraph

3.1 .1

3.2.1.1a

$3.2 .1 .2 \mathrm{a}$

3.3 .1

PART 2 - PRODUCTS

2.1 MATERIALS

2.1.1 Obtain specified soils from excavation or other locations designated by the Construction Engineer. 
2.1.2.1 Structural: Well graded soil mixtures which may contain cobbles up to 3 inches in greatest dimension if uniformly distributed and not constituting more than $20 \%$ of volume of fill.

2.1.2.2 Common: Well graded soil mixtures containing cobbles up to 8 inches in greatest dimension if uniformly distributed and not constituting more than $40 \%$ of volume of fill.

2.1.3 Bedding for Underground Pipe, Conduit, and Cable: Sand, as defined in ASTM D 653, or excavated sandy material having less than $20 \%$ gravel particles, with those particles having a maximum dimension of $1 / 2$-inch.

2.1.4 Stabilization: Crushed rock, with a maximum fragment size of 3/4-inch. for walkways, and under 2 inches fop other areas.

2.1.5 Plastic Sheet Marker: 3-inch wide detectable tape imprinted with a warning, such as "CAUTION - BURIED INSTALLATION BELOW", at intervals of 4 feet maximum; Reef Industries "Terra Tape Sentry Line 620," with "Terra Clips," or an approved substitute.

PART 3 - EXECUTION

3.1 EXCAVATION

3.1.1 Obtain an excavation permit before performing excavation. Excavation permits will be provided by the operating Contractor.

3.1.2 If cultural properties (eg, bones, artifacts) are encountered during excavation, stop work. The Hanford Cultural Resources Laboratory will assess the significance of the find.

3.1.3 Locate and expose underground utilities by hand tools. Use of heavy equipment and machinery requires approval by the Construction Engineer.

3.1.4 Where slopes of excavations will intersect existing underground lines or structures such as building foundations, underground piping, electrical ducts or direct buried electrical lines, install shoring or other means of support to prevent overstressing existing structure or underground ines or prevent interrupting service to existing buildings.

3.1.5 Make excavations to line and grade shown on the Drawings and wide enough to make connections. Excavate with near vertical sides from bottom of trench up to 1 foot above pipe, conduit, and cable. Excavate trench deep enough to permit placement of compacted bedding, 4 inches minimum thickness, beneath pipe, conduit, and cable except where excavation is in undisturbed sand which will serve as bedding or where lines are to be encased in concrete. Pare holes in trench bottoms for pipe couplings so pipe will bear full length of barrel or section. Excavate trench for transfer 7 ines deep enough for 6 inches of compacted bedding.

3.1.6 Install shoring to hold materials and surcharge pressure for full depth of trench. 
3.1.7 Keep trenches free of standing water when laying is in progress.

3.1.8 If over-excavation occurs, correct by placement of structural backfill.

3.1.9 In Situ Soils

3.1.9.1 Salvage in-situ stabilization material and reuse for backfil]ing and compacting. Contact the Construction Engineer for acceptability of backfill material, if required.

3.1.9.2 Conduct in-place density tests on in-situ soils, using nuclear density gage, during excavation. Results of tests will be used for testing compaction of backfill.

3.1.9.3 Excavated material containing concentrations of radioactive materials that can be detected by portable survey instruments normally used for performing radiation surveys is considered contaminated, and shall be sampled and analyzed for content. Contact the Construction Engineer for disposal or reuse within approved contamination level limits set by the operating Contractor.

3.1 .10 Where-stabilization is required, finish-suldrate 3 inches below

elevations shown on the Drawings.

3.2 PLACEMENT

3.2.1 Fill and Backfill

3.2.1.1 General:

a. Backfill Permit: Obtain signatures required on the backfill permit for each element to be filled or backfilled. Work not started within 5 calendar days from the time a permit is approved shall not be started until a new permit has been approved. A continuing job that has not had backfill installed within the past 5 calendar days will require a new backfill permit.

b. Remove debris and organic matter from the area to be filled or backfilled.

c. Use only select materials for fill or backfill. Keep materials free of frozen particles, lumps, organic matter, and trash.

d. Do not place fill or backfill on frozen ground.

e. Filling or backfilling by sluicing or flooding with water will not be permitted.

f. Bring fill or backfill up evenly on sides of walls, structures, and utility lines to avoid unbalanced loading. Written approval shall be obtained from the Construction Engineer for other procedures. 
a. Before $p l a c e m e n t$ of $f i l l$ or backfill, demonstrate by physical test at the worksite, that proposed layer depths and the procedure for compaction of soils will provide compaction specified. Prepare "Soi] Compaction Procedure," Form KEH-0382, in accordance with the instructions.

b. Place backfil1 in accordance with WSDOT M 41-10, Section 2-03.3(14)C and approved procedure as follows.

1) Use Method $\mathrm{C}$ under pipelines.

2) Use Method B within 5 feet of buildings, fences, other structures, or poles supporting electric lines or pipes.

c. Compaction control tests will be in accordance with WSDOT M 41-10, Section 2-03/3(14)D.

\subsubsection{Common:}

a. Place fill or backfill in layers not more than 12 inches thick, loose measurement.

b. Compact each layer, full width, by at least 1 pass of vibratory or rammer-type compactor, pneumatic-tired roller, loaded scraper wheel, grader wheel, or power roller.

c. Mound over top layer of backfill to depth of 1 inch for each

12 inches of trench depth to maximum mound height of 6 inches.

3.2.1.4 Underground piping, conduit, and cable trenches:

a. Bedding placed beneath pipe, conduit, and cable in trenches shall be material specified in 2.1.3. An alternate material, such as select native bedding material, may be used with written approval from the Construction Engineer.

b. Place and compact bedding in trench prepared as specified in 3.1 .5 before laying pipe, conduit, and cable. Compact bedding as specified for structural backfill.

c. Place backfill over joints in underground pipes only after pressure testing of line has been completed.

d. Backfill under conduit and haunches of pipe, around sides, and up to 1 foot above top of pipe, conduit, and cable using bedding material. Place and compact material same as specified for structural backfill. Compact with care, to avoid misalignment of pipe and provide uniform bearing along barrel of pipe. Compact bedding and backfill materials of Transfer lines to 98\% of WSDOT M 46-01, Section 600, Test Method 606. Do not compact within 5 feet of any buried utility of unknown type or any utility which may be susceptible to damage from compaction efforts. This pertains primarily to process lines, identified on the Drawings. 
e. Backfill trenches from elevation 1 foot above top of pipe, conduit, Page 29 and cable as follows.

1) Use structural fill or backfill in locations specified in

2) Use common fill or backfill as specified in 3.2.1.3 for other locations.

f. Do not allow heavy construction equipment to pass over buried lines until at least 2 feet of backfill has been placed over the line or until bridging has been placed across trenching and approved by the Construction Engineer.

3.2.1.5 In situ soils:

a. Compact backfill by depositing soils in 8 inch layers and compacting to density equal to in-situ density determined by tests made during excavation. Maintain uniformity of compaction throughout backfil1.

b. Do not use soils containing rocks larger than 3 inches in greatest dimension for compacted backfili.

3.2.2 Plastic Sheet Marker: Place continuously and directly over buried utility lines, 1 foot below finish grade. Place markers over each outside line of multiple lines, if spacing permits. Place intermediate markers spaced 4 feet maximum.

3.2.3 Finish Grading and Stabilization

3.2.3.1 Rake areas disturbed by work, remove surface stones larger than 6 inches, and dispose of excess material and debris at an area designated by the Construction Engineer.

3.2.3.2 Stabilize areas disturbed by work with a-3 int $\mathrm{ECN}-548$ crushed rock specified in 2.1.4. Finish stabilization course to elevations shown on the Drawings.

$3.3 \quad$ FIELD QUALITY CONTROL

3.3.1 Soil Compaction Tests: Sampling and testing of compacted fill and backfill will be performed. Frequency of testing shall be in accordance with WSDOT M 41-01, Page 9-52 and as directed by the Construction Engineer to ensure uniform compaction of backfill materials.

END OF SECTION 
CHAIN LINK FENCES AND GATES

PART 1 - GENERAL

1.1 REFERENCES

1.1.1 The following documents, including others referenced therein, form part of this Section to the extent designated herein.

1.1.1.1 American Society for Testing and Materials (ASTM)

A 90-81 (1991)

1.1.1.2 Federal Specifications (FS)

RR-F-191K/Gen

RR-F-191/1D

RR-F-191/3D

RR-F-191/4D

1.2 SUBMITTALS: Not Used

1.3 DELIVERY, STORAGE, AND HANDLING

1.3.1 See Section 01610 for general requirements.

PART 2 - PRODUCTS

2.1 MATERIALS

2.1.1 Fence Fabric: FS RR-F-191/1, Type I, 2 inch mesh, 11 gage, 84 inch height, top and bottom salvages twisted and barbed.

2.1.2 Posts, Top Rails and Braces: FS RR-F-191/3, Class 1, Grade A or B, of following sizes.

2.1.2.1 Line posts: SP3.
Test Method for Weight of Coating on Zinc-Coated Galvanized) Iron or Stee 1 Articles

Fencing, Wire And Post, Metal (And Gates, Chain-Link Fence Fabric, And Accessories) (General Specification)

Fencing, Wire And Post, Metal (Chain-Link Fence Fabric)

(Detailed Specification)

Fencing, Wire And Post, Metal (Chain-Link Fence Posts, Top Rails And Braces) (Detailed Specification)

Fencing, Wire And Post, Metal (Chain-Link Fence Accessories) (Detajled Specification) 
2.1.2.2 Terminal posts and posts set at break in grade: SP4.

2.1.2.3 Top rails: SPl.

2.1.2.4 Braces: Diagonal truss and horizontal brace, hot-dip gaivanized steel rods $3 / 8$-inch diameter with turnbuckle.

2.1.2.5 Where posts other than Class 1 are used, they shall be Class 3,4 , or 6 , and of equal strength and stiffness as posts specified in 2.1.2.

2.1.3 Accessories: FS RR-F-191/4.

2.1.3.1 Wire ties and clips: Zinc-coated stee $]$.

2.1.3.2 Tension wire: No. 7 gage zinc-coated steel per FS RR-F-191/4.

2.1.3.3 Miscellaneous accessories: Miscellaneous fittings including bolts, nuts and washers shall be malleable iron, cast iron, or steel, and be hot-dip gaivanized.

2.1.4 Coating: Fence shall have a zinc coating of uniform thickness, weighing at least $1.2 \mathrm{oz} / \mathrm{ft}^{2}$ of surface, as determined by ASTM A 90 . Apply coating to parts after fabrication. Repair welds or breaks in galvanized coatings with zinc-rich coating such as ZRC or Galvacon.

\subsection{MIXES}

2.2.1 Concrete: Minimum compressive strength of $2000 \mathrm{lb} / \mathrm{in}^{2}$ at 28 days.

PART 3 - EXECUTION

3.1 INSTALLATION

3.1.1 Install fence true to line and grade in locations shown on the Drawings and in accordance with this Section.

3.1.2 Setting Posts

3.1.2.1 Set posts in concrete, plumb and true to line. Space line posts eventy, 10 feet maximum, between end and gate posts.

3.1.2.2 Holes for setting line posts shall be 8 inches to 12 inches in diameter and 3 feet deep. Holes for setting gate and end posts shall be 10 inches to 17 inches in diameter and $3^{\prime}-6^{\prime \prime}$ deep. Set post ends 6 inches above bottom of hole.

3.1.2.3 Firmly support posts to prevent movement or deflection until concrete has set 24 hours minimum.

3.1.3 Bracing Posts: Horizontally brace gate, corner and terminal posts with steel pipe using brace attachments, and diagonally brace from the base of gate, corner, and terminal posts to the midheight of adjacent line posts using steel rods with truss attachments. 
3.1.4 Tension Wires: Install top and bottom tension wires to stabilize wire Page 32 fabric.

3.1.4.1 Install top tension wire through $1 / 4$ inch holes drilled in each post, except gate posts drilled 3 inches below the top in each post.

3.1.4.2 Install bottom tension wires through $1 / 4$ inch holes in each post, except gate posts, 4 inches above finish grade.

3.1.5 Attaching and Stretching Fabric

3.1.5.1 Thread tension bars through end loops of each section of fabric and tie to end, corner, and gate posts with tension bands spaced not more than 15 inches on centers.

3.1.5.2 Fasten fabric to posts with ties spaced not more than 14 inches on centers. Topmost tie shall be as near top of fabric as possible; lowest tie as near bottom of fabric as possible.

3.1.5.3 Tie fabric to top and bottom tension wires with wire clips or ties spaced 24 inches maximum on centers.

3.1.5.4 Stretch fence fabric taut.

3.1.5.5 Dress barbed ends of barbed top fabric approximately 2 to 3 inches above top tension wire. Straighten each barb as needed to present unbroken line above and below tension wire.

3.1.5.6 Bottom of fabric shall extend to within 2 inches of finish grade.

3.1.6 Bolt Heads: Locate bolt heads on outside of fence.

END OF SECTION 


\section{CAST-IN-PLACE CONCRETE}

PART 1 - GENERAL

1.1 REFERENCES

1.1.1 The following documents, including others referenced therein, form part of this section to the extent designated herein.

1.1.1.1 American Concrete Institute (ACI)

$117-90$

$301-89$

$306.1-90$
Tolerances for Concrete Construction and Materials

Structural Concrete for Buildings

Cold Weather Concreting

1.1.1.2 American Society for Testing and Materials (ASTM)

A $615-92 b$

A $853-91$

C 94-92a

C 531-85 (1990)

C 579-91

C $827-87$

D $1056-91$

A $185-94$

1.1.1.3 Federal Specifications (FS)

TT-S-00230C

AMD 2
Deformed and Plain Billet-Steel Bars for Concrete Reinforcement

Steel Wire, Carbon, for General Use

Ready-Mixed Concrete

Test Method for Linear Shrinkage and Coefficient of Thermal Expansion of Chemical Resistant Mortars, Grouts and Monolithic Surfaces

Test Method for Compressive Strength of Chemical Resistant Mortars and Monolithic Surfacings

Standard Test Method for Change in Height at Early Ages of Cylindrical Specimens from Cementious Mixtures

Flexible Cellular Materials - Sponge or Expanded Rubber

Steel Welded Wire Fabric, Plain, for Concrete Reinforcement

$\mathrm{ECN}-123$

$\mathrm{ECN}-123$
Sealing Compound: E7astomeric Type, Single Component (For Calking, Sealing, And Glazing In Buildings And Other Structures) 
1.1.1.4 Washington State Department of Transportation (WSDOT)

M 41-10-94

Road, Bridge, and Municipal

Construction 
1.2 .1 See Section 01300 for submittal proces.

1.2 .2 Appoval Required:- None

1.2 .3 Approval- Not Required

1.2.3.1-Comerciat-grade-item dormation: Before fabricationt

installation, stbmit reports of inspections antests of

items sped in 2.3 .1 .

Pá 390

\subsection{QUALITY ASSURANCE}

1.3.1 Deliverable Documentation: The following documents and records, required by this Section, shall be delivered to Construction Document control in accordance with Section 01720.

Document

Pour Slip and Trip Tickets

Material Test Results

\section{Paragraph}

$$
\begin{aligned}
& 3.2 .2 .1 \\
& 2.3 .1 .1,3.4 .1,3.4 .2
\end{aligned}
$$

ECN-290

1.4 DELIVERY, STORAGE, AND HANDLING

1.4.1 See Section 01610 for general requirements.

PART 2 - PRODUCTS

2.1 SUBSTITUTES

2.1.1 See Section 01630 for substitution approvals.

2.2 MATERIALS

2.2.1 Concrete: ACME preapproved mix design No. 6452.

2.2.2 Measuring, Mixing, and De7ivery: In accordance with ASTM C 94.

2.2.3 Reinforcing Stee1

2.2.3.1 Steel bars: ASTM A 615, deformed, Grade 60 .

2.2.3.2 Tie wire: ASTM A 853 carbon steel, 0.062-inch (16-gage) minimum, annealed.

2.2.3.3 Welded wire fabric: ASTM A 185

2.2.4 Joint Materials

2.2.4.1 Epoxy resin: In accordance with WSDOT M 41-10, Section 9-26, Type II, Grade 2, Class B or C; OCM Company EAS8 Class A, Adhesive Engineering "Concresive $1001 \mathrm{LPL}$, " or Protex Industries "Probond 822."

2.2.4.2 Sealant: FS TT-S-00230, Type II. 
2.2.4.3 Gasket: ASTM D 1056; Williams Products Incorporated, Everlastic Closed Page 36 Cell Neoprene Type NN-1 1040 series. 
2.2.4.4 Adhesive: Williams Products Incorporated, No. 37A.

2.2.5 Nonshrink Epoxy Grout: ASTM C 827; U.S. Grout Corporation "Five Star

\section{HF Epoxy Grout" or approved substitute. (10,000 psi min. in 7 days) \\ 2.2.6 Forms: Wood, steel, plywood, or Masonite Corporation "Concrete Form Presdwood," as required for various specified finishes.}

$\mathrm{ECN}-290$

2.2.7 Form Coating Materials: Symons Corporation "Magic Kote," AC Horn Incorporated "Form Shield, "or Burke Company "Burke Release No. 1."

2.2.8 Sealer/Hardener: See Section 09900 .

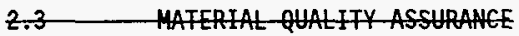

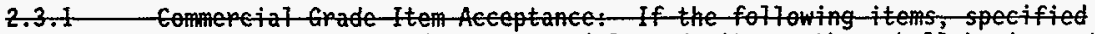
in 2.2 , are proctured as commercial grade-items, they shat be inspected op tested as specified below. Doetment the results in reports.

2.3 .1 .1 Nonshink Epoxy Grout specified in 2.2.5.

a. Crout shall show no shrinkage $(0.0 \%)$ and a maximum $2.0 \%$ expansion ECN-281/ from time of ptacement wen tested accopding to ASTH C 827 , modified to use-a ball-with-a specific-gravity between-0.9-and 1.1.

b. The grout shall show-2 minimum- 7 day-compressive strength of 16,000 ps i when tested according to ASTM-C 579 .

C. The grout shall-show a maximum cofficient of themal-expansion

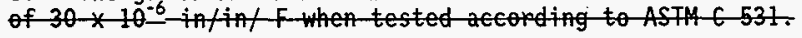

4. The shall show-enequal to op less than $5.0 \times 10^{-3}$ infin

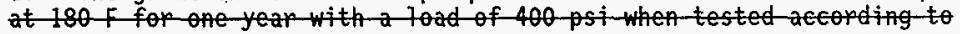
EPR Ereep-Test.

\section{PART 3 - EXECUTION}

\subsection{PREPARATION}

3.1.1 Form Construction

3.1.1.1 Install formwork in accordance with ACI 301, Section 4.2 and approved submittals. Interior shape and rigidity shall be such that finished concrete will meet the requirements of the Drawings within tolerances specified in ACI 117, Section 4.

3.1.1.2 Prepare form surfaces in accordance with ACI 301, Section 4.4 using specified form coating materials, or as described below.

3.1.1.3 Forms for surfaces which will be permanently concealed from view may be saturated with water, before placing concrete, instead of other treatment. In freezing weather forms shall be treated with oil or stearate.

3.1.1.4 Clean forms of foreign material before placing concrete. 
3.1.2.1 Obtain scanning services to locate rebar and embedments, excluding inside surfaces of existing pits and cover blocks.

3.1.2.2 Precautions shall be taken for the containment of drilling lubricants/ water as required.

3.1.2.3 Core drill locations shall be as specifically dimensioned on the Drawings. In the event that a dimension has been specified, and an embedment (rebar, conduit, etc) is detected during scanning, the Construction Engineer shail be contacted for resolution.

3.1.2.4 Verify that the kill switch device on the core drill is operational.

3.1.2.5 Approach surface "breakthrough" cautiously to minimize and controt penetration of the drill.

3.1.2.6 Do not cut rebar embedment unless written permission from design engineer is obtained.

3.1.2.7 Sketch a grid of the rebar and/or embedment location on the outside surface of concrete.

3.1.2.8 Prepare a "Core Ori\}ling Record" form KEH-1969 in accordance with the instructions, identifying the final hole locations and the rebar/grid or embedment.

3.1.3 Joints

3.1.3.1 Clean joints and surfaces to be sealed, adhered, or caulked, removing dirt, dust, oil, grease, mortar, and other foreign materials.

3.1.3.2 Remove loose particles with wire brush. Blow out joints with dry, oil free compressed air. Remove wax or oil using Inland Technologies "CitraSafe," or Xylol.

3.1.3.3 Follow recommendations of manufacturer of sealing, adhesive and caulking materials for each condition of application. Prevent foreign materials from joint and surface cleaning to become intermixed with sealing, adhesive and caulking materials.

\subsection{INSTALLATION}

\subsubsection{Reinforcing Steel}

3.2.1.1 Fabricate bars to dimensions shown on the Drawings, within tolerances shown in ACI 301, Section 5.6.

3.2.1.2 Tag in accordance with the bar list.

3.2.1.3 PTace as shown on the Drawings, within tolerances specified in ACI 117, Section 2.2.

3.2.1.4 Tie to prevent displacement during placement of concrete. 
3.2.1.5 Do not force into concrete after initial set has started.

3.2.1.6 Place with the concrete protection dimension given in ACI 301 , Section 5.7, except where shown otherwise on the Drawings.

3.2.1.7 Reinforcement shall be supported and fastened together to prevent displacement by construction loads, or placement of concrete beyond specified tolerances. Reinforcement supported from the ground shall rest on precast, square concrete blocks, sized $100 \mathrm{~mm}$ (4 inches) minimum, having a compressive strength equal to the specified compressive strength of the concrete being placed. other means of support require prior approval by the Construction Engineer.

3.2.1.8 Over7ap welded wire fabric wherever successive mats or rolls are continuous, in such a way that overlap measured between outermost cross wire of each fabric sheet is spacing of cross wires plus $50 \mathrm{~mm}$ (2 inches) minimum. Tie splices with wire.

\subsubsection{Concrete}

\subsubsection{Before placing:}

a. Approve the "Pour Slip," including identification of sections of structure to be placed, maximum size of coarse aggregate, and design strength.

b. For each truck load, collect the "Trip Ticket." "Trip Tickets" shal1 contain information 1isted in ASTM C 94, Paragraphs 16.1.1 through 16.1.10, and the water/cement ratio.

3.2.2.2 Place in accordance with ACI 301, Sections 8.1, 8.2, and 8.3. Do not drop (free fall) more than 5 feet. Insert vibrator, vertically if possible, into concrete and reach small distance into concrete in next lower layer. Do not insert vibrators into lower courses that have reached initial set. Take care to avoid allowing head of vibrator to come in contact with forms, reinforcement, or embedded items.

3.2.2.3 Temper only as permitted in ACI 301, Section 7.5.

3.2.2.4 Place nonshrink epoxy grout where shown on the Drawings, in accordance with manufacturer's recommendations.

3.2.2.5 Weather conditions: Protect concrete during placement in accordance with ACI 301 , Sections 7.6 and 8.4. Cold weather concreting procedure shall be in accordance with ACI 306.1 .

3.2.2.6 Construction joints: Make in accordance with ACI 301, Section 6.1. Coat joints with epoxy resin, in accordance with manufacturer's recommendations.

3.2.2.7 Embedded items: Install in accordance with ACI 301, Sections 6.4 and 6.5.

3.2.2.8 Placing concrete against earth: Place on or against firm, damp surfaces free of frost, ice and free water. Do not place until required compaction has been obtained. Dampen earth surfaces to receive fresh concrete. 
3.2.2.9 Consolidation: Consolidate concrete slabs in accordance with ACI 301 , Page 40 Section 11.6. 
3.2.3.1 Form removal: Remove in accordance with ACI 301, Section 4.5.

3.2.3.2 Cut back form ties and examine concrete surfaces for defects. Repair only after permission for patching is given by the Construction Engineer.

3.2.3.3 Place concrete repair mortar within 1 hour after mixing. Do not retemper mortar.

3.2.3.4 Repair surface defects in accordance with ACI 301, Sections 9.1, 9.2 and 9.3. Cure concrete repairs the same as new concrete.

3.2.4 Concrete Finishes and Tolerances

3.2.4.1 Formed surfaces: Start finishing following concrete repair and complete within 96 hours after forms have been removed. Finish in accordance with the following ACI 301 sections.
a. Surfaces exposed to
Section 10.2.1 earth backfill
b. Interior surfaces
Section 10.2 .2
c. Exterior surfaces exposed to weather
Section 10.2.2
d. Related unformed surfaces
Section 10.5
e. Surfaces to receive special protective coating
Section 10.3.2

3.2.4.2 Unformed surfaces: Finish in accordance with the following ACI 301 sections.
a. Interior floors
Section 11.7 .3
b. Exterior equipment slabs
Section 11.7 .3
c. Exterior slabs subject to
Section 11.7 .4
foot traffic

3.2.5 Sealant and Caulking

3.2.5.1 Apply adhesives and perform sealing and caulking work using specified materials and proper tools in accordance with manufacturer's recommendations for conditions of each application.

3.2.5.2 Apply exterior sealing material when ambient temperature is 40 to $100^{\circ} \mathrm{F}$.

3.2.5.3 Apply sealing materials with guns having proper size nozzles and sufficient pressure to fill spaces and voids solid. Where use of guns is impractical, hand tools approved by the Construction Engineer may be used. 
3.2.5.4 Tool sealant after installation as required to properly fill joint and Page 42 produce smooth surface.

3.2.5.5 Prevent contact of sealants or caulking with adjacent surfaces. If necessary, apply masking tape in continuous strips in alignment with edge of joint. Remove masking tape after joints have been tooled.

3.3 CURING

3.3.1 Cure concrete in accordance with ACI 301, Section 12.2. Do not use curing compounds on surfaces to receive sealer/hardener.

3.4 FIELD QUALITY CONTROL

3.4.1 Concrete Testing: Sample and test concrete in accordance with ACI 301, Sections $16.3 .4,16.3 .5,16.3 .6$ and 16.3.8. Record the results.

3.4.2 Honshrink-Epoxy Grout-Installation:-The quality-control-inspector will inspect SC1 epoxy grout installations-in accondance with manufacturep's recomendations and paragraph 2.3 .1 .1 of this-Section. Nonshrink Epoxy Grout: Test epoxy grout in accordance with ASTM C-579, Hethod $B$. Testing is required for only one material formulation. Provide six test specimens for each material formulation. Record the results.

PROTECTION

3.5.1 Protect concrete during extreme weather conditions in accordance with ACI 301 , Section 12.3.

3.5.2 Protect concrete from mechanical damage in accordance with ACI 301, Section 12.4 . 


\section{PRECAST CONCRETE}

PART 1 - GENERAL

\subsection{REFERENCES}

1.1.1 The following documents, including others referenced therein, form part of this section to the extent designated herein.

1.1.1.1 American Concrete Institute (ACI)

301-89

$306.1-90$

$349-90$
Structurat Concrete for Buildings

Cold Weather Concreting

Code Requirements for Nuclear Safety Related Concrete Structures

1.1.1.2 American Society for Testing and Materials (ASTM)

\begin{tabular}{|c|c|}
\hline$A-6-942$ & $\begin{array}{l}\text { General Requirements fop Rolles } \\
\text { Structural Steel Bars, Plates, } \\
\text { Shapes, and Sheet Piling }\end{array}$ \\
\hline A-29-93 & $\begin{array}{l}\text { Steel Bars, Carben and Alloy, } \\
\text { Hot Wrought and-Cold Finished, } \\
\text { General Requirements for }\end{array}$ \\
\hline
\end{tabular}

Structural Steel Bars, Plates,

Shapes, and sheet piring

A $36-91$

Structural Steel

A 53-90b

Pipe, Steel, Black \& Hot-Dipped, ZincCoated Welded \& Seamless

A 108-90a

Steel Bars, Carbon, Cold Finished, Standard Quality

A $370-94$

A $615-92 b$
Standard Test Methods and Definitions

for Mehanical Testing of Steel

Products

Deformed and Plain Billet-Steel Bars for Concrete Reinforcement
$\mathrm{ECN}-117$

Standard Test Methods, Practices, and ECN-117

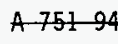
Teminology for Chemical Analysis of Steel products 
HNF-2536, Rev. 0

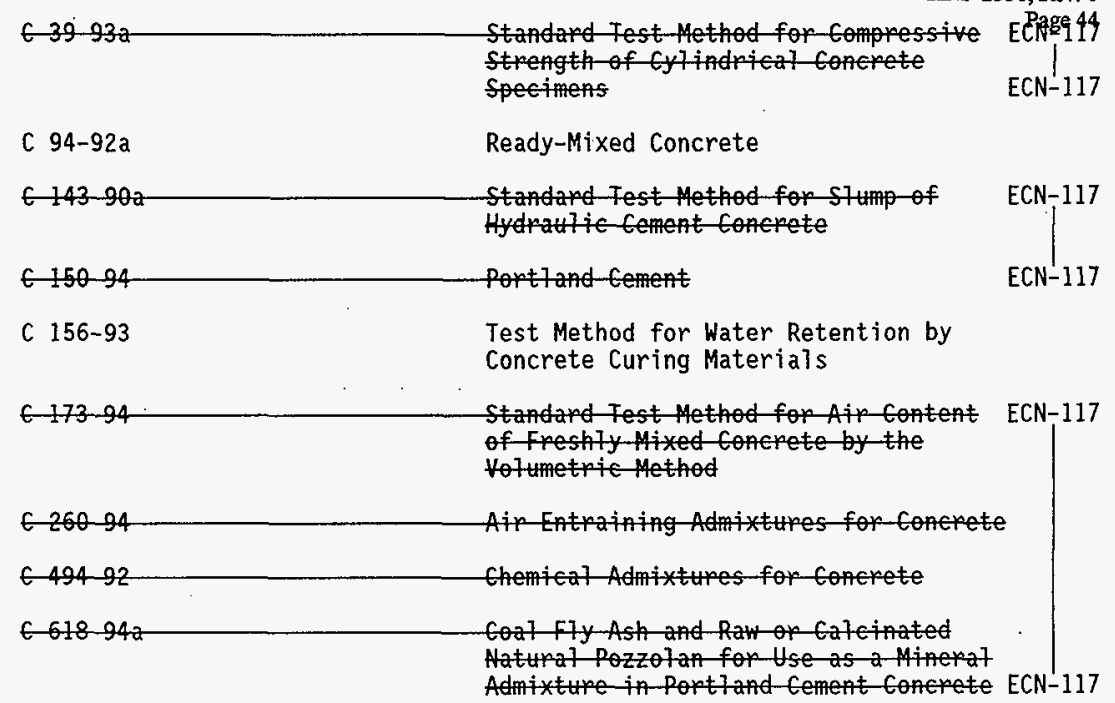

1.1.1.3 American Welding Society (AWS)
D1 . 1-92
Structural Welding Code-Stee?

\subsubsection{Prestressed Concrete Institute (PCI)}

MNL-116-85

Manual for Quality Control for Plants and Products of Precast and Prestressed Concrete Products

1.2 SUBMITTALS: Not Used

1.2.1 See Section 01300-for submittat procedure-

\section{$1.2 .2 \quad$ Approval Required}

1.2.2.1 Concrete data: Before mixing submit proped mix design for ACME pre app mix design No. 6452 for-review and record-purposes.

1.2 .3 Approva? Not Required

1.2.3.1. Commercial grade item documentation.-Before fabrieation/installation, sumit reports of inspections and tests of items specified in 2.3 .1 . 
1.3.I Deliverable Documentation: The following documents and records, required by this Section, shall be delivered to Construction Document control in accordance with Section 01720 .

Document

Pour Slip and Trip Tickets

Materials Test Results

1.4 DELIVERY, STORAGE, AND HANDLING

1.4.1 See Section 01610 for general requirements

PART 2 - PRODUCTS

2.1

2.1.1 See Section 01630 for substitution approvals.

2.2 MATERIALS

2.2.1 Concrete: ACME preapproved mix design No. 6452 .

2.2.2 Delivery: In accordance with ASTM C 94.

2.2.3 Reinforcing Steel

2.2.3.1 Steel bars: ASTM A 615, deformed, Grade 60, except No. 3 ties shall be Grade 40 .

2.2.3.2 Fabricate reinforcing bars within tolerances Tisted in ACI 301 , Sections 5.6 and 5.7, free of bends not required by the Drawings.

2.2.3.3 Tag steel in accordance with the bar list.

2.2.4 Rolled Steel Shapes, Plates, and Bars: ASTM A 36.

2.2.5 Steel Pipe: ASTM A 53 (black), standard weight, Schedule 40.

2.2.6 Weld Studs: Nelson Stud Welding Company, Type H4L.

2.2.7 Forms: Wood, steel, plywood, or Masonite Corporation "Concrete Form Board," as required for various finishes specified in PCI MNL-116, Article 3.5.3.

2.2.8 Bondbreaker: Compatible with adhesive for resilient flooring. 
HNF-2536, Rev. 0 Page 46

2.3.1 Commercial Grade Item Acceptance: If the following items specified in 2.2 are protured as comercial grade-items, they shall be inspected op tested as specified below. Docment the pestlts in reponts.

\subsubsection{Pre appoved concretemix designspecified in 2.2.1.}

4.-Penforman evaluation of the concrete mix proportions in

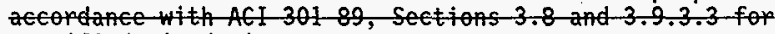
specified mix design.

6. Prenform-an-evaluation of the-concrete-mix-ingredients to ensure compliance with-specifications and applicable codes-and stands. The foliowing is a list of coneretemix ingredients to be-evaluated:

1) Cement in aceordancewith ASTM C 150,-Type-II.

2) Fly Ash in acodance-with-ASTH C-618, C7ass-F. Amoun of fly ash-shall be $25 \% \pm 1 \%$ by weight-of eement.

3) Aggregates in accordance-wh-AST C-33, maximum size of coupse agsegate $3 / 4$ inch.

4) Aip-Entraining Admixture-in aecordance-with ASTHC 260, no-ehloride-aded during-manfatture.

5) Water Reducing Admixture in accopdance-with ASTMC 494, Type-0, no chloride added-during mantfacture.

c. Perfom an evaluation of the concretemix properties to enstife compliance with specifieations and applicable codes and standards. The following-is a tist of concretemix-poperties to be-evaluated:

\section{1) Shump 4 inch \pm 1 inch.}

z) Antont $5 \% \pm 1 \%$

d. Perform the following test procedures on the concretemix at the time of placement in the field. Each test procedure shat7 be performed a minimum of one time for each pour op one time-for each 100 yards derivered for 2 pour, whicherer is greater.

1) STum test in a inch.

2) Air-Content-test in accordance with ASTAC $173-5 \% \pm$ 1\%.

3) Obtain concrete test cylinders in accordance with ASTM C 31 for determination of encrete compressive strength in accordance with ASTM C $39, f^{\prime} \rightarrow 4000$ psi. 
2.3.1.2 Reinforcing steel specified in 2.2.3:- Submit certified test reports (mill test reponts) verifying yield-strength and chemical composition of rebars in accordance with ASTM A-615, grade 60. The test reports-must verify that the material-meets the weight, spacing and height of defomation requirements-in accordance with ASTHA-615, G0.

2.3 .3 .3 Rolled-steel shapes, plates, and bass specified-in 2.2.4.

a.-Pepform a tensile-test in accordance-with ASTM-A 370 to verify the minimum yield-strength of the material is greater than 36,000 -psi-

b. Pepfom a chemical analysis in acomance with-ASTM A-751 to verify the material meets the chemica? requirements of ASTM A 36 -Tale 2 .

E. Perform a check of the dimensions-to verify the plates of shapes are within pemissible variations of ASTM $A-6$.

\section{3 .1 .4 Steel pipe-specified in 2.2 .5 .}

a. Perform a tensile test in accordance-with ASTM A 370 to verify the minimum yield strength of the materiat is greater than 35,000 psi.

b. Perfom \& hemical analysis in acorance with-ASTM A 751 to verify the material mets the chemical requirements-of-ASTM A 53-Table 1 and 2 for Tye 5 , 8 .

\section{3 .1 .5 Weld studs spedin 2.2 .6 .}

a. Perform-2 tensile test to verify that the minimum tensile strength of the studs is 60,000 psi. Tensite test witl be performed in aceopdance with ASTM A 370 and samples selected in zecordance-With-ASTA A 29.

b. Pepform a bending, torquing, or tensioning test in acordance with Alls 01.1, Artic7e 7.6.6-to ensure that the wet attaching the weld stud to the base-fiaterial-will not fait.

6. Perform-a check of the stud dimensions to-ensure permissible-raniations in dimensions are in acodance with ASTM A 29.

4. Perform-visual-inspection of stud-spacings-and-edge distances to rexify that no-stud is placed with less then the minimum- requirement, as specified by the mumfoturer, and more then the maximum requirement, as specified by design:

e. Centificate of conformance will be required from the manufacturer-to ensure-that the studs meet the requirements of ASTH A 108. 
PART 3 - EXECUTION

\subsection{PREPARATION}

3.1.1 Form Construction: Installation, surface preparation, true line setting, and reuse of forms shall be in accordance with PCI MNL-116, Article 5.1.2 and 5.1.3, or as directed by the Construction Engineer.

\subsection{INSTALLATION}

\subsubsection{Reinforcing Steel}

3.2.1.1 Place as shown on the Drawings, within tolerances specified in PCI MNL-I16, Article 6.4.

3.2.1.2 Do not force reinforcing bars into concrete after initial set has started.

3.2.1.3 Minimum concrete protection for reinforcement shal1 be in accordance with ACI 349, Section 7.7.2, except where shown otherwise on the Drawings.

3.2.1.4 Additional reinforcement required for handling and erection shall be the responsibility of the Contractor and manufacturer.

3.2.2 Cast-In Items: Place within tolerances specified in PCI MNL-116, Article 5.1.5. Perform welding and welding inspection in accordance with AWS D1.1.

\subsubsection{Concrete}

3.2.3.1 Before Placing:

a. Approve the "Pour Slip," including identification of sections of structure to be placed, maximum size of coarse aggregate, and design strength.

b. For each truck load, collect the "Trip Ticket." "Trip Tickets" sha11 contain information listed in ASTM C 94, subparagraphs 16.1.1 through 16.1.10, and the water/cement ratio.

3.2.3.2 Place in accordance with ACI 301, Sections 8.1, 8.2, and 8.3. Do not drop (free fal1) more than 5 feet. Insert vibrator, vertically if possible, into concrete and reach small distance into next lower layer. Do not insert vibrators into lower courses that have reached initial set. Take care to avoid allowing head of vibrator to come in contact with forms, reinforcing, or embedded items.

3.2.3.3 Temper only as permitted in ACI 301, Section 7.5.

3.2.3.4 Weather conditions: Protect concrete during placement in accordance with ACI 301, Section 8.4. Cold weather concreting procedure shall be in accordance with ACI 306.1. 
3.2.3.5 Consolidation: In accordance with ACI 301, Section 11.6.

\subsubsection{Form Removal and Concrete Repair}

3.2.4.1 After form removal, cut back form ties and inspect surfaces for defects. Repair only after permission for patching is given by the Construction Engineer.

3.2.4.2 Place concrete repair mortar within one hour after mixing. Do not retemper mortar.

3.2.4.3 Repair surface defects in accordance with PCI MNL-116, Articles 3.5.4 and 3.5.5. Cure concrete repairs the same as new concrete.

\subsubsection{Concrete Finishes and Tolerances}

3.2.5.1 Formed surfaces: Start finishing of concrete following repair and complete within 96 hours after forms have been removed. Finish formed surfaces in accordance with ACI 301, Section 10.3.2.

3.2.5.2 Related unformed surfaces: Finish in accordance with ACI 301 , Section 10.5.

\section{$3.3 \quad$ CURING}

3.3.1 Cure concrete in accordance with ACI 301, Section 12.2. Where curing compound of surface membrane type is used, it shall retain at least $85 \%$ of water in concrete for 72 hours after placement as determined in accordance with ASTM C 156.

3.3.2 Do not use curing compound on surfaces to recejve sealer/hardener or special protective coating.

3.4 FIELD QUALITY CONTROL

3.4.1 Concrete Testing: Sample and test concrete in accordance with ACI 301, Sections $16.3 .4,16.3 .5,16.3 .6$, and 16.3.8. Record the results.

3.4.2 Cracking Acceptability: Kinds, causes of cracking, prevention and control, and recommendations for acceptability shall meet the requirements of PCI MNL-116, Article 6.3.2.

3.4.3 Precast Concrete Cover Blocks: The quality control inspector will ensure aceptance testing-of comerial grade items used to fabricate cover blocks is in accordance with the requipements of paragrats $2.3 .1 .1,2.3 .1 .2,2.3 .1 .3,2.3 .1 .4$, and 2.3 .1 .5 of this fection. Record the results. 
3.5.1 Protect concrete during extreme weather conditions in accordance with ACI 301, Section 12.3.

3.5.2 Protect concrete from mechanical damage in accordance with ACI 301 , Section 12.4.

END OF SECTION 


\section{EXPANSION ANCHOR INSTALLATIONS}

PART 1 - GENERAL

1.1 REFERENCES: Not Used

1.2 SUBMITTALS

1.2.1 See Section 01300 for submittal procedures.

1.2.2 Approval Required

1.2.2.1 Expansion anchor evaluation reports: Before delivery, submit reports as specified in Part 2, and installation requirements.

1.2.3 Approval Not Required: None

1.3 QUALITY ASSURANCE

1.3.1 Deliverable Documentation: The following documents and records, required by this Section, shall be delivered to Construction Document Control in accordance with Section 01720.

\section{Document}

Expansion Anchor Instaltation Reports

\section{Paragraph}

3.4 .2

1.4 DELIVERY, STORAGE, AND HANDLING

1.4.1 See Section 01610 for general requirements.

PART 2 - PRODUCTS

2.1 SUBSTITUTES

2.1.1 See Section 01630 for substitution approvals.

2.2 MATERIALS

2.2.1 Expansion anchors (Safety-C7ases 1 Safety Class and Safety ECN-809 Significant): Hilti Fastening Systems "Kwik-Bolt II" (no substitutes ECN-809 allowed).

2.2.2 Expansion anchors (Safety-Clases 3 and 4 General Service): Industry ECN-809 standard wedge type, having a published evaluation report (by the International Conference of Building Officials), with anchor descriptions, tables of allowable tension and shear loads, and test findings. 


\section{METAL FABRICATIONS}

\section{PART 1 - GENERAL}

1.1 REFERENCES

1.1.1 The following documents, including others referenced therein, form part of this Section to the extent designated herein.

1.1.1.1 American. Society of Mechanical Engineers (ASME)

B\&PVC

Section $V$

Section IX

B31.3-1993
Boiler and Pressure Vessel Code

Nondestructive Examination

Welding and Brazing Qualifications

Chemica] Plant and Petroleum Refinery Piping

1.1.1.2 American Society for Nondestructive Testing (ASNT)

SNT-TC-1A

Recommended Practice (1988 Edition)

1.1.1.3 American Society for Testing and Materials (ASTM)

$$
\text { A } 36-91
$$

A $519-94$

A 307-92a

A $563-92$ a

F 844-90
Structural Steel

Seamless Carbon and Alloy Steel Mechanical Tubing

Carbon Steel Bolts and Studs, 60000 psi Tensile Strength

Carbon Alloy Steel Nuts

Washers, Steel, Plain (Flat), Unhardened for General Use 
1.2.2.1 Drawings: For metal fabrications not shown on manufacturer's data sheets: Before fabrication, submit fabrication drawings and bill of materials. Include plans, elevations, details, sections, and. connections. Show thickness, type, grade, class of metal, fasteners, anchorage, and accessory items where applicable. 


\subsection{EXAMINATION}

3.1.1 Examine areas where expansion anchors are to be installed and notify the Construction Engineer in writing of conditions detrimental to proper and timely completion of work as specified in 3.3. Do not proceed with work untit unsatisfactory conditions have been corrected.

\subsection{PREPARATION}

3.2.1 Prepare setting drawings, diagrams, templates, and instructions for installation of expansion anchors to be embedded in concrete or masonry construction.

\subsection{INSTALLATION}

3.3.1 Install expansion anchors in accordance with manufacturer's recommendations.

3.4 FIELD QUALITY CONTROL

3.4.1 Expansion Anchor Installations: The Quality Control Inspector will inspect Safety Class 1 and 2 installations.

3.4.2 Expansion Anchor Inspection: Document inspection results on the "Expansion Anchor Installation Report," Form KEH-1910. 
1.2 .2 .2 Manufacturer's data: Before delivery, submit the following.

2. Copies of manfacturep's-specifications.

b. Dimensionediagrams.

6. Installation instrutions formanfactured itms.

1.2.3 Approval Not Required: None.

1.3 QUALITY ASSURANCE

1.3.1 Welding Processes - Structural Metal Work

1.3.1.1 Procedures for welding components shall have been qualified in accordance with the following.

a. For structural steel, in accordance with AWS D1.1.

b. For sheet steel (structura7), in accordance with AWS D1.3.

c. For sheet metal (seal welding), in accordance with AWS D9.1.

1.3.1.2 Qualification in accordance with the ASME B\&PVC Section IX may be substituted for the above requirements.

1.3.2 Welding Personnel - Structural Metal Work

1.3.2.1 Personnel performing welding shall have been qualified in accordance with the respective Codes of 1.3.1.1.

1.3.2.2 Qualification in accordance with the ASME B\&PVC Section IX may be substituted for the above requirements.

1.3.3 Welding Nondestructive Examination (NDE) Personne1

1.3.3.I Visual weld examinations shall be performed, and appropriate documentation prepared by Certified Welding Inspectors (CWI) who have received certification in accordance with AWS QC1. Certified Associate Welding Inspectors (CAWI), certified in accordance with the above standard, may perform examinations when under immediate direction of CWIs.

1.3.3.2 Qualification in accordance with the ASME B\&PVC Section V, Article 9 may be substituted for the above requirement.

1.3.3.3 Welding related examination documentation shall be signed or stamped by individuals performing examinations. Where CAWIs perform examinations, documentation shall be signed or stamped by both CAWIs and CWIs under whom examinations were performed.

1.3.3.4 Personnel performing other welding NDE shall be certified in accordance with CONTRACTOR's written practice, which shall meet the requirements of ASNT SNT-TC-IA. 
1.3.4 Deliverable Documentation: The following documents and records, Page 56 required by this Section, shall be delivered to Construction Document control in accordance with Section 01720.

Document

Process and Personnel Qualifications

Weld Examination Results

\section{Paragraph}

$1.3 .2,1.3 .3$

$3.5 .2 .1,3.5 .2 .2$

1.4 DELIVERY, STORAGE, AND HANDLING

1.4.1 See Section 01610 for general requirements.

PART 2 - PRODUCTS

2.1 SUBSTITUTES

2.1.1 See Section 01630 for substitution approvals.

2.2 MATERIALS

2.2.1 Rolled Steel Shapes, Plates, and Bars: ASTM A 36 .

2.2.2 Steel Pipe: See Section 03400.

2.2.3 Round Mechanical Tubing: ASTM A 519, Carbon Steet.

2.2.4 Fasteners

2.2.4.1 Expansion anchors: See Section 05055.

2.2.4.2 Weld studs: Nelson Stud Welding Company Type H4L.

2.2.4.3 Bolts: ASTM A 307, Grade $A$ or $B$.

2.2.4.4 Nuts: ASTM $A$ 563, Grade $A$, heavy hex.

2.2.4.5 Washers: ASTM F 844, circular.

2.2.5 We1ding Electrodes: E70XX.

2.2.6 Nonshrink Epoxy Grout: See Section 03300.

2.2.7 Paint: See Section 09900.

2.2.8 Zinc-Rich Coating: Southern Coating Incorporated "Galvicon, " or ZRC Products Company "ZRC."

\subsection{FABRICATION}

2.3.1 General 
2.3.1.1 Verify measurements and take field measurements necessary before fabrication. Provide miscellaneous bolts and anchors, supports, braces, and connections necessary for completion of metal fabrications. Cut, reinforce, drill, and tap metal fabrications shown to receive finish hardware and similar items. Weld or bolt connections as shown on the Drawings. 
2.3.1.2 Workmanship: Form metal fabrications to shape and size, with sharp Page 58 lines, angles, and true curves. Drilling and punching shall produce clean, true lines and surfaces. Execute and finish work in accordance with fabrication drawings.

2.3.1.3 Jointing and intersections: Accurately made, tightly fitted, and in true planes with adequate fastenings.

2.3.2 Miscellaneous Steel Items: Supply required clips, frames, equipment supports, and other fabrications shown on the Drawings. Fabricate parts from standard structural sections or shapes, to sizes required. Wherever miscellaneous parts are exposed, grind edges, corners, and rough cuts smooth and free of snags. Shop paint parts except those to be embedded in concrete or masonry, or those which require other specific finishes.

2.3.3 Finishes: Prime ferrous metal in accordance with Section 09900. Do not coat members to be embedded in; concrete or masonry, surfaces and edges to be field welded, or items to be galvanized.

PART 3 - EXECUTION

\section{$3.1 \quad$ EXAMINATION}

3.1.1 Examine areas where metal fabrications are to be installed and notify the construction Engineer in writing of conditions detrimental to proper and timely completion of work as specified in 3.3. Do not proceed with work until unsatisfactory conditions have been corrected.

\subsection{PREPARATION}

3.2.1 Prepare setting drawings, diagrams, templates, and instructions for installation of anchorages, such as concrete inserts, anchor bolts, and miscellaneous items having integral anchors, to be embedded in concrete. Coordinate with the Construction Engineer for delivery of items to site.

\section{$3.3 \quad$ INSTALLATION}

3.3.1 Expansion Anchor Installation: See Section 05055.

3.3.2 Install metal fabrications plumb, level or as shown on the Drawings.

3.3.3 Make field connections as neatly as possible with joints flush and smooth. Grind smooth exposed field welds and polish before field painting. Repair welds in galvanized work with 2 coats of zinc-rich coating.

3.3.4 Where dissimilar metals are in contact, or where aluminum is in contact with concrete, mortar, masonry, wet or pressure-treated wood, or absorptive materials subject to wetting, protect surfaces with isolating tape to prevent galvanic or corrosive action. 
3.4.1 After installation has been approved, clean and paint connections with primer. Touch-up shop prime coat wherever damaged. Repair breaks in galvanized coatings with zinc-rich coating.

$3.5 \quad$ FIELD QUALITY CONTROL

3.5.1 Perform visual inspection to verify stud spacings and edge distances as specified and shown on Drawings.

3.5.2 Nondestructive WeTd Examination (NDE)

3.5.2.1 Perform visual examination of welds in accordance with AWS D1.1, paragraph 6.5.5, unless noted otherwise on the Drawings. Record the results.

3.5.2.2 Visual weld examination performed in accordance with requirements of ASME B31.3, Paragraph 344.2.2 may be substituted for the above requirement. Acceptance criteria shall be in accordance with ASME B31.3, Table 341.3.2A. Record the results.

END OF SECTION 
SPECIAL PROTECTIVE COATING

PART 1 - GENERAL

1.1 REFERENCES

1.1.1 The following documents, including others referenced therein, form part of this Section to the extent designated herein.

1.1.1.1 Steel Structures Painting Council (SSPC)

SP 2-82

Hand Tool Cleaning

SP $3-82$

Power Toot Cleaning

1.2 SUBMITTALS

1.2.1 See Section 01300 for submittal procedures.

1.2.2 Approval Required

1.2.2.1 List of materiais: Before delivery, submit complete 1 ist of materials, colors and location to be used, to substantiate compliance with the Drawings and this Section. List shall enumerate percentage of volatile and nonvolatile materials and percentage of component parts of each type of material. Colors will be selected by the Construction Engineer.

1.2.3 Approval Not Required: None

1.3 QUALITY ASSURANCE

1.3.1 Deliverable Documentation: The following documents and records, required by this Section, shall be delivered to Construction Document Control in accordance with Section 01720.

Document

Coating Application Test Results

1.4 DELIVERY, STORAGE, AND HANDLING

1.4.1 See Section 01610 for general requirements.

1.4.2 Do not open containers before inspection and acceptance by the Quality Control Inspector. Labels sha11 not be removed under any circumstance.

1.5 PROJECT CONDITIONS

1.5.1 Environment for Coating: Coat exterior surfaces only when ambient and surface temperatures are 50 to $90^{\circ} \mathrm{F}$, and ambient temperature is at least $5^{\circ} \mathrm{F}$ above the dewpoint. 
PART 2 - PRODUCTS

2.1 SUBSTITUTES

2.1.1 See Section 01630 for substitution approvals.

2.2 MATERIALS

2.2.1 Coating Materials: Products of Protective Coatings Division of Ameron, Brea, California or approved substitute.

2.2.1.1 Primers, thinners, and coating accessory materials shall be produced and/or approved for use by the same manufacturer as the finish coating system.

2.2.2 Concrete Filler: Nu-Klad 114A Epoxy Filler Compound.

2.2.3 Primers:

2.2.3.1 New cover block concrete surfaces: Nu-K1ad 105A Primer and Sealer or Amerlock 400.

2.2.3.2 New cover block/plug ferrous metal surfaces: Amerlock 400.

2.2.4 Finish Coatings:

2.2.4.1 A11 new cover block/plug surfaces: PSX 700 Siloxane.

PART 3 - EXECUTION

3.1 EXAMINATION

3.1.1 Examine surfaces scheduted to receive coatings for conditions that will adversely affect execution, permanence, or quality of work, and which cannot be put into acceptable condition through preparatory work as specified in 3.2 .

3.1.2 Report conditions that could adversely affect proper application of coatings, in writing, to the Construction Engineer as specified in 3.3. Do not begin surface preparation, or coating application, until defects have been corrected, and conditions made suitable.

3.2 PREPARATION

3.2.1 New Cover Block Concrete Surfaces:

3.2.1.1 Before application, sweep and dust space or area to receive coating. 
3.2.1.2 Clean concrete surfaces of laitance, $0 i 1$, stains, dust and other foreigiage 62 material.

a. Where laitance has not been removed, treat concrete with uniform application of 1 of following solutions.

1) 1 part $10 \%$ solution muriatic acid and 3 parts water.

2) $5 \%$ solution of trisodium phosphate.

b. When solution ceases to foam, rinse thoroughly with clean water and scrub with stiff bristle brush. Allow treated area to thoroughly dry. Scratches, cracks, holes and abrasions shall be cut back to proper key and filled with Nu-Klad 114A.

c. Allow concrete to cure 30 days before coating is applied, except coating may be applied after concrete has cured 21 days if moisture content of concrete is less than $12 \%$.

3.2.2 New Cover Block/Plug Ferrous Metal Surfaces:

3.2.2.1 Prepare surfaces for finish systems specified in accordance with recommendations of finish material manufacturers and SSPC-SP 2, -SP 3 .

\subsubsection{Postpriming}

3.2.3.1 Feather abrasions, chips, skips, and holidays occurring in prime coat by sanding and recoat with material and color to minimum dry film thickness specified.

3.2.3.2 Previously coated surfaces shall be recoated only after existing film is completely dry.

3.2.3.3 Protect coating from rain until dry to touch.

3.2.4 Protection

3.2.4.1 Provide and install drop cloths, shields, and other protective devices required to protect surfaces adjacent to areas being coated. Keep spatter, smears, droppings, and over-run of coating materials to minimum and remove as coating work progresses. Report all spills to the Construction Engineer.

3.2.4.2 Remove and store electrical fixtures, outlets and switch plates, mechanical diffusers, escutcheons, surface hardware, fittings and fastenings before starting work. Clean and reinstall upon completion of work in each area. Use no solvent or abrasives to clean hardware that will remove Tacquer finish normally used on some items. 


\subsection{APPLICATION}

\subsubsection{Genera]}

3.3.1.1 Before any surface is coated, it shall be clean, dry, undamaged and free of all contaminants. Round off all rough welds and remove all weld splatter.

3.3.1.2 ATl specified surface preparation shall meet the specification of the Coating Schedule and shall be done before application can begin on the area to be coated.

3.3.1.3 All coatings shall be applied under favorable environmental conditions as specified in manufacturer's product Titerature.

3.3.1.4 Coating shall be prepared and applied in accordance with manufacturer's recommendations, and proper induction time shall be observed for epoxies when required by manufacturer. Failure to comply with this requirement will be cause for rejection of the work.

3.3.2 Apply with equipment recommended by manufacturer.

3.3.3 Identify each coat of opaque material by its relation to color of finish coat. Prime coat shall be darkest tint of specified color with each succeeding coat lighter, up to finish coat, which shall be color, tint and sheen specified. Tints of identical coats of identical color and material shall not vary.

3.4 FIELD QUALITY CONTROL

3.4.1 Inspection: The Quality Control Inspector will perform tests to ascertain that coating materiais have been applied as specified in this Section.

\subsection{CLEANING}

3.5.1 Furnish and maintain at site, closed metal containers for disposal of waste materials. Place materials spotted or soaked with paint, oil, or solvents in containers.

3.5.2 Brushes, rollers, spatulas, and spray equipment shall be thoroughly ctorth use and shati contain no oils, thinners, or other residue after cleaning.

3.5.3 Remove empty cans from site at end of each shift.

3.5.4 At completion of coating work, remove materials, containers, rags, cloths, brushes, and other equipment from site. Clean up spills. 
3.6. COATING SCHEDULE

Minimum Wet Film

Thickness and

Percentage of

Film Forming

Solids by Volume

Minimum

Dry Film

Thickness

3.6.1 New Cover Block Concrete Surfaces

Prime and Sealer: Nu-Klad 105A or Amerlock 400

Second:

PSX 700 Siloxane

Finish:

PSX 700 Siloxane

NA

7
7
NA

$5 \mathrm{mils}$

5 mils

3.6.2 New Cover Block Ferrous Metal Surfaces and Lifting Bails

Prime:

Second:

Finish:
Amerlock 400

PSX 700 siloxane

PSX 700 Siloxane
NA

7
NA

$5 \mathrm{mils}$

$5 \mathrm{mils}$

END OF SECTION. 


\section{PAINTING}

PART 1 - GENERAL

\subsection{REFERENCES}

1.1.1 The following documents, including others referenced therein, form part of this Section to the extent designated herein.

1.1.1.1 American Society for Testing and Materials (ASTM)

D 4258-1983 (R1988)

Surface Cleaning Concrete for Coating

1.1.1.2 Federal Specifications (FS)

SS-S-1996

Reinst
Sealer, Water and Weather Resistant, for Asphalt, Concrete, and Masonry Surfaces

1.1.1.3 Painting and Decorating Contractors of America (PDCA)

Architectural Specification

1984

Manual

1.1.1.4 Steel Structures Painting Council (SSPC)

SP 2-82

Hand Tool Cleaning

SP 3-82

Power Tool Cleaning

SP $5-85$

Blast Cleaning "White" Metal

\subsection{SUBMITTALS}

1.2.1 See Section 01300 for submittal procedures.

\subsubsection{Approval Required}

1.2.2.1 tist of mepials: Before delivery, sumit list in manufuturer' nams, specifications, recomentions, and other data necessary to show-complinee-with-requirements. List of materials: Before delivery, submit complete list of materials, colors and location to be used, to substantiate compliance with the Drawings and this Section. List shall enumerate percentage of volatile and nonvolatile materials and percentage of component parts of each type of material. colors will be selected by the Construction Engineer.

1.2 .2 .2 - color-samples: Before delivery, submit-samples-in form-of 3 by 5 -inch color chips: Deseribe couting material, mufacturep, and colop identification on reverse face-of each chip: folors will be-selected by the construction Engineer. Retain 1 set of approved samples at site-for Hse as quitity-standa of find finishes. 
1.3.1 Deliverable Documentation: The following documents and records, required by this Section, shall be delivered to Construction Document Control in accordance with Section 01720.

Document

Coating Application Test Results

\section{Paragraph}

3.4 .1

1.3.2 Use manufacturers and products 1 isted in the PDCA Architectura] Specification Manual, Chapter 7.

1.4 DELIVERY, STORAGE, AND HANDLING

1.4.1 See Section 01610 for general requirements. Store materials indoors.

1.5. PROJECT CONDITIONS

1.5.1 Environmental Requirements

1.5.1.1 Temperature: Unless otherwise recommended by paint manufacturer, apply coatings when ambient and surface temperatures are 45 to $95^{\circ} \mathrm{F}$, except for water-thinned paints and other special coatings.

a. Apply water-thinned.paints when ambient and surface temperature is 50 to $90^{\circ} \mathrm{F}$.

b. Appty varnish on surfaces with temperatures above $65^{\circ} \mathrm{F}$.

c. Apply epoxy coatings when conditions are within humidity and temperature limits recommended by the coating manufacturer.

d. Provide temporary heat as required until specified surface and air temperatures exist for required time periods. Maintain temporary heat for 24 hours after paint and finish application.

1.5.1.2 Weather: Do no exterior work on unprotected surfaces if it is raining or moisture from other source is present or expected before applied finishes can dry or attain proper cure without damage.

a. Allow surfaces to dry and attain required temperatures and conditions specified before proceeding with work or continuation of previously started work.

b. Do not apply finish in areas where dust is being generated.

c. Humidity: Follow manufacturer's directions for extremes.

1.5.1.3 Ventilation: Provide adequate continuous ventilation required for drying various materials as recommended by the manufacturer.

1.5.1.4 Illumination: Provide temporary lighting to attain minimum surface lighting level of $15 \mathrm{fc} / \mathrm{ft}^{2}$. 
PART 2 - PRODUCTS

2.1 SUBSTITUTES

2.1.1 See Section 01630 for substitution approvals.

2.2 MATERIALS

2.2.1 Furnish materials identified in PDCA Architectural Specification Manual, Chapters 5, 6, and 7 for systems scheduled in 3.6.

2.2.2 Furnish ready-mixed materials.

2.2.3 Concrete Sealer/Hardener

2.2.3.1 New concrete pads: FS SS-S-1996, Type II (Top Surface).

2.2.3.2 New cover biock surfaces: See Section 09805 .

PART 3 - EXECUTION

3.1 EXAMINATION

3.1.1 Examine surfaces scheduled to receive finish for conditions that will adversely affect execution, permanence, or quality of work and which cannot be put into acceptable condition through preparatory work specified in 3.2 .

3.1.2 Report conditions that may affect proper application of finish as specified in 3.3, in writing, to the Construction Engineer. Do not. begin surface preparation or coating application until defects have been corrected, and conditions are made suitable.

3.2 PREPARATION

3.2.1 Protection

3.2.1.1 Protect finished work of other trades and the following.

a. Brass, bronze, copper, plated metals, and stainless steel not scheduled for further finish.

b. Materials having complete factory finish, such as electrical switchplates, lighting fixtures, and finish hardware.

3.2.1.2 As work proceeds, and upon completion of work, promptly remove spills, splashes, or splatters from products by methods not damaging to affected surfaces.

3.2.1.3 Repair or replace surfaces damaged by painting work as directed by the Construction Engineer.

3.2.1.4 Remove electrical outlet and switch plates, mechanical diffusers, escutcheons, registers, surface hardware, fittings, fastenings, and 
similar items before starting work. Carefully store, clean, and reinstall items upon completion of work in each area. Do not use cleaning agents detrimental to permanent lacquer finishes.

\subsubsection{Ferrous Metals}

3.2.2.1 Prepare surfaces for finish systems specified in accordance with recommendations of finish material manufacturers, the PDCA Architectural Specification Manual, Chapters 3 and $3 R$, and SSPC-SP 2, -SP3, and -SP5.

3.2.2.2 Obtain written approval for dry or liquid abrasive blasting from the Construction Engineer.

\subsubsection{Concrete Surfaces}

3.2.3.1 Curing period: Concrete shall be allowed to cure 28 days minimum before the application of a concrete sealer/hardener, or as recommended by the manufacturer of the concrete seater/hardener.

3.2.3.2 Form release agents: Agents used during concrete construction shall be removed, unless known to be compatible with the concrete sealer/hardener selected.

3.2.3.3 Concrete curing compounds: Compounds shall be removed unless known to be compatible with the concrete sealer/hardener selected.

3.2.3.4 Contaminants: $0 i 1$, grease, and materials considered deleterious by the concrete sealer/hardener manufacturer shall be removed in accordance with the manufacturer's written recommendations, followed by washing of contaminated areas with detergent and water in accordance with ASTM D 4258.

3.2.3.5 Sweeping and hosing: Clean areas to be treated with a fine bristle broom, or scrub, hose off with water, and let dry to remove surface dust, dirt, and contamination. Pressurized air may be used provided the equipment is oil-free.

\subsection{APPLICATION}

3.3.1 Do not open containers until approved by the Quality Control Inspector. Labels must not be removed under any circumstances.

3.3.2 Mix materials in an ambient temperature above $45^{\circ} \mathrm{F}$ in a well ventilated and heated area, in accordance with the manufacturer's recommendations.

3.3.3 Perform work in accordance with manufacturers instructions, PDCA Architectural Specification Manual, and this Section.

3.3.4 Take precautions to prevent fire hazards and spontaneous combustion. Place cotton waste, cloths, and hazardous materials in containers and remove from the worksite daily. 
3.3.5 Improperly treated surfaces, and holidays shall be repaired using the Page 70 materials specified for the original work, unless otherwise specified, in accordance with written recommendations of the sealer/hardener manufacturer.

3.4 FIELD QUALITY CONTROL

3.4.1 Inspection and testing will be performed by the Quality Control Inspector. Document results of tests.

3.4.2 Meet the requirements of PDCA Architectural Manual for "CUSTOM" materia] and work, unless otherwise specified.

\section{$3.5 \quad$ CLEANING}

3.5.1 Furnish and maintain at site, closed metal containers for disposal of waste materials. Place materials spotted or soaked with paint, 011 , or solvents in containers.

3.5.2 Brushes, rollers, spatulas, and spray equipment shall be thoroughly cleaned after each use and shall contain no oils, thinners, or other residue after cleaning.

3.5.3 Remove empty cans from site at end of each shift.

3.5.4 At completion of coating work, remove materials, containers, rags, cloths, brushes, and other equipment from site. Clean up spills.

\section{$3.6 \quad$ SCHEDULES}

3.6.1 Paint and Finish

3.6.1.1 Paint exposed miscellaneous carbon steel surfaces, unless otherwise specified, as follows:

a. Apply two coats of Amer7ock-400, 5-mils thick per-coat-(DFT), in aceordance-with the manufacturep's instructions-

a. Apply one prime coat of Ameron "Amerlock 400", 5 mil thick

$(D F T)$, in accordance with manufacturer's instructions.

b. Apply one finish coat of Amerout $450 \mathrm{HS}, 2$ to 3 mils

thick (DFT), in accordance with the manufacturep's instructions.

b. Apply one finish coat of Ameron "PSX 700", 3 mils thick (DFT), in accordance with manufacturer's instructions.

c. In liek-of a, and b. above, paint-miseellaneous-exposed Earbon steel surfaces with Benjamin Moore Ironelad high-gloss enamel in accopdance with manfacturep's instructions.

A.c. Do not paint threaded surfaces before assembly.

ed. Do not paint nameplates. 


\section{INSTRUMENTATION}

PART 1 - GENERAL
1.1
REFERENCES

1.1.1 The following documents, including others referenced therein, form part of this Section to the extent designated herein.

1.1.1.1 National Electrical Manufacturers Association (NEMA)

ICS 6-1993

Enclosures for Industrial Controls and Systems

1.1.1.2 National Fire Protection Association

70 (1993)

National Electrical Code (NEC)

1.2 SUBMITTALS

1.2.1 See Section 01300 for submittal procedures.

1.2.2 Approval Required

1.2.2.1 Approval data: Before installation, submit information listed in the Approval Data List in this Section.

1.2.3 Approval Not Required

1.2.3.1 Vendor information: Before installation, submit information listed in the Vendor Information List in this Section.

1.3 QUALITY ASSURANCE

1.3.1 Electrical/Electronic Product Acceptability: Provide 1abeling and documentation in accordance with Section 01400.

1.3.2 Deliverable Documentation: The following documents and records, required by this Section, shall be delivered to Construction Document control in accordance with Section 01720.

Document

Electrical Test Results

1.4 DELIVERY, STORAGE, AND HANDLING

1.4.1 See Section 01610 for general requirements. 


\section{$2.1 \quad$ SUBSTITUTES}

2.1.1 See Section 01630 for substitution approvals.

\subsection{MATERIALS}

2.2.1 Wiring and other materials required to complete instrumentation installation are specified in Section 16400 and on the Drawings.

2.2.2 Instrument Identification Tags: $3 / 4$ by 2 by 0.0478 -inch (18-gage) minimum thickness stainless steel, with $1 / 8$-inch stamped or engraved characters.

2.2.2.1 Fags-shall-show the following: Field tags, as a minimum, shall show Equipment Part Number:

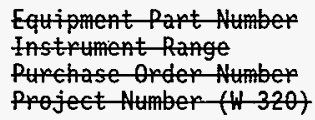

2.2.2.2 Tag Attachment Wire: 20-gage, solid, stainless steel.

2.2.3 Equipment/Instrument Nameplates: Laminated plastic $1 / 16$ inch thick, white surface and black core as shown on Figure 1 .

2.2.3.1 Engrave the nameplates with the information shown on the Drawings and in accordance with Figure 1.

2.2.3.2 Attach nameplates to equipment and panels as shown on the Drawings and in accordance with Figure 1.

\subsection{EQUIPMENT}

2.3.1 Provide instruments consisting of individual instrument devices as specified in the Data Sheets.

2.3.2 Instrument Enclosure: Procure and assemble instrument enclosure IE-0621 as shown on the Drawings.

PART 3 - EXECUTION

3.1 INSTALLATION

3.1.1 Install material and equipment in accordance with the Drawings and manufacturer's instructions. Attach identification tags or nameplates to instruments with wire, or as shown on the Drawings.

3.1.2 Install equipment into enclosure IE-0621 as shown on the Drawings.

3.1.3 Install the completed enclosure IE-0621 in electrical equipment skid (building 241-AY-5I) as shown on the Drawings, and connect all field cabling. 
3.1.4 Mounting of instruments, and other equipment on the existing instrument Page 73 panel shall not interfere with access to connections, removal of adjacent instruments, and normal maintenance.

3.1.4.1 For pressure and flow instrument sensor installation, see jumper Drawings.

3.1.5 Recommended shop equipment for filling the pressure measuring system is shown on Figure 2.

3.1.5.1 Remove the plug from the ball valve and install shop equipment.

3.1.5.2 With the valve opened, and the 3-way ball positioned to allow evacuation, use the vacuum pump to evacuate air from the pressure measurement system cavity.

3.1.5.3 When the pressure gage reads between 25 and 30 inHg, position the 3-way ball to allow silicon oil to be drawn into the system cavity (approximately $30 \mathrm{ml}$ ).

3.1.5.4 After filling, close the valve, remove shop equipment, and reinstall the plug.

3.1.6 Wiring

3.1.6.1 Electrical power wing-and signal-wiring shall be-in acordacewith AFPA 70, Section 16400, and the Drawings: Electrical power wiring, control wiring and signal wiring shall be in accordance with the National Electric Code, NFPA 70 and the Drawings.

3.1.6.2 Instrument signal wiring shall be $\mathrm{ECN}-601$ No. 16 AWG minimum stranded tinned copper wire shielded and twisted unless otherwise recommended by the instrument manufacturer.

3.1.6.2.1 Control wiring shall be Type SIS or THHN and shall not be smal7er than 14 AWG.

3.1.6.3 Instrument and electrical equipment shall be grounded in accordance with NFPA 70 and as shown on the Drawings.

3.1.6.4 Instrument signal wiring routed in parallel with ac power, or control wiring shall be 6 inches minimum distant. Instrument signal wiring crossing power wiring shall be as close to right angles as possible.

3.1.6.5 Wiring within instrument cabinets shall be run open, bundled, and bound with cable ties at regular intervals of 12 inches maximum. Wires within a bundle shall be run parallel to one another. Bundles shall have a uniform appearance, a circular cross section, and be securely fastened to the cabinet framework.

3.1.6.6 Wires shall be identified as shown on the Drawings, at each end, with imprinted tubular plastic wire markers as specified in Section 16400 .

3.1.7 Winch Position Indication (ZI-0621): Confirm that the scale of ZI-0621 has been marked to indicate winch position. If it has not, remove the meter and deliver it to the Construction Engineer for processing. When returned by the Construction Engineer, re-install the meter. 
3.2 FIELD QUALITY CONTROL

3.2.1 Testing

3.2.1.1 Furnish calibrated instruments required to perform testing.

3.2.1.2 Electrical Tests: Test instrument wiring as specified in Section 16400 , and the following.

3.2.1.3 Disconnect wires from instruments and verify continuity of every wire from end to end. Resistance shall be 10 ohms maximum. Record the reading.

3.2.1.4 With conductors disconnected from instruments, but with shields connected to ground, measure and record resistances between each conductor and its related shield. Resistance shall be greater than 100 megohms.

3.2.1.5 Reconnect wires. 


\section{PRESSURE INSTRUMENTS \\ (Based on ISA S20.40a)}

\section{GENERAL}

1. Tag Number:

2. Function:

3. Case: Color:

4. Mounting:

5. Enciosure Class:

6. Power Supply:

10. Output:

17. Service:

18. Element Type:

19. Material:

20. Range:

21. Process Data:

22. Process Conn:
See Note 5

Record - Indicate Service sluice Pressure Trans - $\quad$ Other Iransducer Element

Mfr Std $\underline{X} \quad$ Nom Size $\underline{2^{\prime \prime}} 00 \times 3^{\prime \prime}$ Long

Mfr Std $\underline{X}$$$
\text { Mfr Std } X \text { other }
$$

Fiush _ Surface _ Yoke _ Other Direct

General Purpose _ Weather Proof _ Explosion Proof _

Class For use in intrinsically safe system
Other See Note 2

$117 \mathrm{~V}, 60 \mathrm{~Hz}$ - Other $V$ ac See Note $3 \mathrm{~V} d c$

\section{TRANSMITTER}

4-20 mA - 10-50 mA _ 21-103 kPa (3-15 psig) -

other Compatible with signal conditioner on

Data Sheet Y-0702

For receiver, see Data Sheet $Y-0702$

\section{ELEMENT}

Gage Press $\underline{X}$ Vacuum - Absolute _ Compound Diaphragm _ Helix _ Bourdon _ Bellows _ other Strain gage bonded foil 316 SST $\underline{x}$ Ber Copper _ 0 ther Fixed $\underline{X}$ Adj Range Set at Overrange protection to $50 \%$ (Nom) over range Press: Normal 0-312 psig Max 320 psig Element Range 500 psig (See Note 6) 1/4" npt $\underline{X}$ 1/2" npt _ Other Female thread Location: Bottom $\underline{X}$ Back _ Other 
PRESSURE INSTRUMENTS

(Based on ISA S20.40a)

(Continued)

25. Options:

$$
\text { OPTIONS }
$$
25. Options:
Charts
Diaph
Diaph
Type
Capillary: Length
Conn
Other See Notes 4 and 7
26. Mfr \& Model No.: $\frac{\text { Sensotec Model TJE Code No. AP121CR or an approved }}{\text { substitute }}$ ECN-128

Filter-Rgitr

Supply Gage -

Output Gage -

NOTES:

(1) Items 7 through 9, 11 through 16,23 and 24 are not required.

(2) Item 5: Mfr Std hermetically sealed stainless steel construction, ICS 6, NEMA Type $4 X$.

(3) Item 6: DC voltage input from Receiver Instrument on Data Sheet Y-0702.

(4) Item 25: Mfr standard electrical connector with mating plug, strain relief and 100 feet of cable.

(5) Tag Numbers: PE-0621 and PE-0622.

(6) Instruments shall withstand 30 inches $\mathrm{Hg}$ vacuum on pressure port with no detrimental effects.

(7) Ambient temperature range: $30^{\circ} \mathrm{F}-180^{\circ} \mathrm{F}$. 
RECEIVER INSTRUMENTS

(Based on ISA S20.1a)

1. Tag Number:

2. Function:

3. Case:

Color:

4. Mounting:

6. Power Supply:

9. Scales:

5. Enclosure $\mathrm{Cl}$ ass:

See Note 4

GENERAL

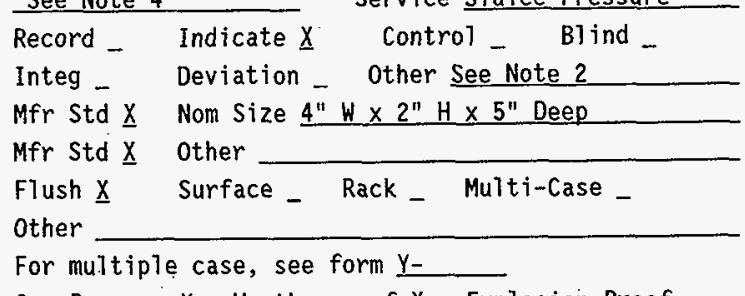

Gen Purpose $\underline{X}$ Weatherproof $\underline{\underline{*}}$ Explosion Proof _

Class

For use in intrinsically safe system _ other

$117 \mathrm{~V}, 60 \mathrm{~Hz} \underline{\mathrm{X}}$ other:

$\checkmark$ ac

$v d c$

Type Digital (PSIG) 4 1/2 Digits

Range 119999 (MAX) 2

3

4

\section{INPUTS}

16. Signals:

17. Number:

18. Power for Xmtr:

4-20 mA -

$$
\text { 10-50 mA _ }
$$$$
21-103 \mathrm{kPa} \text { (3-15 psig) - }
$$

other Compatible with Sensor on Data Sheet $Y-0701$

\section{$1 \underline{x}$}

2.

3 .

4 -

External _ This instrument $\underline{x}$

Number of independent supp Ties one

For transmitters, see Data Sheet Y-0701

ALARMS

19. Switches:

20. Function:

Quantity 2

Form $C$

Measured Variable $\underline{x}$

Contacts to actuate

other

22. MFR \& Model No.: Sensotec Model GM or an approved substitute (Model No. AE213, 516, 52c, 58a, 59b) ECN-166 
NOTES:

(1) Items $7,8,10$ through 15 and 21 are not required.

(2) Item 2: Solid state electronic signal conditioner/amplifier and digital display and low alarm switch for transducer element on Data Sheet Y-0701.

(3) Adjustment: Span, zero and shunt calibration.

(4) Tag Numbers: PISL-0621 and PISL-0622.

(5) Accuracy: $\pm 0.25 \%$ of Full Scale \pm 1 digit. 


\section{ANNUNCIATORS \\ (Based on ISA S20.2a)}

1. Tag Number:

2. Cabinet Size:

3. Hounting:

4. Cabinet Style:

5. Rating:

6. Power Supply:

7. Backi ighted

Nameplates:

8. Alarm Points Per

Lightbox:

Lamps Per ATarm:

GENERAL

ANN-0621

4

Flush Panel $\underline{x}$ Surface

Plug-In Light Boxes $\underline{X} \quad$ Swing Door _

Remote Logic Cabinet -

General Purpose $\underline{X}$

Explosion Proof Group

$117 \mathrm{~V}, 60 \mathrm{~Hz} \underline{\mathrm{X}} 125 \mathrm{~V} \mathrm{dc}$ -

other:
Location Elec. Skid 241-AY-51 Columns Hide

\section{DISPLAY}

White Translucent $\underline{X}$ 0ther $\underline{\text { See Note } 2}$ Size See Note 3

$1-\quad 2 \underline{x} \quad 3-4-$
$1-\quad 2 \underline{x} \quad 3-4-$

LOGIC

11. Logic:

Electro-Mechanical Relay _

Solid-State Electronic $\underline{x}$ Mercury Bottle . Fluidic _

12. Location:

In Display Cab $\underline{X}$

Remote Cab _

Strip Chassis _

13. Style:

\section{Gen Purpose $X$} Weatherproof Explosion Proof Class. Group Division Intrinsically Safe _

14. Field Contact Voltage:

$117 \mathrm{Vac}$ $12 \mathrm{~V} \mathrm{dc}$ $125 \mathrm{~V} \mathrm{dc}$

other $24 \mathrm{~V} \mathrm{dc}$

15. On Alarm, Actuating Contacts: Open - Close - Field Selectable $\underline{X}$. Form 
ANNUNCIATORS

(Based on ISA S20.2a)

\section{FEATURES}

16. Required:

Lock-In of Momentary Alarms $\underline{x} \quad$ Auxiliary Contacts -

Sequential Alarm Circuit

17. Aing-Back Girutt: Via Alam Audible-Signal $\underline{x}$

ECN-128

Ha - Other Audible-Signal-

18. Other:

Fail-Safe Circuit To Signal Own Failure $\underline{X}$

Operational Test _ Lamp Test $\underline{X}$

19. Flasher:

Remote _ In Cabinet $\underline{x}$

20. Acknowledge:

Common $\underline{x}$ Unit _ Light $\underline{x}$ Audible $\underline{x}$

Pushbutton

Location:

In Cabinet $\underline{X}$ Remote - Other

21. Reset:

Common $\underline{X}$ Unit _.

Light $\underline{x}$ Audible _

Pushbutton

Location:

In Cabinet $\underline{x}$ Remote - Other

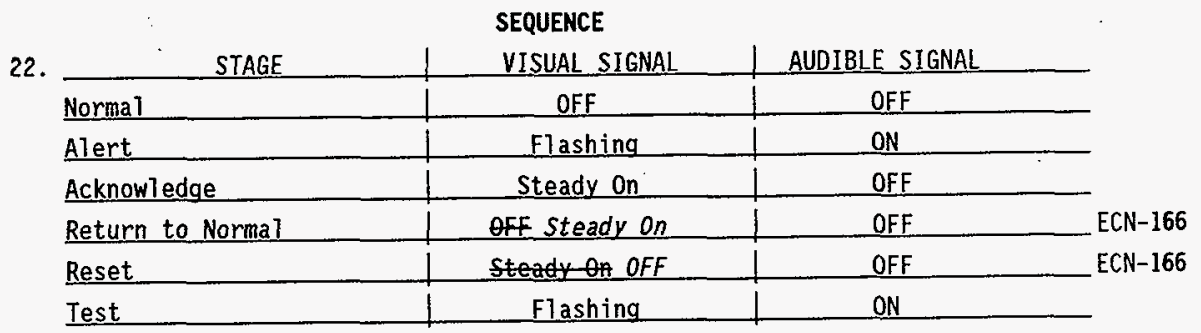

ISA Sequence Number: A M (ISA S18.1)

ECN-166 
ANNUNCIATORS

(Based on ISA S20.2a)

\section{OPTIONS}

27. Power Supply Location:

28. Accessories:

\section{Separate from logic cabinet}

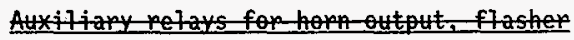

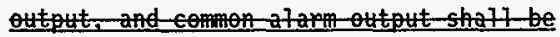

integrally mounted in the logic cabinet

(3 Form $C$ contacts: 5 amps at $120 \mathrm{Vac}-60 \mathrm{~Hz}$ ).

Remote mounted auxiliary relay for

horn output and strobe light ( 3 form $C$

contacts, 5 amps at $120 \mathrm{Vac})$.

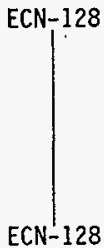

$\mathrm{ECN}-128$

29. Manufacturer:

Panalarm

Model No.:

NOTES:

(I) Items $9,10,17,23$ through 26 are not required.

(2) Item 7: Nameplates shall be white. 6 red and 24 yellow colored filters for installation behind white nameplates shall be provided.

(3) Item 7, Nameplate Size: $17 / 16^{\prime \prime} H \times 35 / 16^{\prime \prime} W$ (Nominal) for each alarm point. 
MAGNETIC FLOWMETERS

(Based on ISA S20.23a)

1. Tag Number:

2. Service:

3. Location:

4. Line Size-Sched:

5. Line Material:

6. Connection Type:

7. Connection Matl:

8. Tube Material:

9. Liner Material:

10. Electrode Type:

11. Electrode Mat1:

12. Meter Casing:

13. Power Supply:

Elec Code:

14. Grounding, Type

\& Material:

15. Enclosure Class:

17. Fluid:

18. Max Flow:
FE-0621

Supernate Flow

Sluice Pit AY-O2E

\section{METERING ELEMENT - CONN}

4 inch sched $40 \mathrm{~S}$

304LSST

300\# Raised face mating flanges (wafer type)

Mfg Std

METERING ELENENT - METER

303 SST

TEFZEL

Mfg std

Tantalum

Mfg std

From associated instrument FIT/FQI-062I

Mfg std

NEMA $4 X$

\section{METERING ELEMENT - FLUID}

Water slurry

350 gpm 
MAGNETIC FLOWMETERS

(Based on ISA S20.23)
19. Nax Velocity:

20. Normal Flow:

Minimum Flow:

21. Maximum Temp:

Minimum Temp:

22. Maximum Press:

Minimum Press:

23. Min Fluid

Conductivity:

24. Vacuum

Possibility:

26. Tag Number:

27. Function:

28. Mounting:

29. Enclosure Class:

30. Length Signa 1 Cable:

31. Type Span Adj:

32. Power Supply:

33. Output:

\section{FLUID (cont)}

$10 \mathrm{ft} / \mathrm{sec}$

$250 \mathrm{gpm}$

$40 \mathrm{gpm}$

$180^{\circ} \mathrm{F}$

$80^{\circ} \mathrm{F}$

320 psig

$-30^{\prime \prime} \mathrm{Hg}$

10 micromhos $/ \mathrm{cm}$

Fu1] vacuum

ASSOCIATED INSTRUMENT

FIT/FOI-0621

Indicate/Transmit/Totalize

Surface

Mfg std

100 feet

Digital DIP switches

$115 \mathrm{~V} \mathrm{ac} 60 \mathrm{~Hz}$

\section{ASSOCIATED INSTR - TRANSMITTER}

4-20 ma DC 


\section{MAGNETIC FLOWNETERS \\ (Based on ISA S20.23)}

\section{ASSOCIATED INSTR-DISPLAY}

35. Scale Size:

Range:

38. Integrator:

\begin{tabular}{l|l} 
Mfg std & \\
\hline $40-400$ gpm & \\
\hline 8 Digit, gals. & \\
\hline
\end{tabular}

\section{ASSOCIATED INSTR-CONTROLLER}

45. Manufacturer:

\begin{tabular}{l|l} 
Flow Element & Remote Electronics \\
\hline Brooks Model 7400 & Brooks Model 3560 \\
\hline (7404C5BIF6AACA) & (356232A3C1) \\
\hline or approved substitutes. &
\end{tabular}

NOTES: (1) Items $16,25,34,36,37,39-44$, and 46 and 47 are not required.

(2) Accuracy: $\pm 0.5 \%$ of Futl Scale flow range. 
RECEIVER INSTRUMENTS

(Based on ISA S20.1a)

1. Tag Number:

2. Function:

3. Case:

Color:

4. Mounting:

6. Power Supply:

9. Scales:

16. Signals:

17. Number:

18. Power for Xmtr:

\section{GENERAL}

See Note 2

Record _ Indicate $\underline{x}$

Integ - Deviation -

Service Various

Mfr Std $\underline{X}$ Nom.Size $\underline{2 " H} \times 4^{\prime \prime} W \times 5^{\prime \prime}$ Deep

Mfr Std $\underline{X}$ other

Flush $\underline{X}$ Surface _ Rack _ Multi-Case _ other

For multiple case, see Form $Y$ -

5. Enclosure Class: Gen Purpose $\underline{X}$ Weatherproof - Explosion Proof Class

For use in intrinsically safe system _ other $117 \mathrm{~V}, 60 \mathrm{~Hz} \underline{X}$ other: $\checkmark$ ac $V \mathrm{dc}$ Type Digital (AMPS) $31 / 2$ digits

\section{INPUTS}

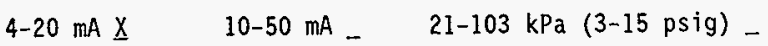
other (Field selectable)

$1 \underline{X} 2$ - 3 - 4 -

External $\underline{x}$ This instrument -

Number of independent supplies

For transmitters, see Form $Y$ - 
HNF-2536, Rev. 0

Form Y-0705 Page 86

Sheet 2 of 2

RECEIVER INSTRUWENTS

(Based on ISA S20.1a)

\section{ALARMS}

19. Switches:

Quantity $\underline{2}$ Form $\underline{C}$

Rating $1 \mathrm{~A} C 120 \mathrm{~V}$ aC

20. Function:

Measured Variable $\underline{X}$ Deviation -

Contacts to actuate on measurement increasing

other Field selectable

21. Options:

Filter-Rgltr -

Supply Gage

Charts _

Internal Illumination - Other

22. Manufacturer/ Model:

Rochester Instrument-Systems moder TM 3481 1-1

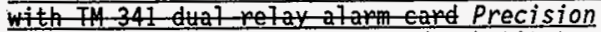
Digital model P0690 or approved substitute.

NOTES:

(1) Items 7,8 and $10-15$ are not required.

(2) Tag numbers: IISH-0621A

ECN-200

(3) Accuracy: $0.25 \%$ Full Scale \pm 1 count. 
RECEIVER INSTRUMENTS

(Based on ISA S20.1a)

GENERAL

1. Tag Number:

2. Function:

3. Case:

Color:

4. Hounting:

6. Power Supply:

9. Scales:

16. Signals :

17. Number:

19. Switches:

20. Function:

22. Manufacturer/ Model:
See Note 2

Record - Indicate $\underline{x}$

Service Various

Integ - Deviation -

Control -

Blind

high value

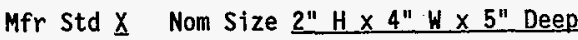

Mfr Std $\underline{X}$ other

Flush $\underline{X}$ Surface _ Rack _ Multi-Case _

other

For multiple case, see Form $Y$ -

Gen Purpose $X$ Weatherproof - Explosion Proof _

class

For use in intrinsically safe system _ other

$117 \mathrm{~V}, 60 \mathrm{~Hz} \underline{\mathrm{X}}$ other:

$\checkmark$ ac $V$ dc

Type Digital ( $\left.{ }^{\circ} \mathrm{F}\right)$

$31 / 2$ Digits

\section{INPUTS}

4-20 mA _ $\quad 10-50 \mathrm{~mA}$ - 21-103 kPa (3-15 psig) other 100 ohm 3 wire RTD

$1 \underline{x}$

2 -

3 -

4

\section{ALARIS}

Quantity $\underline{2}$ Form $\underline{C}$ Measured Variable $\underline{X}$

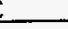

Rating 1 Amp $120 \mathrm{~V}$ ac Contacts to Actuate on measurement increase

other Field selectable

Rochester Instrument Systems-Mode? TH $3483-1-1$ with Im 341 dtal relay atam card Precision Digital model PD750 or approved substitutes.

$E C N-128 / 200$ 


\section{RECEIVER INSTRUMENTS}

(Based on ISA S20.1)

NOTES:

(1) Items $7,8,10-15,18$ and 21 are not required.

(2) Tag Numbers: IISH/IISHH 0621

TISH/TISHH O622

IISHHITISHA 0629

TISHIFISHIL O6210

TISH-0621

TISH-0621

TISH-0622A

TISH-0622B

(3) Accuracy: $0.25 \%$ Full Scale \pm 1 count. 


\section{RECEIVER INSTRUMENTS}

(Based on ISA S20.1)

\section{GENERAL}

1. Tag Number:

2. Function:

3. Case:

Color:

4. Mounting:

5. Enclosure Class:

6. Power Supply:

7. Chant:

8. Chapt- Qrive:

9. Scales:
ZI-0621

Record - Indicate $\underline{X}$

Integ _

Deviation

Service Winch Position

Mfr Std $\underline{X}$

Control

Blind -

Mfr Std $\underline{x}$ Other

Flush $\underline{X}$

Other

For multiple case, see Form Y-.

Gen Purpose $\underline{X}$ Weatherproof

Explosion Proof -

Class

For use in intrinsically safe system _ other

$117 \mathrm{~V}, 60 \mathrm{~Hz} \underline{X}$ other:

$\checkmark$ ac $V \mathrm{dc}$

= Strip___ RolT___C Fold-

Eireular _____ Time-Harks_-

Range Number Power

sped

Type Analog, Vertical

Range $10-300$ inches 


\section{RECEIVER INSTRUMENTS}

(Based on ISA S20.1)

\section{INPUTS}

16. Signals:

17. Number:

18. Power for Xmtr:
4-20.mA $\underline{X}$

$$
\text { 10-50 mA _ }
$$$$
\text { 21-103 kPa (3-15 psig) _ }
$$

other

$1 \underline{X}$

2 -

3 -

4 -

Externat $X \quad$ This instrument Number of independent supplies For transmitters, see Form $Y$ -

\section{ALARMS}

19. Switches: Quantity $\underline{2}$ Form $\underline{C}$ Rating $5 \mathrm{~A}, 120 \mathrm{Vac}$

20. Function: Measured Variable $\underline{X}$ Deviation Contacts to on measurement

other Field Selectable, See Note?

21. Options: Filter-Rgltr _ Supply Gage _ Charts _ Internal Illumination _ other

22. Manufacturer Model No.:

NOTES: (1) Items $7,8,10-15$ and 21 are not required.

(2) One alarm contact to actuate on increasing value (ZSH-0621A); and another independent alarm contact to actuate on decreasing value (ZSL-0621A).

(3) Accuracy: $\pm 0.5 \%$ of full scale span. 

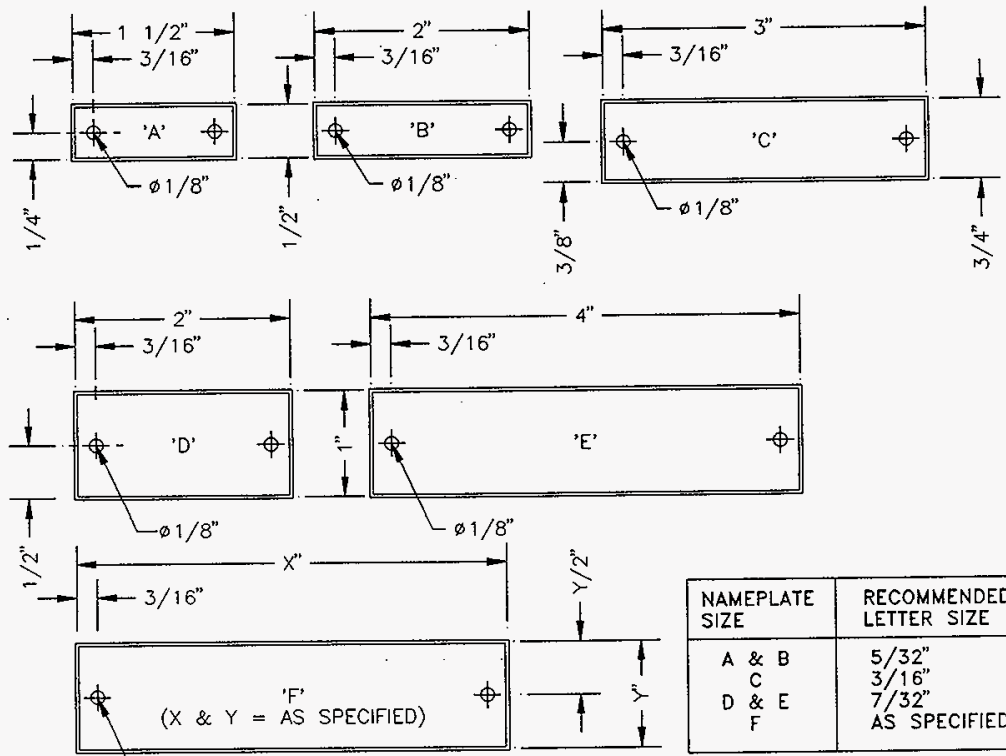

\begin{tabular}{|c|l|}
\hline $\begin{array}{l}\text { NAMEPLATE } \\
\text { SIZE }\end{array}$ & $\begin{array}{l}\text { RECOMMENDED } \\
\text { LETTER SIZE }\end{array}$ \\
\hline A \& B & $5 / 32^{\prime \prime}$ \\
C & $3 / 16^{\prime \prime}$ \\
D \& E & $7 / 32^{\prime \prime}$ \\
$F$ & AS SPECIFIED \\
\hline
\end{tabular}

$\bigsqcup_{\varnothing 1 / 8^{\prime \prime}}$

$\begin{array}{llll}3 / 32^{\prime \prime} & \text { SAMPLE } & 7 / 32 " & \text { SAMPLE } \\ 1 / 8 " & \text { SAMPLE } & 1 / 4 " & \text { SAMPLE } \\ 5 / 32 " & \text { SAMPLE } & 1 / 4 " & \text { SAM } \\ 3 / 16 " & \text { SAMPLE } & 5 / 16 & \text { SAM }\end{array}$

SAMPLE LETTERING SIZES

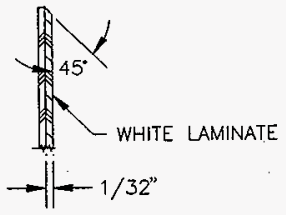

DETAIL OF EDGES

NOTES:

1. MATERIAL SHALL BE $1 / 16^{\prime \prime}$ thICK LAMINATED PLASTIC STOCK WITH WHITE SURface AND BLACK CORE.

2. EDGES OF NAMEPLATES SHALL BE BEVELED AS SHOWN AND SHALL BE SMOOTH AND WITHOUT BURRS. LETTERS SHALL BE SHARP AND CLEAR, SIMILAR TO THE STYLE SHOWN.

3. USE $4-40 \times 3 / 8$ " LONG, BINDING HEAD, SELF-TAPPING MACHINE SCREWS OR PULL STEM RIVETS TO FASTEN PLATES TO PANELS. DRILL NO. 39 HOLES IN PANEL. CONTACT ADHESIVE SHALL NOT BE USED.

\section{EQUIPMENT NAMEPLATE}

Figure 1 


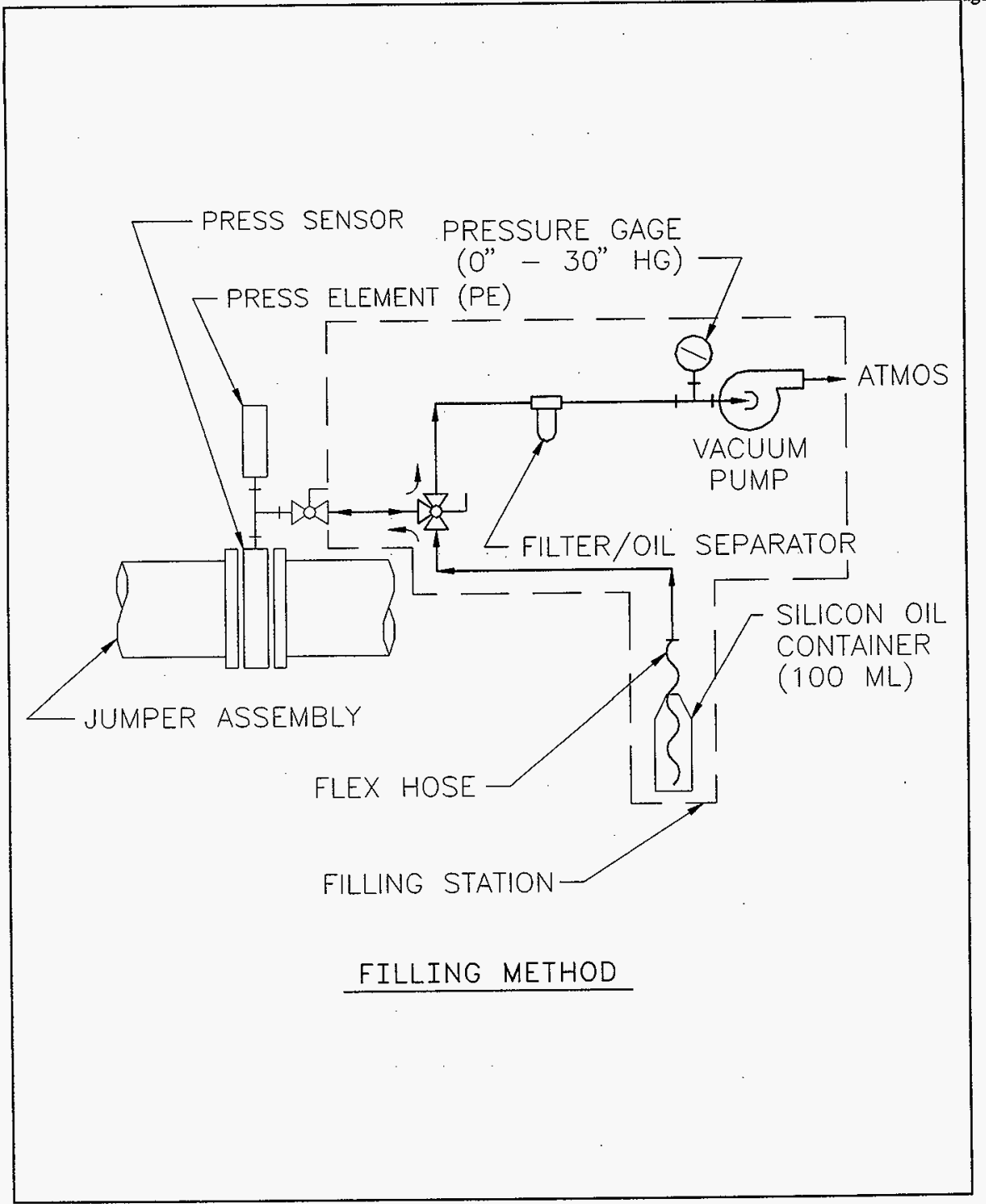

Figure 2 


\begin{tabular}{|c|c|c|c|c|c|c|c|c|c|c|c|c|c|}
\hline \multicolumn{3}{|c|}{ Projoct No. W-320 } & \multirow{3}{*}{\multicolumn{11}{|c|}{$\begin{array}{c}\text { APPROVAL DATA LIST } \\
\text { ("X" Indicates Required Data) }\end{array}$}} \\
\hline \multicolumn{3}{|c|}{ Proloet Title Tank 241-C-106 Sluicing } & & & & & & & & & & & \\
\hline \multicolumn{3}{|c|}{ Spocification Soction 13440} & & & & & & & & & & & \\
\hline \multirow[b]{2}{*}{$\begin{array}{c}\text { EPN } \\
\text { IDENTIFICATION }\end{array}$} & \multirow[b]{2}{*}{ DESCRIPTION } & \multirow{2}{*}{$\begin{array}{l}3 . \\
\text { REFERENCE } \\
\text { DRAWING }\end{array}$} & \multirow{2}{*}{$\begin{array}{l}4 \\
\text { SPECIFICATION } \\
\text { PARAGRAPH }\end{array}$} & \multicolumn{4}{|l|}{5} & \multicolumn{5}{|l|}{ DATA } & \multirow[b]{2}{*}{ REMARKS } \\
\hline & & & & 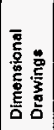 & 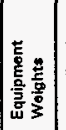 & & 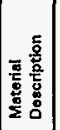 & 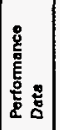 & 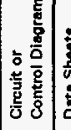 & 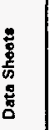 & 疍 & 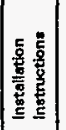 & \\
\hline $\begin{array}{l}\text { PE-0621 } \\
\text { PE-0622 }\end{array}$ & Transducer Element & & $Y-0701$ & $x$ & $x$ & $x$ & & & & $x$ & $x$ & $x$ & \\
\hline $\begin{array}{l}\text { PISL-0621 } \\
\text { PISL-0622 }\end{array}$ & $\begin{array}{l}\text { Indicating Alarm/Signal } \\
\text { Conditioner }\end{array}$ & & $Y-0702$ & & & $x$ & & & & & $x$ & & \\
\hline ANN-0621 & Annunciator & & $Y-0703$ & $x$ & & $x$ & & & $x$ & & $x$ & & \\
\hline FE-0621 & Flow Meter & & $Y-0704$ & $x$ & $x$ & $x$ & & & & $x$ & $x$ & $\mathrm{X}$ & \\
\hline FIT/FO1-0621 & Flow Indicator/Totalizer & & $y-0704$ & & & $\underline{x}$ & & & & $x$ & $x$ & & \\
\hline $\begin{array}{l}\text { IISH-0621 } \\
\text { IISH-0622 }\end{array}$ & Motor Current Indicator & & $Y-0705$ & & & $x$ & & & & & $x$ & & \\
\hline \begin{tabular}{|l} 
TISH-06621 \\
TISH-0.022 \\
TISH-0629 \\
TISH-06210 \\
\end{tabular} & Motor Temp. Indicator & & $Y-0706$ & & & $x$ & & & & & $x$ & & \\
\hline ZI-0621 & Winch Position Indicator & & $Y-0707$ & * & & $x$ & & & & & $x$ & & $\mathrm{ECN}-128$ \\
\hline $\begin{array}{l}\text { LDS-0621 } \\
\text { LSH-0621 } \\
\text { LSL-0621 } \\
\end{array}$ & $\begin{array}{l}\text { Level/Leak Detection } \\
\text { Switches }\end{array}$ & H-2-818573 & & & & $x$ & & & $x$ & & $x$ & & $\begin{array}{c}\mathrm{ECN}-128 \\
1 \\
\mathrm{ECN}-128 \\
\end{array}$ \\
\hline & & & & & & & & & & & & & \\
\hline & & & & & & & & & & & & & \\
\hline & & & & & & & & & & & & & \\
\hline
\end{tabular}




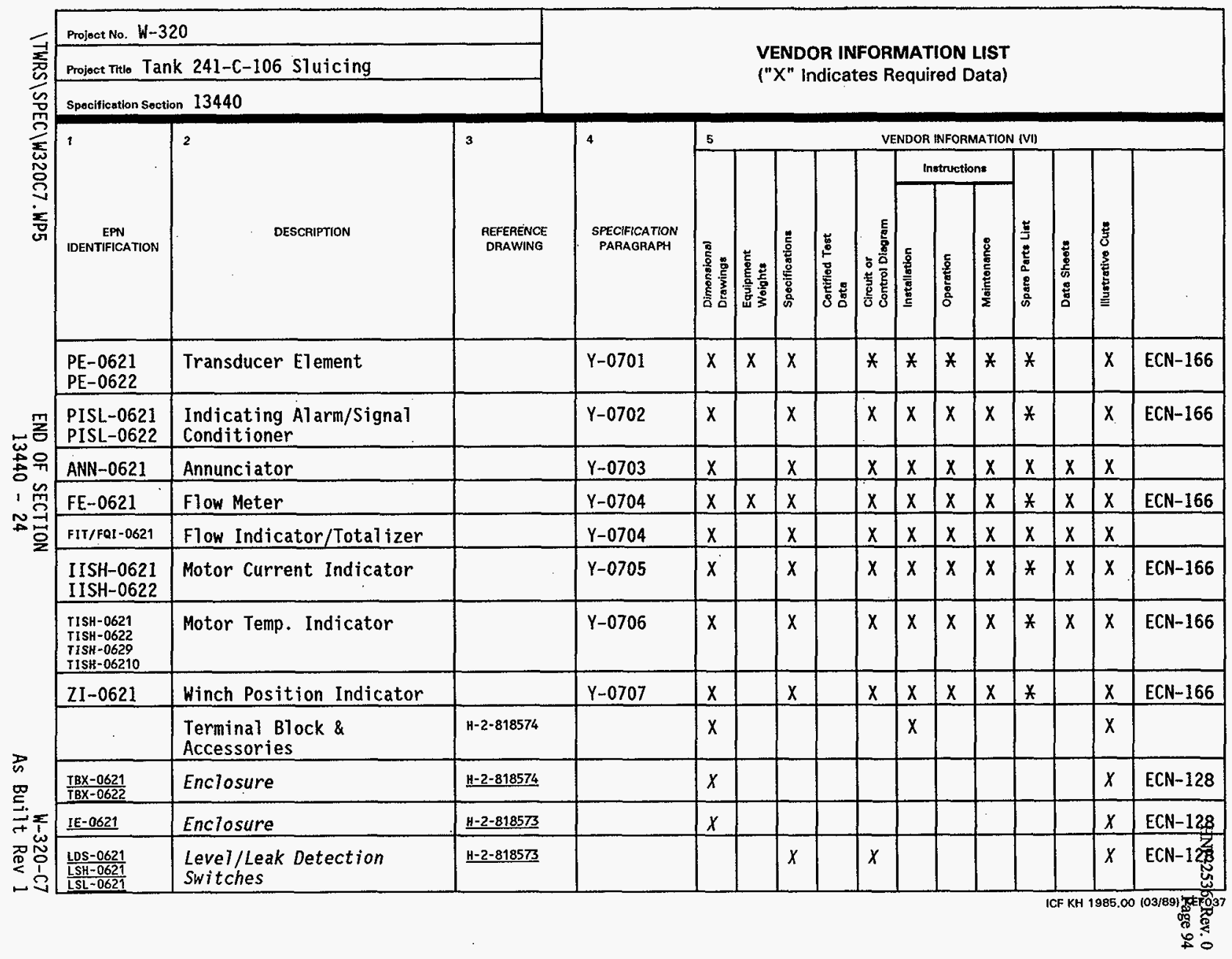




\section{CHEMICAL PROCESS PIPING SYSTEMS}

PART 1 - GENERAL

\subsection{REFERENCES}

1.1.1 The following documents, including others referenced therein, form part of this Section to the extent designated herein.

1.1.1.1 American Society of Mechanical Engineers (ASME)
B16.5-1988
Pipe Flanges and Flanged Fittings
B16.9-1993
Factory-Made Wrought Steel Buttwelding Fittings
B31.3-1993
Chemical Plant and Petroleum Refinery Piping
NQA-1-1994
Quality Assurance Requirements for
Nuclear Facility Applications

1.1.1.2 American Society for Nondestructive Testing (ASNT)

ASNT-TC-1A

Recommended Practice (1988 Edition)

1.1.1.3 American Society for Testing and Materials (ASTM)
A $105-92$
Forgings, Carbon Steel, for Piping Components

A $106-91$

Seamless Carbon Steel Pipe for High

Temperature Service
A $312-92 a$
Seamless and Welded Austenitic
Stainless Steel Pipes
A $580-95$ a
Stainless Steel Wire
$\mathrm{ECN}-662$
A 403-91
Wrought Austenitic Stainless Steel
Piping Fittings

1.1.1.4 American Water Works Association (AWWA)

C213-91

Fusion Bonded Epoxy coating for the Interior and Exterior of Steel Water Pipelines

1.1.1.5 Manufacturers Standardization Society of the Valve and Fittings Industry (MSS)

SP-58, 1988

Pipe Hangers and Supports - Materials, Design and Manufacture 

and Application 
SP-89, 1991 Pipe Hangers and Supports - Fabricatiorpage 97 and Installation Practices

1.1.1.6 Steel Structures Painting Council (SSPC)
SP 3-82
Power Tool cleaning
SP 6-85
Commercial Blast Cleaning

1.1.1.7 American National Standard Institute (ANSI)

ANSI/AWS 01.1-96

Structural Welding Code Steel

1.2 SUBMITTALS

1.2.1 See Section 01300 for submittal procedures.

1.2.2 Approval Required

1.2.2.1 Certified material test reports (CMTRs): Before delivery, submit legible reports, certified by responsible manufacturer of materials used in fabrication of pipe and weld rod for pipe codes and services listed below. Reports shall present results of chemical anatysis and physical tests specified in ASME and ASTM Codes and Standard Specifications for production lots and heats of materials. Material traceability shall be maintained through fabrication for materials requiring CMTRs. Submit separate reports for the following.

a. Pipe Code M-9; Service, Supernate (SN) and Slurry (SL) 1 ines

b. Pipe Code M-26a; Service, Supernate (SN) and Slurry (SL) line encasements

1.2.2.2 Material traceability shall be maintained through fabrication for material requiring CMTRs.

$\mathrm{ECN}-116$ $\mathrm{ECN}-116$

1.2.3 Approval Not Required: None

1.3 QUALITY ASSURANCE

1.3.1 Safety Related Products: Saty Safety Signficant products shall be procured from qualified suppliers. These suppliers shall have quality assurance programs meeting the ASME NQA-1 Basic Requirements 1, 2, 4 through 15 , and 17 .

1.3.2 Welding Qualifications:

1.3.2.1 Qualification of welding personnel and procedures: Personnel and procedures for welding pressure retaining components along with attachments hereto, and pipe supports, shall be qualified in accordance with ASME B31.3, Paragraph 328.2.

1.3.2.2 Qualification of Nondestructive Examination (NDE) Personne]:

a. Visual weld examination shall be performed in accordance with ASME B31.3. 

HNF-2536, Rev. 0 Nhall be certified in accordance with Contractor's written practice, which shall meet the requirements of ASNT-TC-1A. Use Level II personnel to interpret test results. 
1.3.3 Deliverable Documentation: The following documents and records,

required by this Section, shall be delivered to Construction Document

Control in accordance with Section 01720.

\section{Document}

Welding Qualification

Welding Examination Documentation

Flushing/Mechanical Cleaning Verification

Leak/Pressure Test Certification

1.4 DELIVERY, STORAGE, AND HANDLING

1.4.1 See Section 01610 for general requirements.

PART 2 - PRODUCTS

2.1

2.1 .1

2.2

2.2 .1

2.2 .2

2.2.2.1

\section{2 .3}

2.2 .4

2.2 .5

\section{SUBSTITUTES}

See Section 01630 for substitution approvals.

\section{MATERIALS} Drawings.

Protective coating for piping in contact with earth. Scotchkote $206 \mathrm{~N}$ or approved substitute.

Painting: See Section 09900.

Nonshrink Grout: See Section 03300 . the criteria of MSS SP-58.

2.2.6 Jumpers: Jumper fabrication shall be as shown on the Drawings

\section{Paragraph}

3.2 .2 .4

3.2.3.1b

Piping: See the Pipe codes in this Section, and details on the

Carbon steel piping: Field and factory applied exterior protective coating; AWWA C213, fusion bonded epoxy coating of 14 mils thickness,

Pipe Supports: Pipe supports shall be as shown on the Drawings.

Standard components selected in accordance with MSS SP-69, that satisfy and in accordance with Appendix $A$ of this Section.

ECN-662 $\mathrm{ECN}-662$

PART 3 - EXECUTION

3.1 INSTALLATION

3.1.1 General

3.1.1.1 Fabricate and install pipe in accordance with ASME B31.3 (for norma? service), the Drawings and this Section. Pipe Codes $\mathrm{M}-9$ and $\mathrm{M}-26 \mathrm{a}$ piping systems shall be fabricated using welded connections unless otherwise shown on the drawings. 
3.1.1.2 Cut pipe using methods which result in clean, straight cuts. 
3.1.1.3 Ream pipe to nominal inside diameter after cutting. Remove burrs from Page 101 threads before assembly.

3.1.1.4 Tools marked for stainless steel shall be used on stainless steel onty.

3.1.1.5 Bend pipe in accordance with ASME B31.3, and meet tolerances given in ASME B31.3. Use methods and equipment which produce bends substantially free of wrinkles, bulges, or kinks. When wall thickness, diameter, and bend radius indicate possibility of wall collapse during bending, fill pipe with clean siljca sand or fusible material similar to Cerro-bend, manufactured by Cerro Corporation.

a. Application of heat to facilitate a pipe bend shali be brought to the attention of the Construction Engineer for direction and disposition prior to the application of heat.

b. Cold springing pipe permitted only if specified on the Drawings.

3.1.1.6 Carbon steel embedded in concrete shall be bare.

3.1.1.7 Keep piping systems clean. Piping systems shall be inspected before, during and after installation. Once fabrication has started, plug or cap ends of piping when installation is not in progress. Cap or plug openings in fabricated pipe spool assemblies until installation in the piping system. Leave ends of spare lines capped or blind flanged when installation has been completed.

3.1.1.8 High points shall not be provided on SN and SL piping.

3.1.1.9 Pipe supports: Install as shown on the Drawings, in accordance with manufacturer's instructions, and applicable recommended procedures of MSS SP-89.

3.1.1.10 Lead shal] not be allowed for use in remotely replaceable components for counterweighting.

3.1.2 Underground Piping

3.1.2.1 Trenches: Excavate, backfi11, and compact in accordance with Section 02225 .

3.1.2.2 Place piping supports on undisturbed soil, or backfill placed and compacted in accordance with Sections 02200 and 02225 .

3.1.2.3 Survey piping systems for elevation and location before final tie-in welds to pits, risers, or fixed items. Complete placement of supports and meet Specification and Drawing requirements before survey.

Elevation and location shall be in accordance with the Drawings. After

final tie-ins survey piping system again for final acceptance.

\subsubsection{Welding}

3.1.3.1 Weld piping, attachments to pressure retaining components, and pipe supports in accordance with ASME B31.3 and Drawings. 
3.1.3.2 Protect outdoor welding operation from rain and wind by using barriers Page 102 to protect welder and weld joint.

3.1.3.3 Complete piping welds before tie-in welds to pits, risers, or fixed items.

3.1.3.4 Remove backing strips if used.

3.1.3.5 Gas Tungsen Arc Welding (GTAW) process shall be used for root pass welds of carbon steel encasement pipes where stainless steel inner pipes cannot be protected from weld splatter.

\section{1 .4}

Weld Identification

3.1.4.1 Prepare weld maps using Project. Drawings or sketches, which show relative positions of pressure containing welds and attachment welds to pressure retaining components.

3.1.4.2 Assign and record weld numbers on weld maps as welds are made.

3.1.4.3 Place the welder identification symbol and weld number adjacent to welds upon completion. Place the identification symbol approximately every 3 feet on long seams or large weldments, using one of the marking methods specified in Section 01610.

3.1.4.4 Do not reuse weld numbers. If a weld is completely replaced, assign a new number.

3.1.4.5 Show heat/lot numbers on weld maps for materials requiring Certified Material Test Reports.

3.1.5 Perform NDE, flushing and Teak/pressure testing specified in 3.2 before coating application.

3.1.6 Exterior Protective Coating

3.1.6.1 Protect carbon steel pipe and fittings exposed to earth backfill with specified coating.

a. Clean carbon steel surfaces to white metal by sandblasting in accordance with SSPC SP 6 . Where blasting is impracticable, clean by power wire brushing in accordance with SSPC SP 3.

b. Heat and apply specified tape in accordance with AWWA C213.

3.1.6.2 After installation, examine carbon steel pipe having factory applied exterior protective coating, and joints and short lengths of pipe having field applied exterior protective coating materials.

a. Use electrical holiday detector in accordance with AWWA C213.

b. Repair damage to coating in accordance with AWWA C213. 
3.2.1 Nondestructive Examination (NDE) of welds shall be performed to the extent defined in ASME B31.3, Paragraph 341.4.

3.2.1.1 Perform NDE for each pipe code listed in the schedule in 3.3.

3.2.1.2 Visual examination: Perform in accordance with ASME B31.3, Paragraph 344.2 . Acceptance criteria shall be in accordance with ASME B31.3, Table 341.3.2A.

3.2.1.3 Radiographic examination (RT): Perform in accordance with ASME B31.3, Paragraph 344.5. Acceptance criteria shall be in accordance with ASME B31.3, Table 341.3.2A.

a. Identify radiographic film with weld identification number and project or work order number assigned to work covered by this Section.

b. Prepare radiographic examination reports as follows.

1) List each radiographic exposure location $(0-1,1-2, \ldots)$ individually on radiographic examination report.

2) Indicate location acceptability or rejectability and note discontinuities whether rejectable or not.

3) When report includes radiographs of welds which have been repaired, indicate which welds are repair welds and how many times each weld has been repaired.

c. If additional welding is performed on weld area which has already been examined radiographically, this area is repair area. Identify subsequent radiographs by "R-1, R-2," etc.

3.2.1.4 Perform in-process examination in accordance with ASME B31.3, Paragraph 344.7.

3.2.1.5 Perform random visual examination of piping support welds in accordance with ASME B31.3; Paragraph 344.2.

3.2.1.6 NDE documentation:

a. Document examination of pressure containment welds and welds to pressure containing components for piping systems on "NDE/Weld Record," Form KEH-0433. See Form KEH-0433 for instructions for recording weld" maps, weld numbers, welder identification, welding procedure numbers, weld filler material, visual examinations, nondestructive examinations, and for noting satisfactory completion of leak/pressure testing.

b. Required NDE shall be completed and documented before starting leak/pressure testing.

c. NDE/Weld Record information and weld maps specified in 3.1.4 may be incorporated on a single format or traveler for a specific work package. 
d. Document examination of pipe supports by recording on sketches or Page 104 the NDE/Weld Record form.

3.2.1.7 Liquid Penetrant (dye penetrant) Examination (PT): Perform in accordance with ASME B31.3, paragraph 344.4. Acceptance criteria sha71 conform to ASNE B31.3, paragraph 341.3.2.

3.2.2 Cleaning and Flushing

3.2.2.1 After NDE is complete and before leak/pressure testing the system, or before connecting the system into existing systems, clean piping internal surfaces mechanically.

3.2.2.2 Mechanical cleaning: Remove loose dirt, scale, and debris by brushing, wiping, high pressure water jetting, or other mechanical method.

a. When high pressure water jetting or other mechanical cleaning method utilizing water is used, and leak/pressure testing will not be performed immediately after cleaning, dry piping systems by blowing dry oil-free air or nitrogen through lines.

b. Dry until the relative humidity of discharge air is equal to that of inlet air. Use drain taps at low points of piping system to ensure complete drainage and drying. Cap lines or reconnect to system to maintain cleanliness.

\subsubsection{Water flushing}

a. Remove strainer screens before flushing, except those protecting control equipment. Clean screens protecting control equipment before flushing, if necessary, and after flushing is complete. Remove steam traps from line before flushing.

b. Flush piping with water for 1 minute minimum, and until effluent is clean and contains no visible particulate matter. Flushing pressure shall not exceed maximum operating pressure specified in pipe codes: Flushing water supply shall have sufficient capacity to produce a flow velocity of 4 to $6 \mathrm{ft} / \mathrm{s}$ in largest pipe size, with pipe full. Provide flow measurement in flushing water supply line to be used as bas is for verification of flow velocities in piping system by the construction Engineer.

c. When leak/pressure testing will not be performed immediately after flushing, dry tabulated piping systems by blowing dry, oil-free air or nitrogen through lines. Dry until the relative humidity of discharge air is equal to that of inlet air. Use drain taps at low points of piping systems to ensure complete drainage and drying. Cap lines or reconnect to the systems.

3.2.2.4 Pneumatic flushing: For encasement (ENC) lines only.

a. Isolate instruments by valving, plugging or disconnecting. 
b. Blow lines clean with dry, oil-free air or nitrogen at 20 to $30 \mathrm{lb} / \mathrm{in}^{2}$ gage, until discharge air has no visible particulate matter or for 5 minutes minimum. If pipe code maximum operating pressures are lower, use those pressures.

c. If leak/pressure testing is not performed immediately after flushing, cap lines or reconnect to system to maintain cleanliness.

3.2.2.45 Provide documented evidence that flushing or mechanical cleaning has been accomplished as specified in this Section.

3.2.2.6 Pneumatic flushing: For Nitrogen $\left(\mathrm{N}_{2}\right)$

a. Isolate instruments by valving, plugging, or disconnection.

b. Blow lines clean with dry, oil-free air or nitrogen at 20 to $307 \mathrm{~b} / \mathrm{in}^{2}$ gage, until discharge air has no visible particulate matter, or for 5 minutes minimum. If Pipe Code maximum operating pressures are lower, use those pressures.

c. If 7eak/pressure testing is not performed immediately after flushing, cap lines or reconnect to system to maintain cleantiness. 


\subsubsection{General}

a. After completion of flushing, perform leak/pressure testing of pipe in accordance with ASME B31.3 and this Section. Use calibrated gages with ranges $1-1 / 2$ to $Z 4$ times the test pressure.

b. Document testing of each piping system on "Leak/Pressure Test Certification" Form KEH-1757. Use separate forms to describe and record each piping system. Under "Description" describe piping system in enough detail for correlation to weld maps, shop fabrication drawings, or Project Drawings as applicable. For systems tested segmentally, indicate continuity in "Description" to ensure that entire systems have been tested.

c. Pipe joints, welds and other potential leak sources to be tested shall be visible and accessible during tests.

d. Install one temporary relief valve during testing. Relief valve shall have a discharge capacity of $125 \%$ of capacity of the pressurizing device, and be set to operate at 1-1/3 maximum of the test pressure for hydrostatic testing and not higher than test pressure plus the lesser of $50 \mathrm{lb} / \mathrm{in}^{2}$ or $10 \%$ of the test pressure for pneumatic testing. Tag each relief valve used to show serial number, inspector, date, and pressure setting.

e. Install necessary restraining devices, before applying test pressure, to prevent distortion or displacement of piping.

f. Isolate instruments and other items which could be damaged by test pressures.

g. Continuously maintain test pressure for 10 minutes minimum. Examine joints, welds, and connections. Piping system, exclusive of possible localized instances at pump or valve packing, shall show no visual evidence of weeping or leaking.

h. Visually examine piping joints, welds and other potential leak sources, including welds which attach wear plates, anchors, etc to piping systems, during testing.

i. Complete testing of piping before field application of insulation or protective coating. Pipe with factory applied protective coating shall be considered as having been tested before protective coating application.

3.2.3.2 Hydrostatic pressure testing:

a. Perform in accordance with ASME B31.3, Paragraph 345.4.

b. Test piping systems with removable jumper assemblies without jumpers in place. Test jumper assemblies as shown on the Drawings. 

pressure.

d. Coat welded piping joints and other potential leak sources, including welds attaching wear plates, anchors, etc, to piping systems, with a mixture of powdered blue chalk and water or isopropyl alcohol. Allow to dry before filling piping with water and inspecting for leaks.

e. Remove water from tabulated piping systems after testing and dry by blowing dry, oil-free air or nitrogen through lines. Dry until the relative humidity of discharge air is equal to that of inlet air. Use drain taps at low points of piping systems to ensure complete drainage and drying.

3.2.3.3 Pneumatic Pressure Testing: For Encasement (ENC) Tines and Nitrogen $\left(\mathrm{N}_{2}\right)$ lines only.

a. Perform in accordance with ASHE B31.3, paragraph 345.5 .

b. Perform test with dry, oil free air or nitrogen.

\subsubsection{Final Connections:}

Final connections, as defined in this section, shall be exempt from the requirements of Leak/Pressure Testing and shall be In-Process Examined. Welds shall have their first and last pass Liquid Penetrant Examined. See paragraphs 3.2.1.4 and 3.2.1.7 respective7y. Connection welds are defined as follows:

1. 4" SL-100-M9, and 6" ENC-M26a, at N41611.25' and W47872.29'. 


\subsubsection{Schedule of Pipe Weld NDE/Testing}

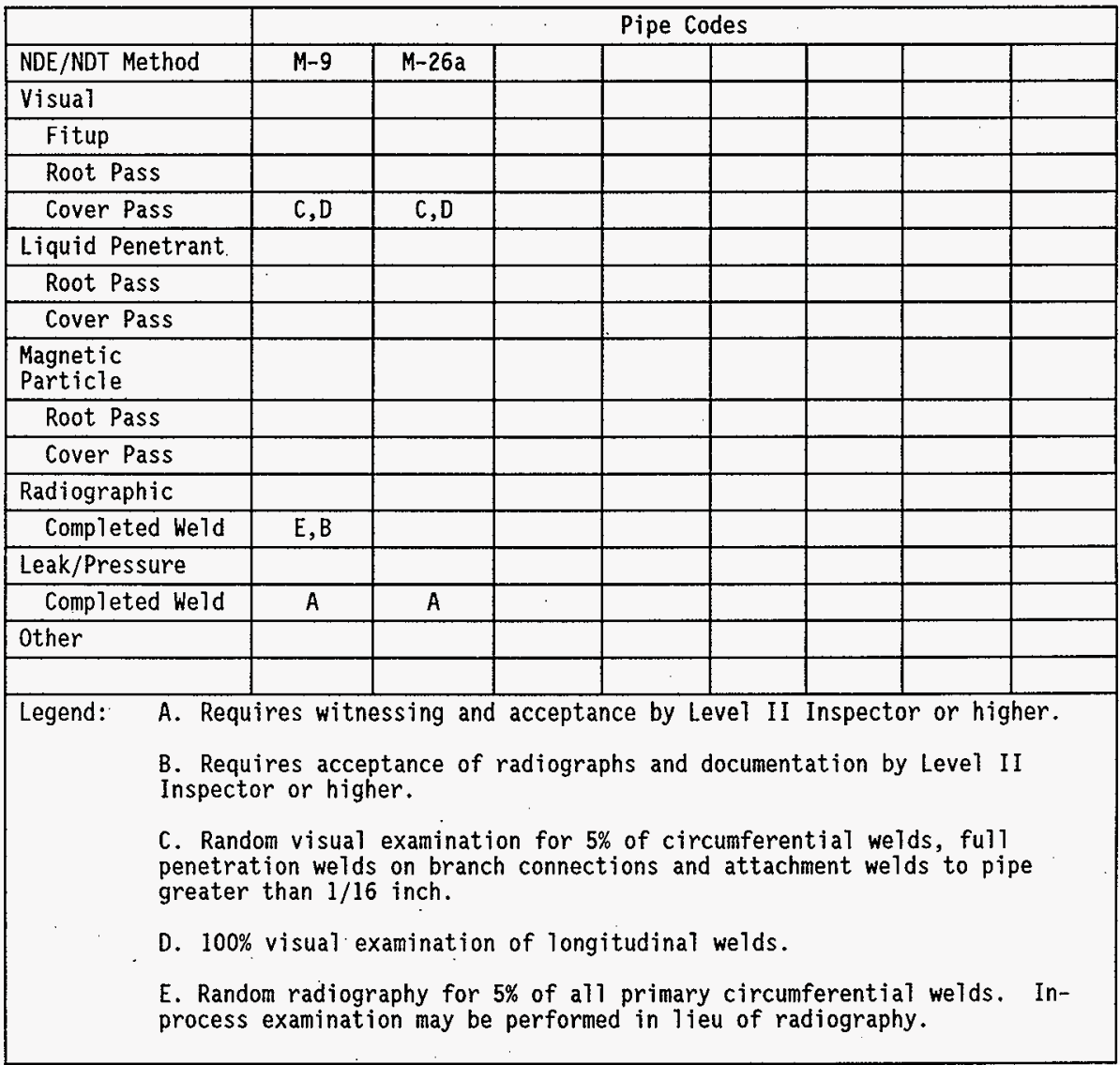


INF. 2536, Rev.0

PIPE CODE M-9 (Safety-Class-2 Safety Significant)

HETRE 809 Rev. 0

\begin{tabular}{|c|c|c|c|}
\hline servige & max operating gressure & lest pres sure & uax operat ing lernp \\
\hline 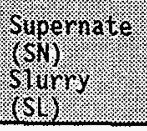 & 320 psig plo & 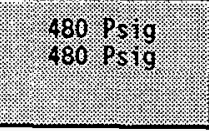 & $180 \%$ \\
\hline Sizes & \multicolumn{3}{|l|}{ A]1 } \\
\hline Pipe & \multicolumn{3}{|c|}{$\begin{array}{l}\text { Stainless Stee1, ASTM A } 312 \text {, } \\
\text { Grade TP } 304 \mathrm{~L} \text {, seamless. }\end{array}$} \\
\hline $\begin{array}{l}\text { Wall } \\
\text { Thickness }\end{array}$ & \multicolumn{3}{|l|}{ Schedule $40 \mathrm{~S}$} \\
\hline Fittings & \multicolumn{3}{|c|}{$\begin{array}{l}\text { Stainless steel, ASTM A } 403 \text {, class WPS } 304 L \text {, buttwelding } \\
\text { in accordance with ASME B } 16.9 \text {, wall thickness to match } \\
\text { pipe. }\end{array}$} \\
\hline
\end{tabular}

Page 109

ECN-116

ECN-116 


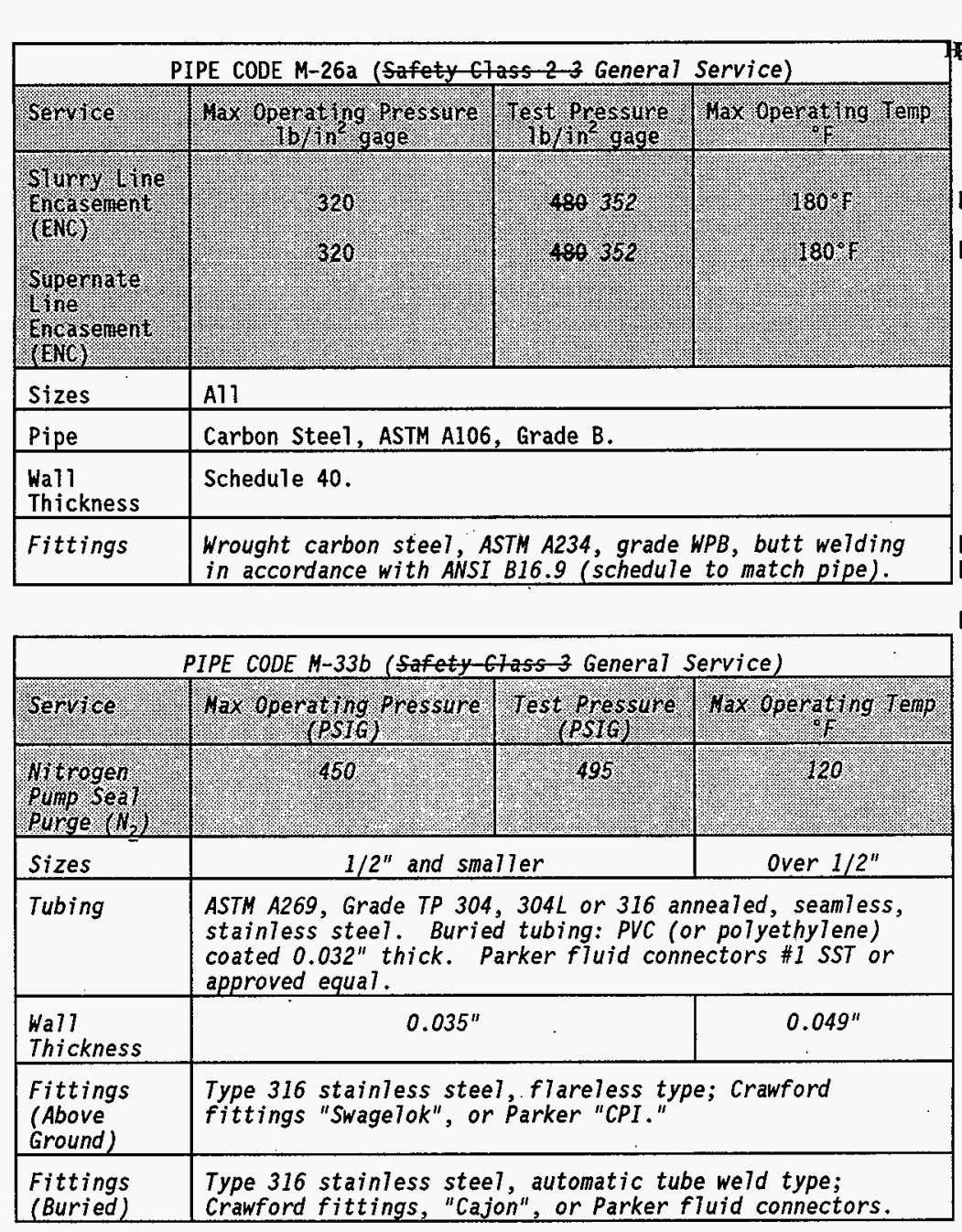

HNF-2536, ReVO सOW25366 R8090

Page 110

$E C N-116$

$E C N-116$

END OF SECTION 
HNF-2536, Rev. 0 Page 111

APPENDIX A $\mathrm{ECN}-662$

JUMPER FABRICATION ECN-662 
TABLE. OF CONTENTS

Section Title.

Table of Contents

SCOPE

APPLICABLE DOCUMENTS

REQUIREMENTS

3.1 Conflicts

3.2 Materials

3.3 Tolerances, Finishes, Positioning, and Bends

3.4 Special Engineered Equipment

3.5 Electrical Requirements

3.6 Welding

3.7 Lubricants

3.8 Threaded Joints

3.9 Balance Requirements

3.10 Testing

3.11 Cleaning and Painting

.

QUALITY ASSURANCE PROVISIONS

PREPARATION FOR DELIVERY AND STORAGE

NOTES

ECN-662 
1.1 Scope: This Specification establishes the requirements for fabrication, assembly, painting, identification and testing of process pipe and jumpers for use in 241-AY-02A Pump Pit and 241$A Y-02 E$ S7uice Pit for Project W-320. Definitions are in Section 6 .

APPLICABLE DOCUMENTS

Applicability: The following documents of the MOST RECENT issue form part of this Specification to the extent specified herein. In the event of a conflict between the documents cited and the contents of this Specification, Engineering shall be notified.

Industry Codes and Standards

American Society of Mechanical Engineers (ASHE)

B31.3-1993 w/addenda $a, b$ \& $c \quad$ Chemical Plant and Petroleum Refinery Piping

American National Standards Institute (ANSI)

ANSI/AWS D1,1-96 Structural Welding Code - Steel

American Society for Testing and Materials (ASTM)

A 580-95a Stainless Steel Wire

National Fire Protection Association (NFPA)

NFPA 70

National Electrical Code

3.1 Conflicts: The design drawings and this Specification are the primary documents on which shop fabrication of jumpers depends. In the event this Specification conflicts with the design drawings, the drawings shall take precedence.

3.2 Materials: Materials, or engineering approved equals, shall be as specified on the jumper drawings. Material certification requirements are imposed on the jumper drawings and/or procurement documents. The following is a list of materials used in this Specification. These materials are not specified on the jumper drawings.

\section{Description}

Moly Disulfide (Tubricant)

Blue Goop (lubricant) 
Nickel Antiseize thread Sealer \& Lubricant - Nuclear Grade

Teflon Tape (sea7er)

Teflon Paste; Federal Process Co. "JC-30"

Glyptal Red Ename7; Product No. 1201

Amerlock 400 Steel Primer

Amerlock 400 or 351 Base Coating

Amerlock 351 Intermediate and Finish Coating

Statico Anti-Static Spray

3.3 Tolerances, Finishes, Positioning, and Bends

3.3.1 Tolerances

3.3.1.1 "Critical dimensions" are those which locate connectors and nozzles to a close tolerance to ensure proper jumper fit. Unless otherwise specified on the jumper drawing, critical dimensions shall be $\pm 1 / 16$ inch tolerance.

3.3.1.2 The tolerances for fabrication of individual parts (parts dimensioned in the parts 7ist or detailed individually in the field of drawing) except gussets shall be as follows unless otherwise specified.

$$
\text { Fractions } \pm 1 / 8 \quad \text { Angles } \pm 2 \text { degrees }
$$

3.3.1.3 The tolerance for the cutting of structural shapes (dunnage) and gussets shall be as follows unless otherwise specified.

$$
\text { Fractions } \pm \frac{1}{4} \quad \text { Angles } \pm 5 \text { degrees }
$$

3.3.1.4 Quality Assurance verification of dimensions of items listed in Paragraphs 3.3.1.2 and 3.3.1.3 are not required unless otherwise specified.

\subsubsection{Finishes}

3.3.2.1 Remove burrs and break all sharp edges.

\subsubsection{Positioning}

3.3.3.1 Jumper components and dunnage envelope shall be located within $\pm \frac{1}{2}$ inch of the nominal design jumper dimensions unless otherwise specified on jumper drawing.

3.3.2.2 The sharp edge surfaces of dunnage, kickplates etc., shall have $1 / 32$ inch minimum chamfer.

3.3.3.2 Angles, un7ess toleranced otherwise, which locate parts less than 3 feet apart, shall have a tolerance of \pm 2 degrees. Angles locating parts more than 3 feet apart shall have a \pm 1 degree tolerance. 
3.3.4.1 Rigid pipe bends shal7 have a minimum radius of 5 times their diameters (nominal size) and meet the requirements of ASME B31.3, Paragraph 332, "Bending and Forming."

3.3.4.2 Tubing bends shall have a minimum radius of three times their diameter.

3.3.4.3 Electrical conduits shall have a minimum radius in accordance with Article 346-10 of the NEC.

3.4 Special Engineered Equipment

3.4.1 Equipment which requires calibration such as control valves, limit switches, gauges or probes shall be tested, adjusted, calibrated and certified prior to installation into a jumper. Fabrication Services shall be responsible for installation and control of this equipment and shall not alter or adjust calibration. Quality Control shall verify that the equipment is in satisfactory condition and calibration is current prior to actual installation and to assure items were not damaged during fabrication, shipment or storage.

3.4.2 Structural and/or dunnage member may be coped to a maximum depth of $3 / 8$ inch, where necessary, to avoid interferences with valve actuation and fit-up. Structural and/or dunnage members requiring coping of more that $3 / 8$ inch shall require engineering approval.

3.4.3 Pipe supports utilizing pipe sleeves may require the sleeve to be split for ease of fabrication. In the case of splitting the pipe sleeve, the following weld shall be used for fabrication:

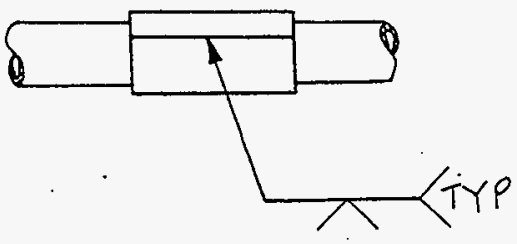

3.4.4 Actuators of pneumatically operated ball valve (POV) shall be rotated for proper orientation as shown on the drawing.

\subsection{Electrical Requirements}

3.5.1 Caution shall be used during the installation of cable or wire to avoid scuffing or cutting of insulation.

3.5.2 Substitution of cable or wire sha7l have prior engineering approval. 
3.5.3 Electrical wiring shall be installed in accordance with the electrical diagram provided on the Drawings.

3.5.4 Threaded connections on electrical components shall be assembled and then sealed against moisture penetration using a nuclear grade sealer and 7ubricant.

3.5.5 All materials used shall be compliant with standing Order 97-01 for applicable Ignition Control Set requirements specified. Questionable materials shall be approved by the Flammable Gas Equipment Advisory Board (FGEAB).

3.6 Welding

3.6.1 Weld Categories: Piping containment welds, attachments to containment piping, lifting bails, and their attachment welds require individual weld documentation. Carbon and stainless steel bail attachment welds shal7 be HT/PT examined, as applicable, on their final pass. Carbon steel and stainless steel support structure welds and connector block rotation stops (rattle bars) welds do not require individual weld documentation.

Steel support dunnage members shall be welded and inspected per AWS DI.1 (cyclically loaded).

3.6.2 Welding and inspection of carbon steel and stainless components of all process jumpers shall conform to the requirements of ANSI B31.3. Containment boundary welds shal7 be VT examined on the first and final passes. In-Process Examination per ASME B31.3 may be substituted for any or all other examination requirements. A7l other welds shall be VT final pass.

3.7 Lubricants

See Paragraph 3.2 .

3.8 Threaded Joints

3.8.1 Prior to final pressure testing, threaded pipe joints shall be lubricated, see Paragraph 3.2 for lubricants.

3.8.2 Connector tie bolts and operating screw threads shall be lubricated, see Paragraph 3.2 for Tubricants.

3.8.3 Connector tie bolts shall be safety wired in pairs using the double-twist method. Hire shall conform to ASTH A 580, any 300 series stainless steel, condition ' $A$ ' wire. Wire size shall be a minimum of 0.032 inch and a maximum of $0.048 \mathrm{inch}$.

3.8.4 Stainless steel flanges shall be bolted using stainless steel stud bolts, double nutting, with 4 nuts per stud bolt (preferred) or 2 nuts and 2 spring lock washers per stud bolt. Stud bolt length may vary depending on flange type and stud bolt locking methods used. Carbon steel flanges sha77 use carbon steel stud bolts and nuts. 
3.9.1 Balancing is performed to locate the point at which to attach a bail for remote handling of jumpers.

3.9.2 The sketch below illustrates the general rule for balancing jumpers having one horizontal and one vertical connector and no dip tubes or entry stubs:

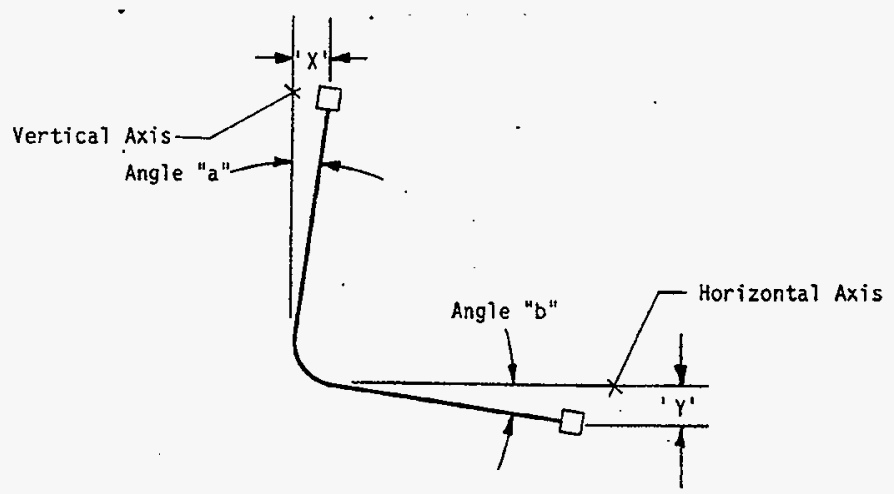

3.9.3 On jumpers where either horizontal or vertical legs exceed 5 feet:

$$
\text { Distance " } X \text { " or " } Y \text { " }=2 \text { inches maximum for longest leg }
$$

3.9.4 On shorter jumpers where neither leg exceeds 5 feet:

$$
\text { Angle " } a \text { " or " } b \text { " } 2 \text { degrees } \pm 1 \text { degree }
$$

If above dimensions for " $X$ and " $\gamma$ " and angles " $a$ " and " $b$ " are exceeded, Design Engineer shall be notified.

3.9.5 The following jumpers shall be balanced so that all connectors or flanges mate at the same time ( " $X$ " and " $Y$ " above = zero $\pm \frac{1}{2}$ inch)

- Jumpers having 2 or more horizontal connectors

- Jumpers having 2 or more vertical connectors

- Jumper having trunnions as primary position devices.

3.9.6 Jumpers which do not fit into any of the definitions above shall be balanced by instructions on the engineering drawing. 
3.10 Testing

3.10.1 Hydrostatic Testing

3.10.1.1 The completed process jumper assemb7y shall be hydro tested in accordance with ASME B31.3. Hydro test pressure shal7 be as noted on the drawing. Special equipment/components like pressure transducers that cannot withstand the Hydro test pressure shall be isolated or special engineering instruction shall be provided. The pressure shall be maintained throughout the full test.period for a minimum of 10 minutes. No leakage is permitted.

3:10.1.2 Jumpers with two-way valves shall be hydro tested with the valve in both the open and closed position. In the closed position both legs shall be independently tested. Jumpers with three-way valves shall be hydro tested with the valve in all operational positions such that the entire jumper is subjected to the pressure test. The three-way valve shall be positioned such that each leg to be isolated by a valve setting sha7l be independently tested.

3.10.1.3 When it is necessary to open or close a POV during testing or flushing of a jumper, the pov shall be operated by using the manual over-ride on the actuator.

3.10.2 Electrical testing.

3.10.2.1 After pulling wire or cable through conduit, but before connecting to instrument or electrical devices, test wire installation in accordance with Article 110-7 of the NEC using a megohm meter at 500 volts. An exception to this requirement shall be wire which is factory affixed to an over current protective device and/or an instrument device.

3.10.2.1 Instrumentation located in jumpers shall be tested for: (1) resistance, (2) continuity, (3) open circuits, and (4) short circuits after final assemb7y, using a multi-meter or equal. High voltage on high current test devices shall not be used.

3.11 Cleaning and Painting

3.11.1 After testing is completed, the outside of the jumper shall be cleaned in preparation for painting. Removal al7 carpenter's chalk, grease, rust, etc.

3.11.2 Clean and air dry internal components of process jumper.

3.11.3 Stainless steel components do not require painting except as needed for identification or for targeting. 
3.11.4 Carbon steel dunnage, and components shall be painted with Amerlock 400 and 351, or approved equal, applied in accordance with the manufacturer's specifications. The coating schedule shall be as follows:

\begin{tabular}{lll} 
Coat & \multicolumn{1}{c}{$\begin{array}{l}\text { Minimum } \\
\text { Color }\end{array}$} & $\begin{array}{l}\text { Dry Film } \\
\text { Thickness }\end{array}$ \\
Prime: & $\begin{array}{l}\text { May be applied in single } 7.0 \mathrm{mil} \\
\text { coat if base coat is self priming }\end{array}$ & $3.0 \mathrm{mils}$ \\
Base: & $\begin{array}{l}\text { May be applied in single } 7.0 \mathrm{mil} \\
\text { coat if base coat is self priming }\end{array}$ & $4.0 \mathrm{mils}$ \\
Intermediate: & $\begin{array}{l}\text { May be applied in single } 8.0 \mathrm{mil} \\
\text { coat medium gray }\end{array}$ & $4.0 \mathrm{mils}$ \\
Finish: & $\begin{array}{l}\text { May be applied in single } 8.0 \mathrm{mil} \\
\text { coat medium gray }\end{array}$ &
\end{tabular}

3.11.4.1 Carbon steel components of connector assemb7ies shall not be painted except for those items identified in Section 3.11.6.1 which are painted yellow for targeting (this painting is to assist the crane operator during jumper installation).

3.11.5 It is not mandatory to coat inaccessible areas. Some surfaces/ areas of structural shapes may fall into this category. A77 surfaces shall be drainable when jumper is installed.

3.11.6 Special Marking for Targeting

3.11.6.1 Parts 7isted below sha7l be coated with Amer7ock 400 and 351, or approved equal, in the areas specified. The coating shall be applied in accordance with the manufacturer's specifications and to the same schedule as above, para 3.11.4. Final color shall be yellow.

Bails

Kickplates

Connector operating screw nuts

Funnel Guides

Trunnions
Top 8 inches

Top face (not nozzle)

Top of operating screw only (not threads)

Inside Surface Only

All Surfaces

3.11.6.2 Remote blank connector assemblies shall be painted red enamel except for operating screw nut.

3.11.7 Identification information shall be stenciled on rigid jumpers with the same type of paint applied to the jumper. Letters and numbers shall be $\frac{1}{2}$ to $1-3 / 4$ inch high block type, black on yellow 
background. Combination rigid and flexible jumpers shall be identified 2536 , Rev. 0 per the rigid jumper requirements only. Identification information

should be readable from above if possible. Process flexible jumpers

shall have a $12^{\prime \prime}$ wide yellow bend painted on the braid adjacent to each end.

Information shall include drawing number, drawing revision number, and the location number, which reflects the use-location of the assembly.

The preferred arrangement of the identification information is shown below:

$\begin{array}{llc}\text { Location No. Drawing No. } & \text { Rev. No. } \\ x x(x x-x x) x & H-2-x x x x x & x\end{array}$

An alternate arrangement may have the location number above the drawing number, eg,

$$
\text { Location number: } x x(x x-x x) x
$$

Drawing and revision number: $H-2-x x x x x \quad x$

NOTE: Location Identification numbers are taken from the drawing title block and indicates the jumper use location.

3.11.8 On jumpers, stamp the project Number (Project W-320) with 1/8"-1/4" metal stamps on base of bail or an easily identified area of the dunnage (nearby). If painted, this stamping shall be readable after painting. If jumper has more then one bail stamp one bail only.

4.1 Welding inspection shall be as specified in Section 3.6 of this specification.

4.2 Jig inspection shall determine if the critical dimensions for the jumper have been met per the drawing and if the jumper, as designed, can be handled properly. The suggested methods of inspection are:

4.2.1 Before fabrication, verify jig settings to determine if critical jumper dimensions are correct.

4.2.2 After fabrication, loosen one connector to determine that the jumper "kickoff" is functioning.

4.2.3 Remove jumper from jig and determine if jumper can be easily reattached to jig.

The jig setting shall be inspected and approved by Quality Control (QC).

4.3 Hydro test performed, as required by Paragraph 3.10.1, shall be witnessed and approved by $Q C$.

4.4 Electrical testing as required by paragraph 3.10 .2 shall be witnessed and approved by $Q C$. 
5.1 After final inspection and acceptance by $Q C$ of shop fabrication of jumper, it shal7 be protected/packaged for outside storage. The jumper connectors shall be closed with a plastic plug and wrapped with a double layer of reinforced polyethylene sheeting.

Instruments and valves and valve activities sha7l also be wrapped with a double layer of reinforced polyethylene sheeting. Poly sheeting shall be used with 10 gauge minimum soft aluminum wire.

5.2 Tapes are prohibited for use when direct contact is made with stainless steel and nonferrous alloys.

5.3 A77 adhesive-backed tapes are prohibited form contact with connector of nozzle mating parts.

3.5.6 After assemb7y and prior to shipment all exposed plastic/polymer surfaces to include electrical wiring and hoses shall be coated with an anti-static spray.

6

NOTES

6.1

Jumpers are remotely removable sections of piping. Jumpers are installed in valve pits or in pump pits. They serve to connect permanent wal7 connections and removable components in the pump pit or between adjacent components or between permanent wall connections. Jumpers are designed to permit remote hand7ing by means of lifting bails. Sealed connections are made by using a remotely operated impact wrench. 
PART 1 - GENERAL

1.1 REFERENCES

1.1.1 The following documents, including others referenced therein, form part of this Section to the extent designated herein.

1.1.1.1 Air Movement and Control Association (AMCA)
99-1986
Standards Handbook

1.1.1.2 American National Standards Institute (ANSI)
A13.1-1981
Scheme for the Identification of Piping Systems

1.1.1.3 American Society of Mechanical Engineers (ASME)

B16.9-1993

Factory-Made Wrought Steel Buttwelding Fittings

B31.3-1993

Chemical Plant and Petroleum Refinery Piping

1.1.1.4 Air-Conditioning and Refrigeration Institute (AIR)

AIR 590-1986

Reciprocating Water-Chiller Packages

1.1.1.5 American Society for Nondestructive Testing (ASNT)

SNT-TC-1A

Recommended Practice (December 1988)

1.1.1.6 American Society for Testing and Materials (ASTM)
A $53-93 a$
Pipe, Steel, Black and Hot-Dipped, Zinc-Coated Welded and Seamless
A $106-94$
Seamless Carbon Steel Pipe for High Temperature Service
A $234-92$ a

Piping Fittings of Wrought Carbon Stee] and Alloy Steel for Moderate and Elevated Temperatures

\subsubsection{American Water Works Association (AWWA)}

C209-90

Cold-Applied Tape Coatings for Exterior of Special Sections, Connections, and Fittings for Steel Water Pipelines 
TT-S-00230C, AMD 2

TT-E-489H
Sealing Compound: Elastomeric Type, Single Component (For Caulking, Sealing and Glazing In Buildings and other Structures)

Enamel, Alkyd, Gloss, Low VOC Content

1.1.1.9 Federal Standards (FED STD)

FED-STD-595B

Colors Used in Government Procurement

1.1.1.10 Manufacturers Standardization Society of the Valve and Fitting Industry (MSS)

SP-89, 1991

Pipe Hangers and Supports - Fabrication and Installation Practices

1.1.1.11 National Electrical Manufacturers Association (NEMA)

MG 1-1993

Motors and Generators

1.1.1.12 Steel Structures Painting Council (SSPC)

SP 3-82

SP 6-85

\section{1 .1 .13}

1.2

1.2.1 See Section 01300 for submittal procedures.

1.2.2 Approval Required

1.2.2.1 Approval data: Before delivery, submit information listed in the Approval Data List in this Section.

1.2.3 Approval Not Required

1.2.3.1 Vendor information: Before installation, submit information listed in the Vendor Information List in this Section.

\subsection{SYSTEM DESCRIPTION}

1.3.1 System is a chill water system with carbon steel piping. Chill water system includes a chiller unit, piping and a fan coil unit. The fan coil unit will be installed in a contaminated sluice pit. 
1.4.1 Welding Qualifications

1.4.1.1 Qualification of welding and procedures: Personnel and procedures for welding pressure retaining components along with attachments hereto, and pipe supports, shall be qualified in accordance with ASME B31.3, Paragraph 328.2.

1.4.1.2 QuaTification of Nondestructive Examination (NDE) personnel:

a. Visual weld examination shall be performed in accordance with ASME B31.3.

b. Personnel performing other NDE shall be certified in accordance with Contractor's written practice, which shall meet the requirements of ASNT-TC-IA. Use Level II personnel to interpret results.

1.4.2 Deliverable Documentation: The following documents and records, required by this Section, shall be delivered to Construction Document Control (Buyer) in accordance with Section 01720.

Document

Welding Qualification

Welding Examination Documentation

Flushing/Mechanical Cleaning Verification

Leak/Pressure Test Certification
Paragraph

1.4 .2

$3.2 .1 .5 a$

3.2 .5

$3.2 .6 .1 b$

1.5 DELIVERY, STORAGE, AND HANDLING

1.5.1 See Section 01610 for general requirements.

PART 2 - PRODUCTS

2.1 SUBSTITUTES

2.1.1 See Section 01630 for substitution approvals.

2.1.2 See Section 01019 for items furnished for construction.

2.2 MATERIALS

2.2.1 Pipe and Fittings: See the Pipe Codes in this Section, and details on the Drawings.

2.2.1.1 Material and weight shall be as specified in the Pipe Code for each piping system.

2.2.1.2 Close or butt nipples are not permitted, unless shown on the Drawings. 
2.2.2 Pipe Joint Sealant (Lubricant) for Threaded Joints

2.2.2.1 Use nonhardening teflon paste: Chesterton "Goldend" No. 7298, Federal Process Company "JC-30, " or Lake Chemical Company "S1 ic-Tite."

2.2.3 Painting: See Section 09900.

2.2.4 Glycol Solution: Glycol solution shall consist of $46 \%$ glycol and $54 \%$ distilled water by volume. Total system volume is approximately 30 gallons. The glycol shall be an industrially inhibited propylene glycol (phosphate based) with dyed color to facilitate leak detection. Contractor shall be responsible for disposal/handling of glycol.

2.2.5 Pipe Supports: Standard, manufactured components as shown on the Drawings. - Pipe supports and attachments welded to pressure containment boundaries may be noncertified material, provided the material bears a type identifying mark, is suitable for welding, and compatible with the material to which it is attached.

2.2.6 Identification Tags: 0.0478-inch (18-gage) minimum thickness stainless stee1. Tag attachment wire: 20-gage, solid, stainless steel.

2.2.7 Protective coating for piping in contact with earth or concrete, and not cathodically protected.

2.2.7.1 Carbon steel piping: Tapecoat Company Tapecoat "H30" and primer meeting requirements of AWWA C209 specification for cold applied tape.

2.2.8 Expansion Anchors: See Section 05055.

2.3 EQUIPMENT

2.3.1 Valves: Specified in Pipe Codes, unless shown otherwise on the Drawings.

2.3.2 Pit Cooling System: System shall be a split system consisting of a fan coil unit mounted in an existing pit, a packaged outdoor liquid chiller providing chilled propylene glycol/water solution to the fan coil unit, and fan controls and instrumentation. Air moving equipment ratings and sizes are based on AMCA Standard 99. Fan construction sha7l be in compliance with AMCA Standard 99-0401-86 Classifications for Spark Resistant Construction. Fan installation shall be in accordance with vendor installation instructions and recommendations. Equipment ratings shown below are minimum acquirements.

2.3.2.1 Chiller unit (R-0621): The liquid chiller shall be weatherproof for outdoor use, UL approved, in accordance with AIR 590. The packaged outdoor liquid chiller shall be air cooled and deliver $4 \mathrm{gpm}$ of chilled $46 \%$ propylene glycol/54\% water solution at $60^{\circ} \mathrm{F}$ to the fan coil and have a maximum coolant return temperature of $80^{\circ} \mathrm{F}$. The chiller shall be capable of providing the required cooling to the fan coil in ambient temperatures of $2^{\circ} \mathrm{F}$ to $106^{\circ} \mathrm{F}$ dry bulb (FDB) $/ 67^{\circ} \mathrm{F}$ wet bulb (FWB). The chiller control panel shall have a NEMA-1 enclosure and be inside the raintight chiller enclosure. The chiller shall be an Edwards 
Engineering Model CE-2-AHP, $460 \mathrm{~V} / 60 \mathrm{~Hz} / 3$ phase, round style or HNF-2536, Rev. 0 approved substitute. Provide base support anchorage details to ICF KH supplied 6-inch concrete pad.

a. The chiller shall contain a low ambient control package, compressor short cycle protection, and a high pressure lock-out circuit. The chiller shall have system bypass and check valve and large coolant reservoir to prevent compressor short cycling.

b. The chiller shall have a 2 pump circuit, 1 for coolant supply to the process, 1 for coolant circuit by-pass.

c. The chiller shall be equipped with an expansion tank, automatic air vent, drain provisions and a process pump capable of delivering the propylene glycol/water mixture at 4 gallons per minute at 50 feet total design head.

d. The chiller shall be provided with a control panel with the necessary instruments and controls for controlling the entire system including the compressor, pumps, condenser fan, and fan coil unit.

e. In addition to the controls necessary to operate the chiller, a temperature indicating and control system shall be provided and mounted on the control panel to control the pit air temperature between $90^{\circ} \mathrm{F}$ and $110^{\circ} \mathrm{F}$. This indicating controller shall indicate the actual coil air inlet temperature and the setpoint and shall have a separately adjustable alarm contact (SPDT) to actuate at $115^{\circ} \mathrm{F}$ for Buyer's use.

2.3.2.2 Fan coil unit (FC-0621): The fan coil unit shall be capable of delivering $12,000 \mathrm{Btu} / \mathrm{h}$ with an entering air condition of $110^{\circ} \mathrm{FDB}$ and $91^{\circ} \mathrm{FWB}$. Coolant supply temperature sha11 be $60^{\circ} \mathrm{F}$ and coolant temperature leaving the fan coil shall not exceed $80^{\circ} \mathrm{F}$. The fan coil unit shall be housed in a stainless steel enclosure. The fan coil unit shall be an Edwards Engineering Model No. CSB-18-4-600-H or an approved substitute.

a. The fan coil-motor shall be a 120 V/60 Hz/1-phase, Totally

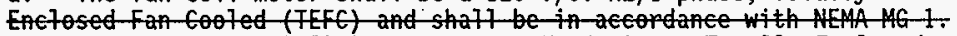
The fan coil motor shall be a $120 \mathrm{~V} / 60 \mathrm{~Hz} / 1$-phase, Totally Enclosed Fan Cooled (TEFC) and shall be in compliance with NFPA 70 (1996), Class 1, Division 2, Group B criteria (as a minimum, non-sparking under normal operation). Fan coil motor installation shall be in accordance with vendor installation instructions and recommendations. Motor power cable shall be 30 foot length, measured from where cable exits the fan coil, for routing to Buyer's chiller unit (R-0621). Power cable insulation shall be rated for $600 \mathrm{~V}$ ac. The cable's overall jacket shall be ultraviolet resistant. The cable shall be cut to length during field installation.

b. The cooling coil shall be constructed of copper tubing and fins. Water pressure drop across the coils shall not exceed 10 psi maximum.

c. The fan coil unit shall include a temperature sensor (TE-06213, $100 \mathrm{ohm}$ platinum RTD) to detect the air inlet temperature to the fan coil unit. The sensor and it's attached electrical cable shall be weatherproof and sealed against intrusion of moisture. The conductors shall be tagged to indicate their connection points to the RTD elements. 
HNF-2536, Rev. 0

RTD Teads shall be shielded, \#16 AWG contained within a cable or sheathPage 127 and shall be 30 foot length, measured from where cable exits the RTD 
Box, for routing to Buyer's chiller unit (R-0621). The cable's overall Page 128 jacket shall be ultraviolet resistant. The cable may be cut to length during field installation.

d. The maximum fan coil enclosure size shall be 40.75 inches 1 ong by 6 inches wide by 17.5 inches high. The air intake shall be on the bottom of the unit and the air discharge sha7l be on the 4340.75 -inch ECN-197 length side. The inlet and outlet coolant connections, 3/4-inch MNPT, shall be on the left side when facing the air discharge and approximately 4.5 inches from the bottom of the coil unit. Two mounting channels shall be provided on top of the unit running along the 4340.75 -inch length with hex nuts welded to the channel to provide ECN-197 6 attachment points to $3 / 8$ inch l6UNC-2A bolts supplied by Buyer.

\section{PART 3 - EXECUTION}

\subsection{INSTALLATION}

\subsubsection{Equipment}

3.1.1.1 Install as shown on the Drawings and in accordance with the manufacturer's instructions.

3.1.1.2 Prime and paint carbon steel supports in accordance with Section 09900. Paint containing lead is not acceptable.

\subsubsection{Piping}

3.1.2.1 Fabricate and install pipe and tubing in accordance with ASME B31.3 (for Category $D$ service), the Drawings, and this Section. Pipe Code M-4 piping system shall be fabricated from carbon steel components using welded connections unless otherwise shown on the drawings.

3.1.2.2 Cut pipe and tubing using methods which result in clean, straight cuts. Do not use tubing cutters on tubing utilizing compression fittings.

3.1.2.3 Ream pipe and tubing to nominal inside diameter after cutting. Remove burrs from threads before assembly.

3.1.2.4 Bend pipe and tubing in accordance with ASME B31.3, and meet tolerances given in ASME B31.3. Use methods and equipment which produce bends free of wrinkles, bulges, or kinks. When wall thickness, diameter, and bend radius indicate possibility of wall collapse during bending, fill pipe or tubing with clean silica sand or fusible material similar to Cerro-bend, manufactured by Cerro Corporation.

a. Application of heat to facilitate a pipe bend shall be brought to the attention of the responsible engineer for direction and disposition.

b. Cold springing pipe permitted only if specified on the Drawings.

3.1.2.5 Make joints in threaded piping systems with joint sealant specified. Apply sealant to male threads only.

3.1.2.6 Install tubing fittings in accordance with the manufacturer's instructions. 
3.1.2.7 Carbon steel embedded in concrete shall be bare.

3.1.2.8 Keep piping systems clean. Once fabrication has started, plug or cap ends of piping when installation is not in progress. Cap or plug openings in fabricated pipe spool assemblies until installation in the piping system. Leave ends of spare lines capped or blind flanged when instaliation has been completed.

3.1.2.9 Pipe supports: Install as shown on the Drawings, in accordance with manufacturer's instructions, and applicable recommended procedures of MSS SP-89.

3.1.3 Underground Piping Excavating

3.1.3.1 Trenches: Excavate, backfill, and compact in accordance with Section 02200 and Section 02225.

3.1.3.2 Survey piping systems for elevation and location before final tie-in welds to valve pits, risers, or fixed items. Complete placement of supports and meet Specification and Drawing requirements before survey. Elevation and location shall be in accordance with the Drawings. After finat tie-ins survey piping system again for final acceptance.

3.1.4 Welding

3.1.4.1 Weld piping, attachments to pressure retaining components, and pipe supports in accordance with ASME B31.3.

a. Protect outdoor welding operation from rain and wind by using barriers to protect welder and weld joint.

b. Complete piping welds before tie-in welds to valve pits, risers, or fixed items.

c. Remove backing strips if used.

3.1.5 Weld Identification

3.1.5.1 Prepare weld maps using Project Drawings or sketches, which show relative positions of pressure containing welds and attachment welds to pressure retaining components.

3.1.5.2 Assign and record weld numbers on weld identification drawings as welds are made.

3.1.5.3 Place the welder identification symbol adjacent to welds upon completion. Place the identification symbol approximately every 3 feet on long seams or large weldments, using one of the marking methods specified in Section 01610.

3.1.5.4 Do not reuse weld numbers. If a weld is completely replaced, assign a new number. 
3.1.5.5 Maintain material traceability (including heat/lot numbers) through Page 130 fabrication.

3.1.6 Perform NDE, flushing, leak/pressure testing, and disinfecting specified in 3.2 before coating application.

\subsubsection{Exterior Protective Coating}

3.1.7.1 Protect short lengths of bare carbon steel pipe and fittings exposed to earth backfill with specified coating.

a. Clean carbon steel surfaces to white metal by sandblasting in accordance with SSPC SP 6 . Where blasting is impracticable clean by power wire brushing in accordance with SSPC SP 3.

b. Apply specified tape and primer in accordance with AWWA C209, Section 3, and manufacturer's instructions.

3.1.7.2 After installation, examine carbon steel pipe having factory-applied exterior protective coating, and joints, fittings, and short lengths of pipe having field applied exterior protective coating materials.

a. Use electrical holiday detector in accordance with AWWA C209, Section 4.4.

b. Repair damage to coating in accordance with AWWA C209, Section 3.4.

3.1.8 Piping Identification: Identify exposed piping systems as to fluid carried and direction of flow as specified in Appendix A.

3.1.9 Identification Tag Features

3.1.9.1 Blanks: $3 / 4$ by 2 inches (unless legends require longer tags), with a $1 / 8$-inch attachment wire hole $3 / 16$ inches in from one end.

3.1.9.2 Characters: Use 1/4-inch stamped or engraved characters.

3.1.9.3 Legends: Provide the. following information, unless otherwise specified on the Drawings. Obtain information from the Data Sheets in this Specification, or Drawings.

a. Buyer part number.

3.1.9.4 Attach identification tags to valves, instruments and other equipment, as required.

3.1.10 Wiring: For wiring requirements refer to Sections 13440 and 16400 . 
3.2.1 Nondestructive Examination (NDE) of Welds for Piping

3.2.1.1 Perform NDE for each Pipe Code listed in the schedule in 3.3. Extent of required examination shall be in accordance with ASME B3I.3, Paragraph 341.4.1. Acceptance criteria for NDE shall be in accordance with ASME B31.3, Paragraph 341.3.

3.2.1.2 Visual examination: Perform in accordance with ASME B31.3, Paragraph 344.2.

3.2.1.3 Radiographic examination (RT): Perform in accordance with ASME B31.3, Paragraph 344.5.

a. Identify radiographic film with weld identification number and project or work order number assigned to work covered by this Section. In process examination in accordance with ASME B31.3, Paragraph 344.7 may be substituted for radiography.

b. Prepare radiographic examination reports as follows.

1) List each radiographic exposure location $(0-1,1-2, \ldots)$ individually on radiographic examination report.

2) Indicate location acceptability or rejectability and note discontinuities whether rejectable or not.

3 ) When report includes radiographs of welds which have been repaired, indicate which welds are repair welds and how many times each weld has been repaired.

c. If additional welding is performed on weld area which has already been examined radiographically, this area is repair area. Identify subsequent radiographs by "R-1, $R-2$," etc.

3.2.1.4 Perform 5\% random examination of piping supports in accordance with ASME B31.3, Paragraph 344.2.

3.2.1.5 NDE documentation:

a. Document examination of pressure containment welds and welds to pressure containing components for piping systems on NDE/Weld Record Form KEH-0433 or similar. See Form KEH-0433 or similar for instructions for recording weld maps, weld numbers, welder identification, welding procedure numbers, weld filler material, visual examinations, nondestructive examinations, and for noting satisfactory completion of leak/pressure testing.

b. Required NDE shall be completed and documented before starting leak/pressure testing. 
c. NDE/Weld Record information and weld maps specified in

paragraph 3.1 .5 may be incorporated on a single format or traveler for a specific work package.

d. Document examination of pipe supports by recording on Sketches or NDE/Weld Record form.

3.2.2 Flushing/Testing Preparation: Obtain direction for disposal of waste flushing and testing water, prior to generation of wastes, from the operating Contractor.

3.2.3 Cleaning and Flushing

3.2.3.1 After NDE is complete and before leak/pressure testing the system, or before connecting the system into existing systems, clean piping internal surfaces mechanically or by flushing as follows.

\begin{tabular}{|c|c|c|}
\hline Service & Pipe Code & Cleaning Method \\
\hline Chill Water & M-4 & Water Flush or 3.2 .4 \\
\hline
\end{tabular}

3.2.3.2 Mechanical cleaning: Remove loose dirt, scale, and debris by brushing, wiping, high pressure water jetting, or other mechanical method approved by the Construction Engineer (Buyer).

a. When high pressure water jetting or other mechanical cleaning method utilizing water. is used, and leak/pressure testing will not be performed immediately after cleaning, dry piping systems by blowing dry oi1-free air or nitrogen through lines.

b. Dry until the relative humidity of discharge air is equal to that of inlet air. Use drain taps at low points of piping system to ensure complete drainage and drying. Cap lines or reconnect to system to maintain cleanliness. Note, humidity measurements from inlet and exhaust shall be converted to the same pressure to verify equality.

\subsubsection{Water flushing:}

a. Remove strainer screens before flushing, except those protecting control equipment. clean screens protecting control equipment before flushing, if necessary, and after flushing is complete.

b. Flush piping with water for 1 minute minimum, and until effluent is clean and contains no visible particulate matter. Flushing pressure shall not exceed maximum operating pressure specified in Pipe Codes. Flushing water supply shall have sufficient capacity to produce a flow velocity of 4 to $6 \mathrm{ft} / \mathrm{s}$ in largest pipe size, with pipe full. Provide flow measurement in flushing water supply line to be used as basis for verification of flow velocities in piping system by the Construction Engineer (Buyer).

3.2.4 Mechanical cleaning may be substituted for flushing if approved by the Construction Engineer (Buyer). 
3.2.5 Provide documented evidence that flushing or mechanical cleaning HiNF-2536, Rev. 0 been accomplished as specified in this Section.

3.2.6 Leak/Pressure Testing of Piping

3.2.6.1 General:

a. After completion of flushing, perform leak/pressure testing of pipe in accordance with ASME B31.3, paragraph 345 and this Section. Use calibrated gages with ranges $1-1 / 2$ to $z 4$ times the test pressure.

$\mathrm{ECN}-2 \mathrm{ag}$

b. Document testing of each piping system on "Leak/Pressure Test Certification" Form KEH-1757 or similar form. Use separate forms to describe and record each piping system. Under "Description" describe piping system in enough detail for correlation to weld maps, shop fabrication drawings, and Project Drawings as applicable. For systems tested in segments, indicate continuity in "Description" to assure that entire systems have been tested.

c. Pipe joints, fittings, and other potential leak sources to be tested sha1l be visible and accessible during tests.

d. Install 1 temporary relief valve during testing. Relief valve shall have a discharge capacity of $125 \%$ of capacity of the pressurizing device, and be set to operate at $1-1 / 3$ maximum of the test pressure for hydrostatic testing and not higher than test pressure plus the lesser of $50 \mathrm{lb} / \mathrm{in}^{2}$ or $10 \%$ of the test pressure for pneumatic testing. Tag each relief valve used to show serial number, inspector, date, and pressure setting.

e. Install necessary restraining devices, before applying test pressure, to prevent distortion or displacement of piping.

f. Isolate instruments and other items which could be damaged by test pressures.

g. Continuously maintain test pressure for 10 minutes minimum. Examine joints and connections. Piping system, exclusive of possible localized instances at pump or valve packing, shall show no visual evidence of weeping or leaking.

h. Visually examine piping and tubing joints, fittings, and other potential leak sources, including welds which attach wear plates, anchors, etc to piping systems, during testing.

i. Complete testing of piping before field application of protective coating. Pipe with factory applied protective coating shall be considered as having been tested before protective coating application.

j. All threaded connections shall be subjected to an initial service test in accordance with ASME B31.3-1993 Edition paragraph 345.7 .

\subsubsection{Hydrostatic pressure testing:}

a. Perform in accordance with ASME B31.3, Paragraph 345.4. 
b. Purge air from piping systems during filling, before applying $\mathrm{HF}-2536$, Rev. 0 pressure.

c. Coat welded piping joints, fittings, and other potential leak sources, including welds attaching wear plates, anchors, etc, to piping systems, with a mixture of powdered blue chalk and water or isopropyl alcohol. Allow to dry before filling piping with water and inspecting for leaks.

d. Remove water from tabulated piping systems after testing and dry by blowing dry, oil-free air or nitrogen through lines. Dry until the relative humidity of discharge air is equal to that of intet air. Use drain taps at low points of piping systems to ensure complete drainage and drying. Note, humidity measurements from inlet and exhaust shall be converted to the same pressure to verify equality.

\begin{tabular}{|c|c|}
\hline Service & Pipe Code \\
\hline Chill Water & M-4 \\
\hline
\end{tabular}

3.2.7 Chilled Water System Filling: After completion of pressure testing, fill the chill water system with glycol/water mixture. 


\subsubsection{ScheduTe of Pipe Weld NDE/Testing}

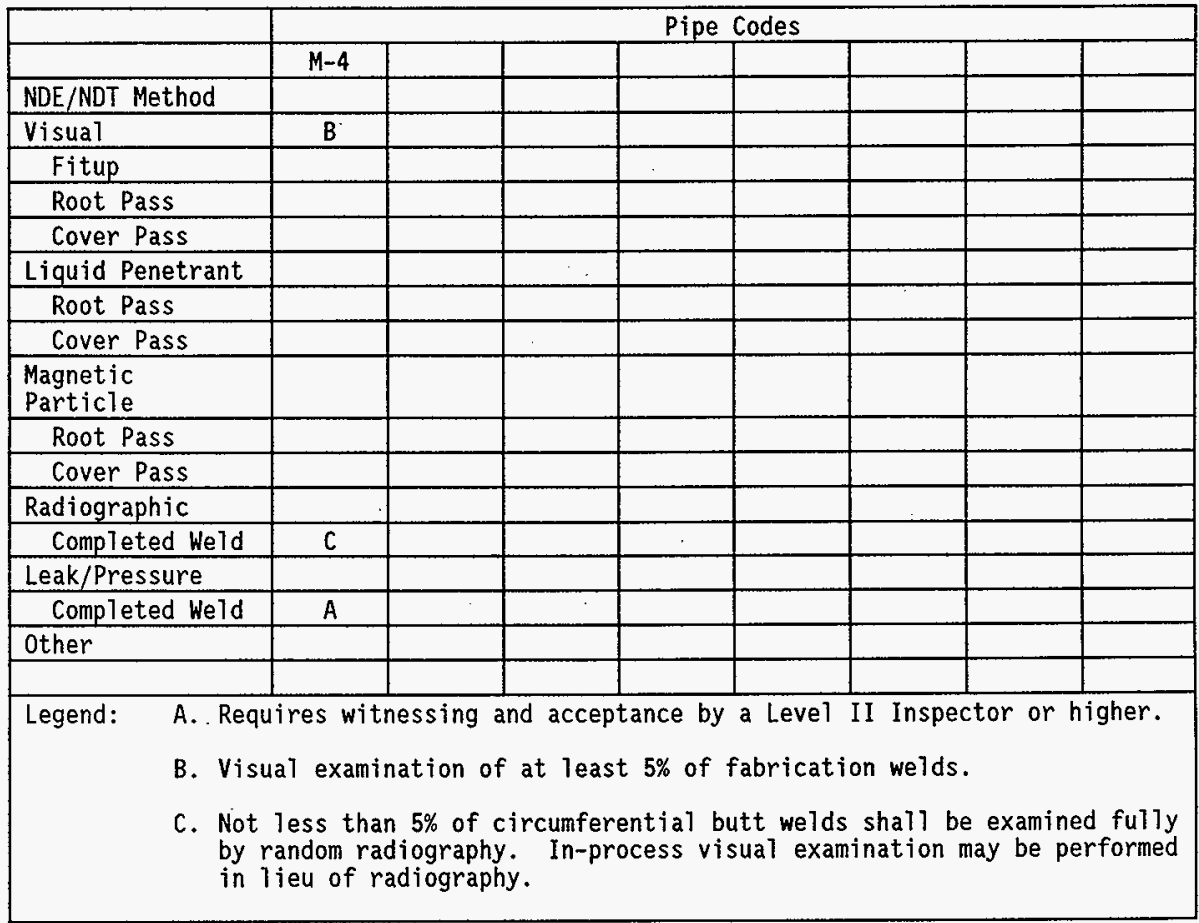




\begin{tabular}{|c|c|}
\hline \multicolumn{2}{|c|}{ 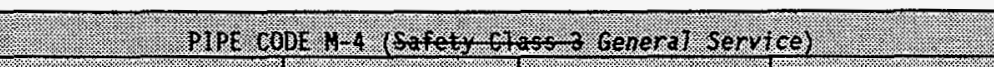 } \\
\hline service & 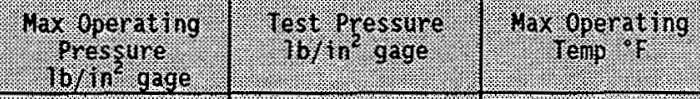 \\
\hline 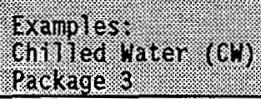 & 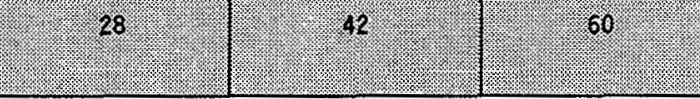 \\
\hline Sizes & All sizes \\
\hline Pipe & $\begin{array}{l}\text { ASTM A } 53, \text { Type E or S, Grade B black steel or } \\
\text { ASTM A } 106 \text { GR B }\end{array}$ \\
\hline Wall Thickness & Schedule 40 \\
\hline Nipples & Same schedule as pipe. \\
\hline Fittings & $\begin{array}{l}\text { ASTM A 234, Grade WPB, wrought steel, buttwelding } \\
\text { in accordance with ASME B16.9. Wa11 thickness to } \\
\text { match pipe. }\end{array}$ \\
\hline Unions & As shown on Drawings. \\
\hline Valves & \multirow{2}{*}{$\begin{array}{l}\text { Pittsburg Brass Manufacturer Co., Mode] SP, } \\
\text { Standard Trim, Carbon steel, Class 150, BW ends }\end{array}$} \\
\hline BaI1 & \\
\hline
\end{tabular}




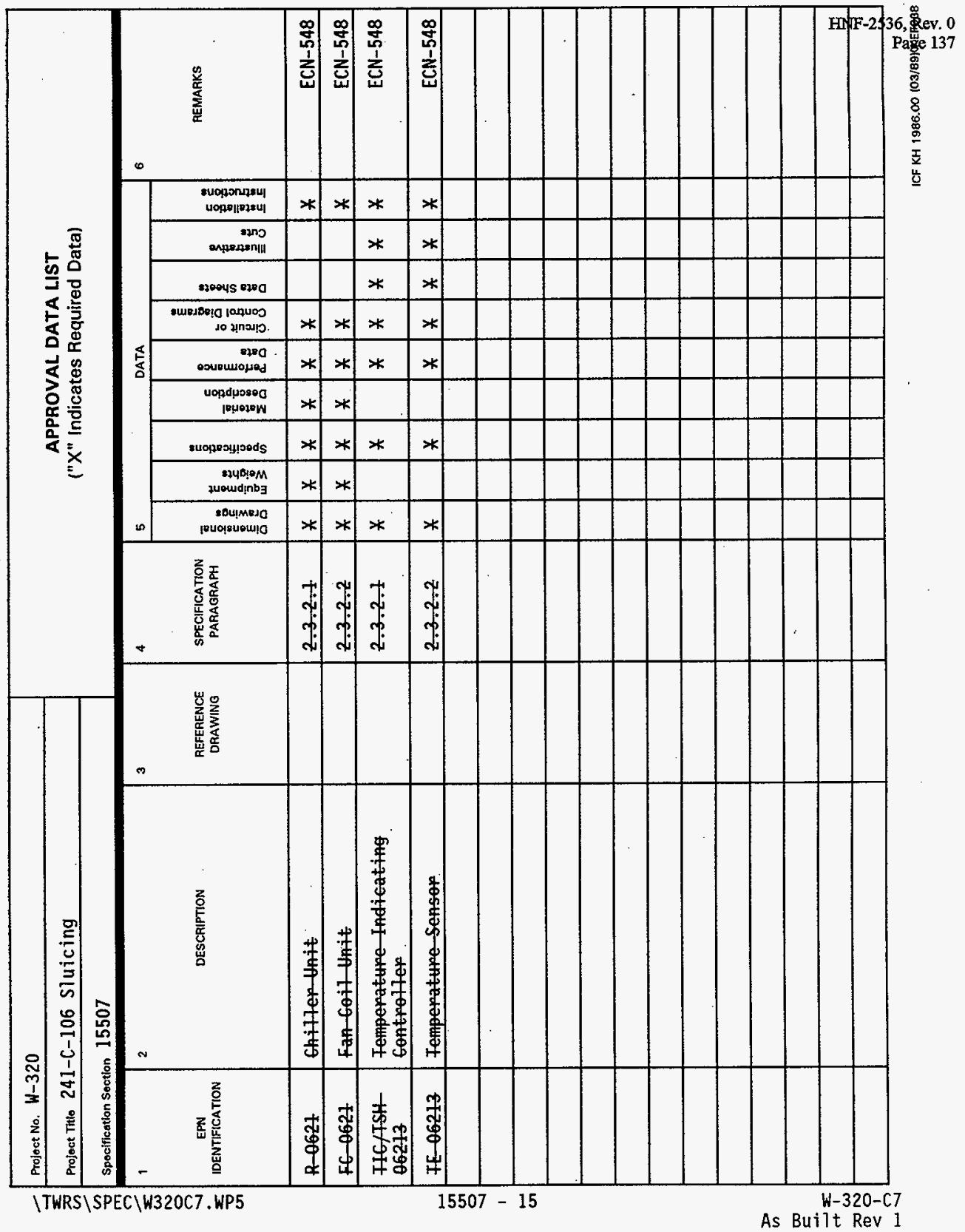




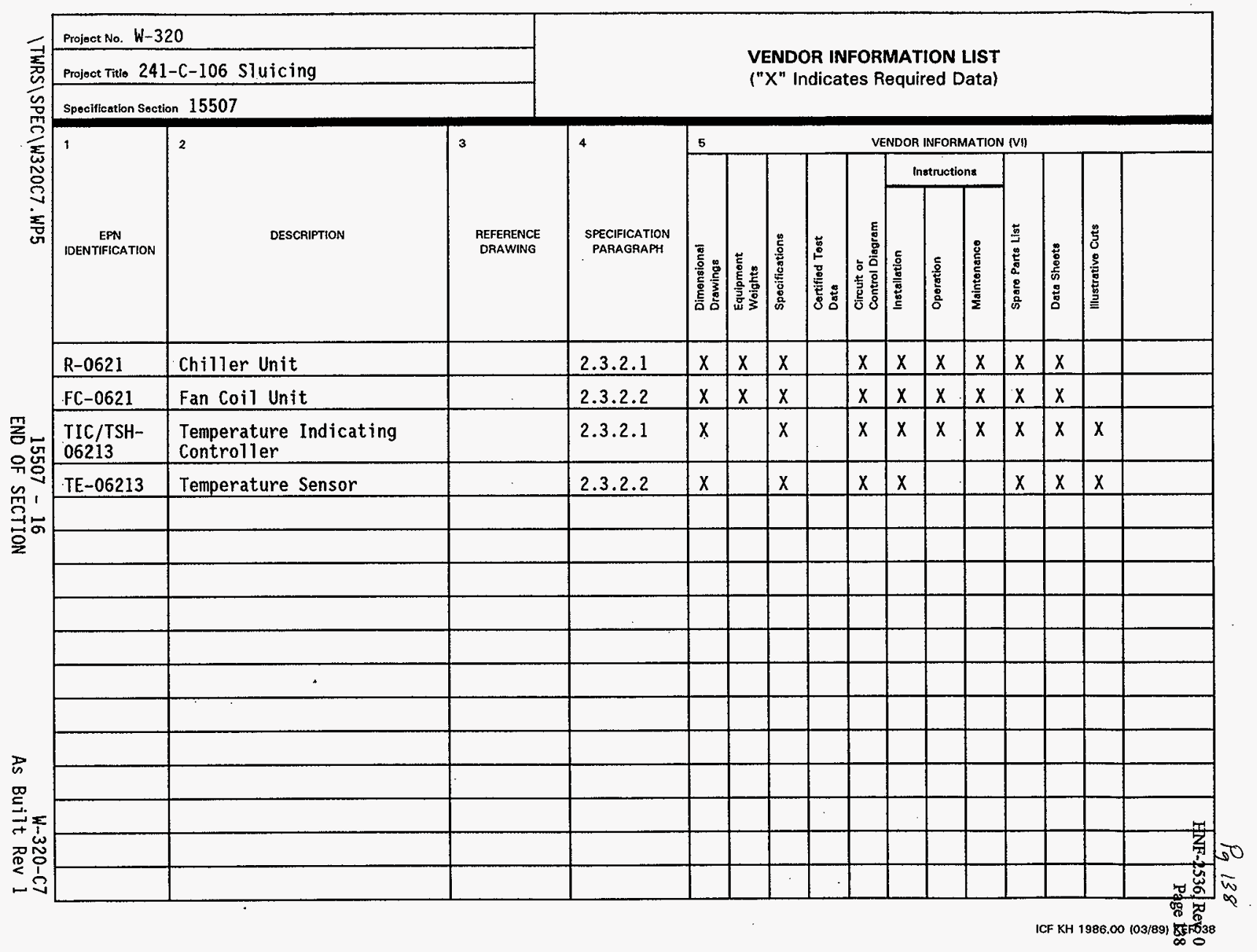


1. GENERAL

The identification of piping systems shall' be in accordance with the American Standard Scheme for the Identification of Piping Systems, ANSI A13.1, as supplemented herein.

2. $\quad$ LOCATION

a. Except as provided below, identification shall be located adjacent to outlets, valves, flanges, unions, changes-in-direction, where pipes pass through walls, floors, or ceilings, and along an uninterrupted length of pipe at maximum intervals of 50 feet. Each line or branch in a room shall have at least one identification.

b. Where a number of outlets, valves, flanges, unions, or changes of direction make identification at each item impracticable, they may be spaced at approximate 6 foot intervals, preferably adjacent to valves.

c. Legend shall be located on the pipe so that it can be read easily from the operator's normal viewing position. Labels shall be placed on the readily visible lower quadrant of overhead pipes, and on an upper quadrant of pipes below normal eye level. Above ceilings, labels shall be $p l a c e d$ in locations most readily visible from access positions.

3. LEGEND

a. Positive identification of a piping system content shall be by lettered legend giving the name of the content in full or abbreviated form. Legends may also be as specified on drawings or in other specifications.

b. Abbreviation of words in the legend may be used only where unavoidable due to space limitations.

c. The legend shall include the nominal operating pressure for steam, compressed air, and when specified, the pressure or temperature for other materials.

d. An arrow indicating the direction of flow shall be placed near the legend on pipes normally having a flow in one direction only. The color and size of the arrow shall be consistent with the color and size of the legend Tetters.

e. Legend shail be located on or adjacent to the classification color band. 
a. Legend and color classification may be accomplished by the use of approved Tabels conforming to this Standard and which are suitable for the temperature of the surface to which they are to be applied.

Approved labels include the following.

\section{ALL-TEMPERATURE PIPE MARKERS}

W. H. Brady Company

727 West Glendale Avenue

Milwaukee, Wisconsin 53201

TEL-A-PIPES

Westline Products Division

Thomas \& Betts Company

220 South Rose Street

Los Angeles, California 90012

b. Single-word labels may be combined to form complete legends.

Individual-letter labels shall not be so combined.

c. Labels shall be installed after painting is complete.

5. CLASSIFICATION COLOR

a. When use of classification colors is specified, they shall conform to Table 1.

\begin{tabular}{|c|c|c|c|}
\hline \multicolumn{4}{|c|}{ Table 1} \\
\hline crassificat on & Band or label & LegendfArrow & $\begin{array}{l}\text { Approxinate } \\
\text { Corlor Noo. } \\
\text { (CEO-STO } 595)\end{array}$ \\
\hline Dangerous & Yellow & Black (17038) & 13655 (yel low) \\
\hline Safe & Green & Black (17038) & 14260 (green) \\
\hline
\end{tabular}

b. Paint, if used, shall conform to FS TT-E-489, Class A, for synthetic gloss enamel.

c. Classification colors shall conform to Table 2.

\begin{tabular}{|c|c|}
\hline Table 2. Classification Colors. \\
\hline Material & Color \\
\hline Chill Water $(\mathrm{CH})$ & Green \\
\hline
\end{tabular}


TESTING, ADJUSTING, AND BALANCING

PART 1 - GENERAL

\subsection{REFERENCES}

1.1.1 The following documents, including others referenced therein, form part of this Section to the extent designated herein.

1.1.1.1 Sheet Metal and Air Conditioning Contractors National Association (SMACNA)

HVAC Systems--Testing, $\quad 1983$, lst Edition

Adjusting and Balancing

1.2 SUBMITTALS

1.2.1 See Section 01300 for submittal procedures.

1.2.2 Approvat Required: None

1.2.3 Approval Not Required

1.2.3.1 Testing data: Upon completion of testing and adjusting submit records on SMACNA forms or similar forms, dated and signed by the subcontractor who performed the work verifying results of tests per paragraph 3.3 .

1.3 QUALITY ASSURANCE

1.3.1 See Section 01400 for quality assurance.

PART 2 - PRODUCTS

Not Used

PART 3 - EXECUTION

3.1 EXAMINATION

3.1.1 Testing shall be performed on heating and c00ling units $A C-0621$ and $A C-0622$ on seismic enclosures (241-AY-51A and 241-AY-51B), airconditioning unit on electrical equipment skid (241-AY-51).

3.1.2 Examine systems to be tested, and their associated Project Record Documents. Verify that equipment has been prepared for operation in accordance with factory instructions, that equipment operation has been checked in accordance with system specification requirements, and that cleaning has been completed as required. 
3.2.1 Verify that filters of the required sizes and types are in place and clean. 
3.2.2 Inspect all factory and field wiring for loose connections.

\subsection{FUNCTIONAL TESTING OF HVAC SYSTEMS}

3.3.1 Electric Heating Unit(s)

3.3.1.1 Set the thermostat for a heating demand, turn on power to the unit.

3.3.1.2 Check unit voltage with unit running. Power must be within range shown on unit nameplate or vendor data. Check amperage draw of unit. Refer to unit nameplate or vendor data for correct running amps and verify compliance with measured value.

3.3.1.3 Verify unit operates satisfactorily.

\subsubsection{Cooling Unit(s)}

3.3.2.1 Compressor-condensing (or heat pump, as applicable) unit test and startup seration (NDE) of necessary tests and make necessary adjustments, such as leak testing, evacuation, and dehydration using a high vacuum pump, charging the unit and piping systems and start-up, in accordance with the manufacturer's specifications.

3.3.2.2 Set the thermostat for a cooling (or heating, as applicable) demand, turn on power to the unit.

3.3.2.3 Check unit voltage with the unit running. Power must be within the unit nameplate range, or vendor data. Check amperage draw of the unit. Refer to the unit nameplate, or vendor data, for correct running amperage. Verify compliance with the measured value.

3.3.2.4 Measure inlet air dry-bulb and wet-bulb temperature. Measure outlet air dry-bulb and wet-bulb temperature. Verify unit performance is within manufacturer's performance specifications. 


\section{SERVICE AND DISTRIBUTION}

\section{PART 1 - GENERAL}

\subsection{REFERENCES}

1.1.1 The following documents, including others referenced therein, form part of this Section to the extent designated herein.

1.1.1.1 American National Standards Institute (ANSI)

C57.13-1978

C $80.1-1990$

C80.3-1983

C82.1-1990
IEEE Standard Requirements for Instrument Transformers

Rigid Steel Conduit--Zinc Coated

Electrical Metallic Tubing-Zinc Coated

Fluorescent Lamp Ballasts

1.1.1.2 American Society of Mechanical Engineers (ASME)

NQA-1-1994

Quality Assurance Requirements for

Nuclear Facility Applications

1.1.1.3 American Society for Testing and Materials (ASTM)

B3-90

Soft or Annealed Copper Wire

1.1.1.4 Code of Federal Regulations (CFR)

Tit]e 47

Part 18

1.1.1.5 Federal Specifications (FS)

W-F-406E

TT-S-00230

AMD 2

Wh-C-566C
Telecommunication

Industria1, Scientific, and Medical Equipment
Fittings For Cable, Power, Electrical And Conduit, Metal, Flexible

Sealing Compound: Elastomeric Type, single Component (For Caulking, Seating, And Giazing In Buildings And other Structures)

Conduit, Metal, Flexible

1.1.1.6 Institute of Electrical and Electronic Engineers (IEEE) $587-1980$

Guide for Surge Voltages in Low-Voltage AC Power Circuits 
1.1.1.7 National ElectricaT Manufacturers Association (NEMA)
AB $1-1986$
Molded Case Circuit Breakers and Molded Case Switches

FB $1-1988$

Fittings, Cast Metal Boxes, and Conduit Bodies for Conduit and Cable Assemblies

FU 1-1986

Low Voltage Cartridge Fuses

ICS 2-1993

Controllers, Contractors, and Overload Relays

ICS 6-1993

Enclosures

WC 7-1988

Cross-Linked-Thermosetting-

Polyethylene-Insulated Wire and Cable for the Transmission and Distribution of Electrical Energy

1.1.1.8 National Fire Protection Association (NFPA)

70 (1993)

National Electrical Code (NEC)

1.1.1.9 Revised Code of Washington (RCW)

Tit7e 19

Chapter 19.28

1.1.1.10 Underwriters Laboratories (UL)

467-1993

Grounding and Bonding Equipment

$508-1988$

797-1993

$1062-1993$
Business Regulations - Miscellaneous

Electricians and Electrica] Installations 
1.2.1 See Section 01300 for submittal procedures.

1.2.2 Approval Required: None

1.2.3 Approval Not Required

1.2.3.1 Vendor information: Before installation, submit information Tisted in the Vendor Information List in this Section.

1.2.3.2 Electrical contractor's license: Before installation, submit a copy of license required by RCW 19.28 and WAC 296-46-940.

1.3 QUALITY ASSURANCE

1.3.1 Contractor's Quality Assurance Program: See Section 01400.

1.3.2 Safety $\mathrm{Class} \pm$ (SCZ) Products: SCt items shall be procured from qualified suppliers. These suppliers shall have a quality assurance program in accordance with ASME NQA-1.

1.3.3 Electrical/Electronic Product Acceptability: Provide Tabeling and documentation in accordance with Section 01400 .

1.3.4 Maintain electrical contractor's license in current status. Ensure that personnel performing work under this Section have certificates of competence required by RCW 19.28 and WAC 296-401. Certificates shall be available at worksite for review.

1.3.5 Deliverable Documentation: The following documents and records, required by this Section, shall be delivered to Construction Document Control in accordance with Section 01720.

Document

Electrical Test Results

\section{Paragraph}

3.3 .2 .3

\subsection{PERMITS}

1.4.1 Obtain and conspicuously post following permits before starting work under this Section.

a. Core Drilling/Tie-In Permit (Form WHC A-5600-118): Required for each element of work involving core drilling or utility tie-in.

b. Hot Work Permit (Form KEH 2235.00): Required for each location in which work involves welding, cutting, grinding, soldering, heating, spark generation or open flame.

1.5 DELIVERY, STORAGE, AND HANDLING

1.5.1 See Section 01610 for general requirements. 
1.6.1 The following items will be furnished for installation under this

Section. Upon request, one copy of approved vendor data submittals will also be furnished. See Section 01019.

1.6.1.1 Electrical Equipment Skid. W-320-P33

1.6.1.2 Seismic Shutdown Systems (Safety Class $z$ ) - 2 each. W-320-P35

1.6.1.3 Seismic Shutdown System Environmental Enclosures (Missile Shields) 2 each. W-320-P36

1.6.1.4 Variable speed drive. W-320-P17

PART 2 - PRODUCTS

2.1 SUBSTITUTES

2.1.1 See Section 01630 for substitution approvals.

2.2 MATERIALS

2.2.1 Conduit, Fittings, and Boxes

2.2.1.1 Conduit: ANSI C80.1, C80.3, FS WW-C-566, and UL 797 .

2.2.1.2 All conduit shall have an integral ground conductor.

2.2.1.3 Fittings for rigid steel and EMT conduit: NEMA FB 1. Use compression type, threadless fittings with EMT.

2.2.1.4 Fittings for flexible metal conduit: FS W-F-406, squeeze type.

2.2.1.5 Use "Myers" type watertight fittings, or sealing type locknuts, for conduit entries into sides or tops of NEMA ICS 6 Type 3, 3R, or 4 enclosures.

2.2.1.6 Couplings: Erickson type.

2.2.2 Conductors: NEMA WC7, stranded copper, rated for $90^{\circ} \mathrm{C}$, with Type THWN/THHN or XHHW insulation, of type and AWG size specified on the Drawings.

2.2.3 Ground Conductors: Grounding cable shall be stranded copper wire in accordance with ASTM B 3 and size specified on the Drawings.

2.2.4 Ground Rods: Copper bonded ground rods as shown on the Drawings, in accordance with UL 467. 
2.2.5 Connectors and Terminal Lugs: Solderless, pressure type, rated for use Page 148 with copper or aluminum conductors, with insulating caps or covers rated for system utilization voltage. Connectors shall be spade type with turned up tips and as specified below. See 2.3.12 for terminal blocks to be used for instrumentation and control circuits.

2.2.5.1 For conductors No. 8 AWG and smaller:

a. Ideal Industries, Incorporated "Wire-Nuts."

b. Thomas and Betts Company "Sta-Kon."

c. $3 M$ Company "Scotchlok."

2.2.5.2 For conductors No. 6 AWG and Targer:

a. Burndy Engineering Company "Screw Pressure Connectors" or "Hylug."

b. Thomas and Betts Company "Lock-tite."

2.2.5.3 Cable connector: Relief type as shown on the Drawings.

2.2.5.4 Ground studs: Burndy Type K2C "Servit Post"; size as required.

2.2.6 Wire Pulling Compound: Electro Compound Company "Y-er Eas," or American Polywater Corporation "Polywater."

2.2.7 Tape

2.2.7.1 Plastic insulating tape: 3M Company "Scotch No. 33+."

2.2.7.2 Conduit protection tape: 3M Company "Scotchrap No. 50."

2.2.7.3 Underground conduit plastic sheet marker: See Section 02225 .

2.2.8 Insulating Putty: 3M Company "Scotchfi1," General Electric Company No. 8389, or Kearney Company "Airsea1."

2.2.9 Conduit Sealing Compound: Porcelain Products Company "Sealex," or Kerite Company "Kerite."

2.2.10 Penetration Sealants: FS. TT-S-00230, Type II, Class A, 1-component polyurethane, nonsag type, light-colored.

2.2.11 Supports

2.2.11.1 Individual conduit hangers: Factory-made springable wrought steel clamps, or malleable iron split and hinged rings. For suspended conduit, clamps or rings shall be bolted to, or interlocked with threaded suspension rod.

2.2.11.2 Conduit supports: 1-hole clamps with clampbacks, or Unistrut with clamps. 
2.2.11.3 Equipment supports: 1-5/8-inch channel; Unistrut or Kindorf.

2.2.11.4 Expansion anchors: See Section 05055.

2.2.12 Wiremarkers: Imprinted tubular plastic.

2.2.13 Conduit Labels: Brady marking film.

2.2.14 Equipment Nameplates

2.2.14.1 Laminated plastic, 1/16-inch thick with white surface and black core.

2.2.14.2 Manufacturer's standard equipment nameplates may be used instead of those specified herein, if they display the required information, and are equivalent in quality and legibility. They need not be of the same material, or have the same form of imprinting.

\subsubsection{Nameplate features:}

a. Blanks: Select sizes appropriate for required characters and legends. Smooth edges and bevel 1/32-inch at 45 degrees.

b. Characters: Use 3/16 to 5/16-inch characters for equipment names, and $3 / 32$ to $3 / 16$-inch characters for other information. Engrave sharp and clear. Refer to 13440 Figure 1.

c. Legends: Provide the following information, unless otherwise specified on the Drawings. For equipment names use the generic/ functional designations shown on the Drawings.

1) Equipment name.

2) Equipment number.

2.2.14.4 Make sheet steel nameplates for equipment items that do not have surfaces suitable for attachment of plastic nameplates. Make nameplates when cylindrical surfaces of adequate size are available. When not, make nametags. Provide the information required above.

\subsection{EQUIPMENT}

2.3.1 Electrical equipment shall be PCB free.

2.3.2 Equipment Enclosures: NEMA ICS 6 Type 1, 3, 3R, and 4, as shown on the Drawings. Use Type $3 R$ (with gaskets) if Type 3 is not commercially available.

2.3.2.1 Motor starter enclosure (inside electrical equipment skid housing): Type 1, "Multi-Pak" group control motor starter enclosure, 48 inches wide by 26 inches high by 7 inches deep for combination starters, Westinghouse No. 6262A70G02 or approved substitute. To be provided as a part of the starter and circuit breaker modules identified in 2.3.5 and 2.3.7. 
2.3.3 Electrical Equipment Skid Mini-Power Panel: UL 1062, dry-type, $60 \mathrm{HF}$, 2536 , Rev. 0 $15 \mathrm{kVA}$, wall mounted, with minimum of 2 full current $5 \%$ taps below nominal rated voltage. Secondary of transformer shall be $120 / 240 \mathrm{~V}$ ac. Insulation system shall be rated $30^{\circ} \mathrm{C}$ with $60^{\circ} \mathrm{C}$ winding temperature rise above ambient. Unit shall have a main circuit breaker, a minimum of sixteen 1-pole breakers, a ground bar, and a separate neutral bar. Westinghouse Minipower Center P48G11S15P or Square D MPZ15S40F MiniPower Zone. A panelboard schedule shall also be included.

2.3.4 Power Distribution Blocks (At Pit:PTBX-0621): Copper, 3-pole, as required per Drawings, Square D, No. LBA362101 and LBA364101 or approved substitutes.

2.3.5 Combination Motor Starters: NEMA ICS 2, $600 \mathrm{~V}$ ac, 3-phase, minimum 14000 AIC, horsepower rated, capable of starting energy efficient motors. 2 NO and 2 NC auxiliary contacts rated $120 \mathrm{~V}$ ac, $10 \mathrm{~A}$ continuous with an inductive load, shall be provided in accordance with NEMA AB 1 and UL 508. The coils of contractors and starters sha17 be rated for $120 \mathrm{~V} \mathrm{ac}$. Motor circuit protector (MCP) type circuit breaker having adjustable, magnetic only, instantaneous trip elements. Relays shall be the sealed type. Devices shall be labelled/identified.

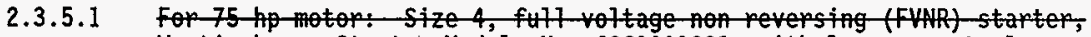
Westinghouse Starter Module-No.-6263A03601, with Tapger-control

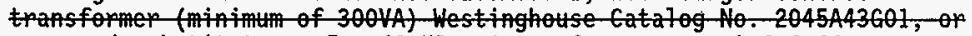
sustitutes- For 40 HP motor: See paragraph 2.3.10.

2.3.5.2 For 1.5-hp motor: Size 1, full voltage reversing (FVR) starter, Westinghouse Starter Module No. 6263A04G0I or approved substitute.

2.3.5.3 Overload relays: Bimetallic or melting alloy type, complete with heaters, and sized for motor size. Overload relays shall be manualiy reset on front of cover. Field adjustable solid-state overload trip units are acceptable as an alternative to overload relays.

NOTE: Order overload heaters separately.

2.3.5.4 Control and indication devices shall be provided as shown on the elementary diagrams on Drawing $\mathrm{H}-2-818698$. Control and indication devices shall be corrosion resistant, heavy-duty and oil-tight.

a. Pilot lights shall be push to test, $120 \mathrm{~V} \mathrm{ac}, 60 \mathrm{~Hz}$, nontransformer type, red (ON), green (OFF), with a legend plate.

b. Selector switches and pushbuttons shall be momentary and as shown on the elementaries, $120 \mathrm{~V}$ ac, $60 \mathrm{~Hz}$, with a legend plate. "Stop" pushbutton to be red. "Start" pushbutton to be green.

c. Control transformers: 1 for each starter or contractor compartment, rated $480-120 \mathrm{Vac}, 60 \mathrm{~Hz}$, and protected by 2 primary fuses, and 1 secondary fuse in the ungrounded side of the control circuit. The control transformer for the $75 \mathrm{HP}$ motor starter is larger than the standard size; refer to 2.3.5.1. 
d. Current transformer shall have a minimum ANSI C57.13 metering accuracy class of 0.6 with burden designation B-0.5. At rated amperes and under usual service conditions, no part of the current transformer shall exceed the heating limits as specified in ANSI C57.13. Current transformers shall have a ratio determined by the Seller.

e. Amp transducer shall receive a nominal 0 to 5 ac ampere input signal from Seller supplied current transformer. Output of amp transducer shall be 4 to 20 milliamps dc. Unit shall be powered from control transformer. Unit shall have calibration adjustment which can be accessed while mounted within the motor starter enclosure. Accuracy of unit shall be $0.50 \%$ of full scale at $25^{\circ} \mathrm{C} \pm 2^{\circ} \mathrm{C}$. Unit shall be equivalent to Rochester Instrument Systems CCC-1BC5E1XAF60Z0A1.

2.3.6 Motor Load Fuses: NEMA FU 1, and be the following types.

2.3.6.1 $250 \mathrm{~V}$ rated: Buss, Fusetron, Catalog No. FRN.

2.3.6.2 $600 \mathrm{~V}$ rated: Buss, Fusetron, Catalog No. FRS.

2.3.7 Circuit breaker, for installation in "Multi-Pak" group control unit, $600 \mathrm{~V}$ ac.

2.3.7.I For pit cooling system: $30 \mathrm{~A}, 3$-poles, thermal magnetic, Westinghouse Feeder Air Circuit Breaker Module No. 6263A16G03 or approved substitute.

2.3.7.2 For minj-power center: $70 \mathrm{~A}, 3$-poles, thermal magnetic, Hestinghouse Feeder Air Circuit Breaker Module No. 6263A16G06 or approved substitute.

2.3.8 Safety Switch: Heavy-duty, non-fusible, single-throw, NEMA 3R enclosure, UL listed, sized in accordance with following.

2.3.8.1 $600 \mathrm{~V} \mathrm{ac}, 3$-pole, 3-wire, $600 \mathrm{~A}$, "service entrance rated" Westinghouse Catalog No. RHU366 plus equipment ground kit Westinghouse Catalog No. GNK60 or approved substitutes.

2.3.8.2 $600 \mathrm{~V} \mathrm{ac}, 3$-pole, 3-wire, $60 \mathrm{~A}$, Westinghouse Catalog Nos. RHUN362 plus GNK60 or approved substitutes.

2.3.9 Tap Bus Assembly: Enclosed NEMA 3R, 3-phase, 4-wire, $600 \mathrm{~V} \mathrm{ac,} 600 \mathrm{~A}$ rated, tinned aluminum or bare copper bus bars, Circle AW Catalog No. Ri123HDD plus grounding lug kit, Circle AW Catalog No. $10184 \mathrm{C}$ or approved substitutes (see 3.2 .2 .4 ).

2.3.10 "Soft Start" Unit

2.3.10.1 The following requirements shall be satisfied:

a. Reduced voltage to prevent inrush.

b. Starting torque control up to $500 \%$ current limit for up to 20 seconds.

c. Controlled acceleration for extended start time (2 to 30 seconds). 
d. Controlled deceleration time (2 to 60 seconds)

e. Jam protection

k. Status pane1.

1. Acceleration control by voltage or current ramp

m. Five-cycle "ride-through" capability and phase reversal/phase unbalance protection.

n. The soft start unit shall use a minimum of 6 power switching devices for reduction of noise to the power system and smoothest input to the motor.

0. Optional starting modes shall include Kickstart (an initial boost to the motor), full voltage start, and current limited starting.

2.3.10.2 Enclosed, non-combination motop-controllen sized to control the stantingECN-167 of $a-75-H P,-480-Y a C, 3$ phase, 60 Hz motor. HEXA-Fype-1 rentilated enclosure. Allen Bradley- fatalog No. 150 -A97BBDA (includes "Soft-Stop" option op Solid State Reduced Voltage Starter, for 75 hp motor, Culter-Hammer mode7 EA135PN, with options (Smooth Stop, Kick start, Ammeter), with associated interconnecting cables, mounted in NEMA $12^{2}$ Enclosure (maximum size $36^{\prime \prime} \mathrm{H} \times 24^{\prime \prime} \mathrm{W} \times 10^{\prime \prime} \mathrm{D}$ ), configured as shown on elementary diagram on dwg H-2-818698, with ETL 7 abe7.

2.3.11 Terminal Cabinet: A17 weather, NEMA ICS 6 Type 4, size and model as shown on the Drawings.

2.3.12 Terminal blocks: For Instrumentation/Control wiring, as shown on the Drawings or an approved substitute.

2.3.12.1 For No. 10 AWG conductors and smaller: Either 1-piece or factoryassembled sectional double terminal, barrier type, with binder screw terminals. Terminal ampacities shall be equal to or greater than conductor ampacities; Marathon or Buchanan.

2.3.12.2 For No. 8 AWG conductors and larger: Either 1-piece or factoryassembled sectional barrier type with box lug terminals having pressure plate between screw and conductor. Size terminals for conductors to be connected.

2.3.12.3 Provide covers to cover live parts of terminations for circuits of $150 \mathrm{~V}$ or more to ground. Provide with means for ready inspection and ful1 width marking areas.

2.3.13 Equipment Rack (Inside Electrical Equipment Skid): Rack shall be fieldassembled "Unistrut" channel as shown on the Drawings. Field modifications are acceptable.

2.3.14 Receptacles: GFCI, $15 \mathrm{~A}, 120 \mathrm{~V}, 3$-wire grounding type with metal covers. Outside receptacles shall have weatherproof wallplate/cover. 
2.3.15 Lighting: Furnish fixtures with parts and fittings necessary to in accordance with the manufacturer's instructions.

2.3.15.1 Fixtures of each type described shalt be from 1 manufacturer, and identical in finish and appearance.

2.3.15.2 Fluorescent fixture ballasts: ANSI C82.1, IEEE 587 Category A, 47 CFR 18, Subpart C; high power factor, high performance Class $P$, with automatic resetting thermal protection and rapid start, rated for the voltage shown on the Drawings or in this Section and suitable for fixture temperature environments. Eletenic ballast-is-for use with Fo series lamps.

2.3.15.3 Catalog numbers, when specified, are for individual units. Where 2 or more units are combined for continuous row installation, furnish necessary accessories to complete installation.

2.3.15.4 Fixture types: As shown on the Drawings.

2.3.15.5 Photoelectric cell controls: Diecast aluminum weatherproof housing with hermetically sealed light sensitive element, having manualiy adjustable light level slide with turn-on range of 2 footcandles, as shown on the Drawings.

2.3.16 Toggle Switches for Lighting Inside Electrical Equipment Skid Housing: 3-way, $15 \mathrm{~A}, 277 \mathrm{~V}$ ac, commercial grade, ivory color. The switches located outside shall have a weatherproof wallplate/cover.

2.3.17 Pilot Light: Heavy duty, standard, $120 \mathrm{~V}, 60 \mathrm{~Hz}$, with red glass lens. Light illuminates when the inside lights are on.

PART 3 - EXECUTION

3.1 PREPARATION

3.1.1 Field Measurements: Scale dimensions on the Drawings show desired and approximate locations of equipment. Actual locations, distances, and levels shall be governed by field conditions.

3.1.2 Contractor shall prepare an installation procedure for installation of SCI equipment in accordance with ASME NQA-1. The installation procedureECN-809 shall be reviewed and approved by the design engineering group. See Section 01400 for witness and hold points.

\subsection{INSTALLATION}

3.2.1 General

3.2.1.1 Perform work in accordance with NFPA 70. For the area inside the tank farm boundary fence, buried rigid steel conduits that are 4 inches and smaller are allowed to have a minimum burial depth of 12 inches in accordance with a DOE waiver approval dated August 2, 1995. Refer to the Drawings. 
3.2.1.2 Fasten equipment to structural members of building or metal supports 2536, Rev. 0 attached to structure, or to concrete surfaces.

a. Use clamping devices for attachments to structural stee1. When clamping is impractical, obtain approval from the Construction Engineer before drilling, punching, cutting, or welding to building structura] steel members for support attachments.

b. Fasten equipment to concrete or masonry with expansion anchors. c. Fasten equipment to metal wall panels with weld studs, bolts or self-tapping metal screws.

3.2.1.3 Locate equipment, boxes, and conduit approximately where shown in relation to equipment served.

3.2.1.4 Do not install conduit, raceways, and boxes in positions that interfere with work done by other trades.

3.2.1.5 Identify components with nameplates bearing legends shown on the Drawings.

3.2.1.6 Attach nameplates on or near equipment, with metal screws. Attach panelboard nameplates on fronts, above doors. RTV sealant may be used when screws are not practical.

3.2.1.7 Use appropriate calibrated special tools when installing devices for which special installation tools are recommended by the manufacturers.

3.2.1.8 Expansion anchors: See Section 05055 .

3.2.2 Grounding Systems

3.2.2.1 Underground conductors, electrodes, and connections: Install in accordance with the Drawings. Make joints connecting copper and galvanized steel conductors above grade and in dry locations. Connections may be made with exothermic welds or Burndy Hyground connectors.

3.2.2.2 System and equipment grounding: Solidly ground neutral conductor of 3-wire, 1-phase and 4-wire, 3-phase, wye-connected distribution systems. Ground equipment and enclosures in accordance with the Drawings and NFPA 70.

3.2.2.3 Static grounding: Ground skid to the grid, as shown on the Drawings. Ground metal siding as noted on the Drawings.

3.2.2.4 At tap bus assembly, convert fourth "bottom" bus to a ground bus. Attach fourth "neutra]" bus to enclosure and other grounds. Use "equipment" grounding lug kit listed in 2.3.9. 
3.2.3.1 For excavation and backfill of soil, see Section 02225 .

3.2.3.2 Use rigid steel where subject to mechanical damage, or installed in concrete floors and walls, exposed to weather, or 4 feet maximum above floors. Use rigid steel where conduit is in contact with the earth. Electrical metallic tubing may be used elsewhere.

3.2.3.3 Install 14-gage galvanized steel pull wire or $1 / 8$-inch polyethylene rope in spare conduits.

3.2.3.4 Install concealed conduits as directly as possible and with bend radii as long as possible.

3.2.3.5 Make elbows, offsets, and bends uniform and symmetrical. Bend conduit with approved bending devices.

3.2.3.6 Cut conduit ends square, ream, and remove burrs. Conduit shall be clean, dry, and free of debris. Immediately after installation, plug or cap exposed ends with standard accessories until wires are installed.

3.2.3.7 Use galvanized steel locknuts and insulated bushings for attachment to enclosures except threaded hubs or sealing type locknuts shall be used outdoors or where moisture is present. Threadless fittings are not permitted for rigid conduit. Use Erickson-type couplings where required. Do not use running threads.

3.2.3.8 Install without moisture traps wherever possible. Where practicable, provide drain holes in pullboxes or fittings at low points in raceway systems and remove burrs from drilied holes.

3.2.3.9 Flexible conduit:

a. Use to make connections to motors and other equipment subject to vibration. Use liquidtight flexible metal conduit where conduit and fittings are installed outdoors or exposed to moisture or chemical fumes indoors.

b. Use in 4 foot maximum lengths for other equipment as shown on Drawings, with approval of the Construction Engineer.

3.2.3.10 Set up joints in conduit installed in concrete, underground, or exposed to weather, with high temperature, antiseize, conductive thread lubricant and sealant.

3.2.3.11 Verify stub-up locations with final equipment arrangements. Install exposed conduit stubbing up through floor slab straight and plumb, lined up, and uniformly spaced. Instal1 at sufficient depth below slab to eliminate part of bend above top of slab. Cap or plug stub-up before placing concrete. 
3.2.3.12 Wrap conduit passing from concrete to air or to direct earth burial witage 156 conduit protection tape from 3 inches in concrete to 12 inches minimum in earth, or 3 inches in air.

3.2.3.13 Seal openings around conduit at concrete or block fire walls and floor penetrations. Use fire barrier sealing compound for openings to 1/4-inch maximum, and grout for larger openings. Make seals waterproof, and finish sealant flush with surrounding wall surfaces.

3.2.3.14 Apply sealing compound after installation of conductors, at boxes, in conduits that penetrate walls or floors.

3.2.3.15 Cover conduit installed below on-grade floor slab with 3 inches minimum of concrete.

3.2.3.16 Permanently label conduits at both ends with numbers shown on the Drawings. For short (10 foot maximum length) conduits, place labels at the centers only.

3.2.4 Underground Conduit Banks

3.2.4.1 For excavation and backfill of soil, see Section 02225.

3.2.4.2 Use rigid steet in sand bed, as shown on the Drawings.

3.2.4.3 For single conduit runs, use rigid steel conduit in a sand bed.

3.2.4.4 Install underground conduits in accordance with the Drawings and route without drains where possible.

3.2.4.5 Where drains or risers are required, install in accordance with the Drawings. Seal conduit at both ends with duct sealing compound.

3.2.5 Boxes, Enclosures, and Wiring Devices

3.2.5.1 Install boxes firmly in position and plumb.

3.2.5.2 Install dust covers on junction, pull, and outlet boxes, and other types of wiring outlets at initial installation. Replace with permanent covers or devices after wires are installed.

3.2.6 Conductors

3.2.6.1 Do not bend cables installed in raceways to less than manufacturer's recommended minimum bending radii. Bind power and control circuits separately with nylon cable ties, at 18-inch intervals. Lay cables in raceways in straight parallel lines, and avoid crossing.

3.2.6.2 Use lubricant recommended by the cable manufacturer, or wire pulling compound specified, when pulling wire and cable through conduit.

3.2.6.3 Do not install or handle wires with thermoplastic insulation or jacket when ambient temperature is $15^{\circ} \mathrm{F}$ or below. 
3.2.6.4 Identify conductors, by wire numbers shown on the Drawings, with wiremarkers. Attach wiremarkers at termination points within 2 inches of wire terminations. Marker nomenclature shall be visible without moving wires or markers. Similarly, install "Wire Markers" at and around each wire run identified.

3.2.6.5 Paint or pressure-sensitive colored tape may be used for coding conductors instead of colored insulation on No. 8 AWG and larger wire for phase (ungrounded) conductors, and No. 4 AWG and larger wire for neutral (grounded) conductors and equipment grounding conductors on $7 y$. Maintain phase color coding, in accordance with the following table, for branch and feeder circuits up to and including equipment connections. Use colored tape to properly code existing conductors in which the color. does not comply.

\begin{tabular}{|c|c|c|}
\hline Conductor on $1 \mathrm{gln}$. & Conductor & insulat an $\mathrm{colan}$ \\
\hline $\begin{array}{l}480 Y / 277 \mathrm{~V}, 3 \text {-phase } \\
\text { systems, transformers, } \\
\text { panels, switchboards, etc }\end{array}$ & $\begin{array}{l}\text { Phase A } \\
\text { Phase B } \\
\text { Phase C } \\
\text { Neutral } \\
\text { Equipment ground }\end{array}$ & $\begin{array}{l}\text { Red } \\
\text { Yellow } \\
\text { Blue } \\
\text { White or Gray } \\
\text { Green (or bare) }\end{array}$ \\
\hline $\begin{array}{l}120 / 240 \mathrm{~V}, 1 \text {-phase } \\
\text { transformers, panels, } \\
\text { switchboards, etc }\end{array}$ & $\begin{array}{l}\text { Hot Number } 1 \\
\text { Hot Number } 2 \\
\text { Neutral } \\
\text { Equipment ground }\end{array}$ & $\begin{array}{l}\text { Black } \\
\text { Brown } \\
\text { White or Gray } \\
\text { Green (or bare) }\end{array}$ \\
\hline
\end{tabular}

\subsubsection{Splices, Taps; and Cable Terminations}

3.2.7.1 Make splices and taps in building wire with solderless connectors specified in 2.2.5. Use connectors in accordance with the manufacturer's instructions.

3.2.7.2 Use plastic insulating tape for uninsulated splices and taps. Apply tape to thickness at least equal to conductor insulation. Where bolted splice or connection presents irregular surface, apply insulating putty to joints before taping.

3.2.7.3 Use crimp-on type spade lugs with turned up tips for wire terminations of stranded conductors to binder screw or stud type terminals. Lugs shall have insulated sleeves.

3.2.7.4 Strip wires for use with pressure plate terminal strips so that no more than 1/8-inch of bare conductor is exposed after insertion beneath plate.

\subsubsection{Electrical Equipment Skid}

3.2.8.1 Anchor the skid/shelter to the concrete pad as shown on the Drawings. 3.2.8.2 Install equipment wiring as shown on the Drawings. 
3.2.9 Motor Operated Equipment: Connect the winch and pump drive motor 5 In ${ }^{2536, \text { Rev. } 0}$ accordance with the Drawings, this Section, and the manufacturer's

instructions. Install wiring to devices which do not appear on the Drawings, but are included in installation shown on the manufacturer's drawings,

3.2.10 Variable Speed Drive

3.2.10.1. Install in accordance with equipment manufacturer's instructions and this Section.

3.2.10.2 Anchor both front and back to the electrical equipment skid floor with 2 anchors minimum, as shown on the Drawings. Ensure floor decking is secured to framing under equipment.

3.2.11 Seismic Shutdown System Equipment: Assemble system components on seismic concrete foundations in accordance with manufacturer's instructions. Install interconnect conduit and vendor-supplied cabling. Anchor the cabinets as shown on the Drawings and in accordance with the manufacturer's written procedure.

3.3 FIELD QUALITY CONTROL

3.3.1 For SCt Components: SCZ equipment and materials shall be stored, handled and installed in accordance with written procedures that satisfy ASME NQA-1 requirements; see 3.1.2.

3.3.2 Testing

3.3.2.1 Furnish equipment and instruments required to perform testing.

3.3.2.2 Use instruments which bear calibration stamps showing dates of calibration and expiration dates of stamps. Calibration and accuracy of instruments shall be certified by an independent testing laboratory having standards traceable to the National Institute of Standards and Technology.

3.3.2.3 Test the equipment grounding system for ground continuity, and measure ground resistance. Test the equipment and wiring for continuity and unintentional grounds. Verify proper phase sequence and voltage at equipment served before attempts are made to operate equipment. Notify the Quality Control Inspector before start of tests. Record the results. Additional tests for the wiring are as follows:

a. Megger conductors rated $600 \mathrm{~V}$ and used for services, feeders or branch circuits over $150 \mathrm{~V}$ to ground, phase-to-phase, and phase-toground. Minimum acceptable value of insulation resistance is 200 megohms. The megger manufacturer's instruction booklet, furnished with megger, shall be used for conducting tests. Disconnect devices not capable of withstanding voltage or current of megger test, such as indicating instruments, relays and lamps, before test is made. Voltage output of megger shall be $1000 \mathrm{~V}$ dc nominal. 
b. Fest-wiring operating at less than $150-\gamma$ to and mint ional gound. Resistance-shall not-exeed 1-ohm-on continty wiring operating at less than $150 \mathrm{~V}$ to ground for continuity and unintentional ground. Resistance shall not exceed $1 \mathrm{ohm}$ for continuity checks of wiring larger than \#16 AWG and 3 ohms/for wiring \#16 AWG and smaller."

3.3.2.4 Calibration of overload protective devices shall be in accordance with UL 508 .

3.3.2.5 Motors: Check for correct rotation.

3.3.3 Reconnect devices disconnected during testing. 
Pg 160

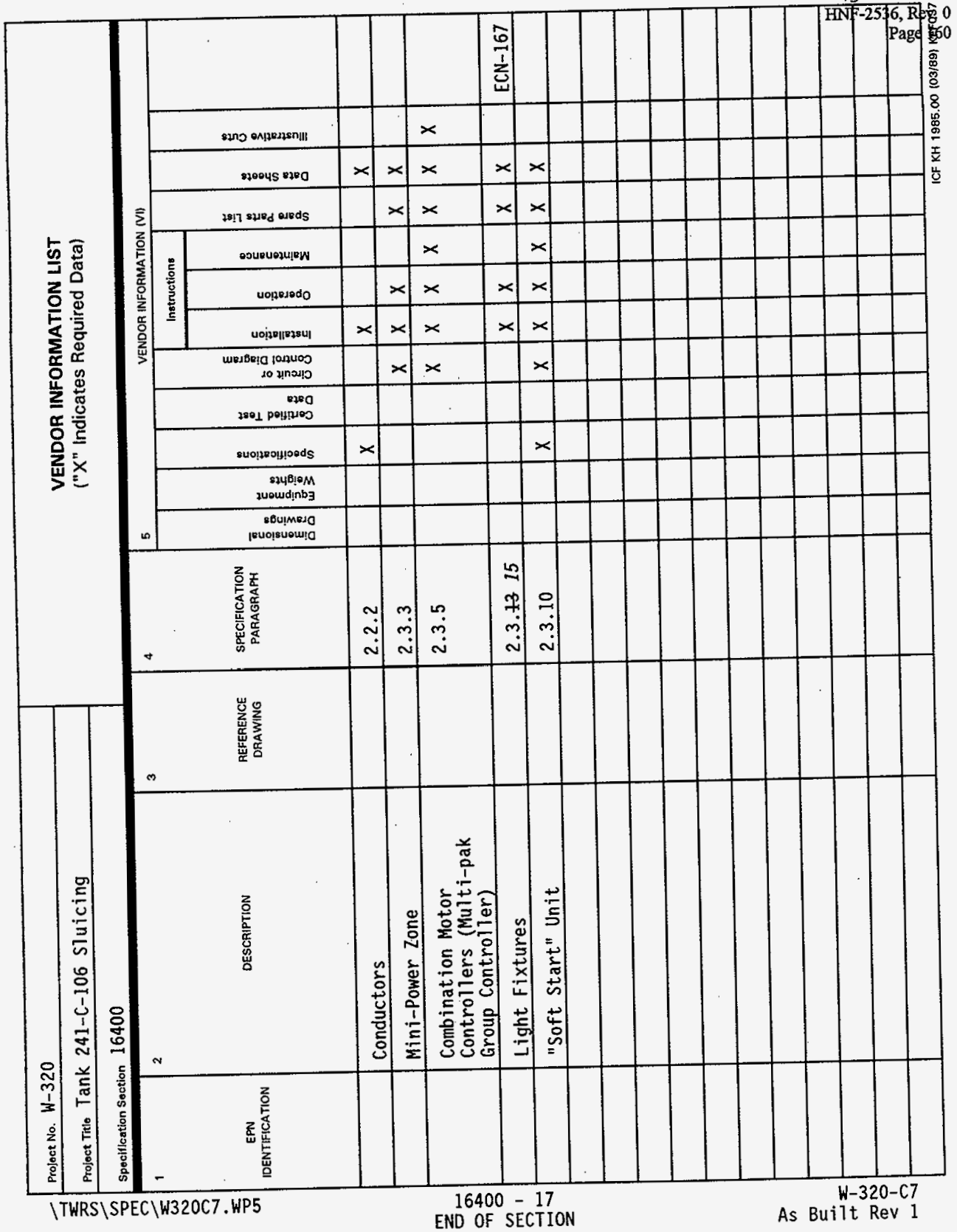




\section{CATHODIC PROTECTION}

PART 1 - GENERAL

\subsection{REFERENCES}

1.1.1 The following documents, including others referenced therein, form part of this Section to the extent designated herein.

1.1.1.1 American Society for Testing and Materials (ASTM)

C $177-85$

C $518-91$

D $1621-73$ (1979)

D $1622-93$

D 2842-69 (1990)

D 2856-87

D $3487-88$

\subsubsection{Federal Specifications (FS)}

TT-S-00230C

AMD 2
Test Method for Steady-State Heat Flux Measurements and Thermal Transmission Properties by Means of the Guarded-Hot-. Plate Apparatus

Test Method for Steady-State Heat Flux Measurements and Thermal Transmission Properties by Means of the Heat Flow Meter Apparatus

Test Method for Compressive Properties of Rigid Cellular Plastics

Test Method for Apparent Density of Rigid Cellular Plastics

Test Method for Water Absorption of Rigid Cellular Plastics

Test Method for Open Cell Content of Rigid Cellular Plastics by the Air Pycnometer

Mineral Insulating $0 i 1$ Used in Electrical Apparatus 

467-1993
Grounding and Bonding Equipment
486A-1992
Wire Connectors and Soldering Lugs for Use with Copper Conductors
486C-1992
Splicing Wire Connectors
510-1994
Insulating Tape
651-1989 5th edition,
Rev. through $12 / 4 / 89$
Schedure 40 and 80 Rigid PVC Conduit

1.1.1.5 National Fire Protection Association (NFPA)

70 (1993)

National Electrical Code (NEC)

1.2 SUBMITTALS

1.2.1 See Section 01300 for submittal procedures.

1.2 .2 Appovat Required

1.2.2.1 Fest-Station Skethes.-Before-installation, sumit sketches required in 3.2.3.3.

1.2.32 Approval Not Required

ECN-597

1.2.32.1 Vendor information: Before installation, submit information listed in ECN-597 the Vendor Information List in this Section.

1.3 QUALITY ASSURANCE

1.3.1 Electrical/Electronic Product Acceptability: Provide labeling and documentation in accordance with Section 01400.

1.3.2 Deliverable Documentation: The following documents and records, required by this Section, shall be delivered to Construction Document Control in accordance with Section 01720.

Document

Continuity Tests

Existing Pipe Exothermic Weld Documents

New Pipe Exothermic Weld Documents

Functional Test of Reference Electrodes
Paragraph

3.3.1.2

3.3.2.1

3.3 .2 .1

3.3 .2 .2 
1.4 DELIVERY, STORAGE, AND HANDLING

1.4.1 See Section 01610 for general requirements.

1.5 FURNISHED EQUIPMENT

1.5.1 Cathodic protection rectifier and rectifier disconnect switch.

PART 2 - PRODUCTS

2.1 SUBSTITUTES

2.1.1 See Section 01630 for substitution approvals.

2.2 MATERIALS

2.2.1 Terminal Lugs: UL 486A, crimp type with ring tongue or spade lug with turned-up tips and insulated or noninsulated sleeve.

2.2.2 Compression Splice Connectors: UL 486C, for use with cable splice or cable tap, size as required.

2.2.3 Exothermic Fusion Weld Molds, Weld Metal, and Conductor Sleeve

2.2.3.1 Existing Pipe: Use a or $b$ below or approved substitute.

a. Low emission type mold, part number as shown in manufacturer's catalog based on conductor and pipe size, with electric starter, Erico Products "Cadweld" part number XLB971Al.

b. Standard type mold, part number as shown in manufacturer's catalog based on conductor and pipe size.

c. Weld metal: Low emission type as recommended by weld mold manufacturer with igniters and filters, or standard type "Cadwe $1 d "$ CA15.

d. Sleeve for use with No. 8 AWG conductor "Cadweld" No. CAB-133-1L.

e. Ensure manufacturer's installation and inspection procedures are provided with product. Procedures for "Cadweld" items are contained in Enrico Products "Installers and Inspectors Guide" (A-7D-01, 1985).

2.2.3.2 New Pipe: Use a or b below or approved substitute.

a. Low emission type mold with electric starter, Erico Products

"Cadweld" part No. XLLMCEGIH or approved substitute.

b. Standard type mold, "Cadweld" No. LMC, suffix based on size of conductor.

c. Weld metal: Low emission type, "Cadweld" No. XL, No. 90 with igniters and filters or standard type "Cadweld" No. 150.

d. Sleeve for use with No. 8 AWG conductor "Cadwe1d" No. CAB-133-1L. 
2.2.4 Pipe Ground Clamp Connector: UL 467, bronze, size as required.

2.2.5 Conduit: UL 651, schedule 40, for use with test stations.

2.2.6 Conductors: NEMA WC 5 stranded copper, $600 \mathrm{~V}$ rating, high molecular weight low density polyethylene, Type "CP." Size specified on the Drawings.

2.2.7 Conductor Splice Kit: Epoxy potting compound for encapsulating electrical wire splices buried underground. Scotchcast Brand, Catalog No. 82-B1 or 90-B1, or approved substitute.

2.2.8 Tape

2.2.8.1 Plastic insulating: UL 510, 3/4 inch wide.

2.2.8.2 Electrical splice insulating: UL 510 self-vulcanizing rubber, $3 / 4$ inch wide.

2.2.9 Plastic Sheet Marker: See Section 02225.

2.2.10 Wiremarkers: Tubular plastic, imprinted or typed with indelible ink, or plastic tags typed with indelible ink, fastened securely to wire with plastic wire ties.

\subsubsection{Equipment Nameplates}

2.2.11.1 Laminated plastic, 1/16-inch thick with white surface and black core.

2.2.11.2. Manufacturer's standard equipment nameplates may be used instead of those specified herein, if they display the required information, and are equivalent in quality and legibility. They need not be of the same material, or have the same form of imprinting.

\subsubsection{Nameplate Features}

a. Blanks: Select sizes appropriate for required characters and legends. Smooth edges and bevel 1/32-inch at 45 degrees.

b. Characters: Use $1 / 8$ to 5/16-inch characters for equipment names, and $3 / 32$ to $3 / 16$-inch characters for other information. Engrave sharp and clear. Refer to Section 13440, Figure 1.

c. Legends: Provide the following information, unless otherwise specified on the Drawings. For equipment names use the generic/ functional designations shown on Drawings.

1) Equipment name.

2) Manufacturer's identification. 
3) Manufacturer's model or assembly number.

4) Serial number.

2.2.11.4 Make sheet steel nameplates for equipment items that do not have surfaces suitable for attachment of plastic nameplates. Make nameplates when cylindrical surfaces of adequate size are available. When not, make nametags. Provide the information required above.

2.2.12 Cable Marker: Metal auger, flush with grade type, 17-inch long by 6-inch circular top with raised words "CATHODIC PROTECTION."

A.B. Chance Company, Catalog No. C554-0001 with installation tool, Catalog No. CWFA, or approved substitute.

2.2.13 Rigid Polyurethane Insulation: Sprayed foam-in-place 2-component system with minimum apparent overall density of $2.4 \mathrm{ib} / \mathrm{ft}^{3}$ in accordance with ASTM D 1622, approximately $95 \%$ closed cells in accordance with ASTM D 2856, water absorption approximately $0.051 \mathrm{~b} / \mathrm{ft}^{2}$ of surface area in accordance with ASTM D 2842, "k" Factor of approximately $0.15 \mathrm{Btu} \cdot \mathrm{in} / \mathrm{h} \cdot \mathrm{ft}^{2}$ at $75^{\circ} \mathrm{F}$ after aging 10 days at $140^{\circ} \mathrm{F}$ in accordance with ASTM C 177 or ASTM C 518, and minimum compressive strength of $451 \mathrm{~b} / \mathrm{in}^{2}$ parallel to rise and $27 \mathrm{ib} / \mathrm{in}^{2}$ perpendicular to rise when tested in accordance with ASTM D 1621. Polythane Systems, Incorporated urethane foam PSI-S200-25 systems, Polymer Development Laboratories, Inc 110 system, $3 \mathrm{lb} / \mathrm{ft}^{3}$ density, or Burtin Urethane Corporation "Buc 114, " $3 \mathrm{lb} / \mathrm{ft}^{3}$ density, or Universal Foam Systems, Inc. $2.81 \mathrm{~b} / \mathrm{ft}^{3}$ density.

2.2.14 Survey Marker Nameplate: Brass, 2-inch diameter, 5/8-inch by 2-1/2-inch shank, Surveyors Service Company, No. 2132 or approved substitute.

2.2.15 Sealant: FS TT-S-00230, clear RTV silicone.

2.2.16 Duct Sealing Compound

2.2.17 Rectifier 0i7: ASTM D 3487, Type II.

2.2.18 Liquid epoxy coating, Scotchkote 312 by $3 M$ Company or approved

ECN-121 substitute.

2.3 EQUIPMENT

2.3.1 Electrical equipment shall be PCB free.

2.3.2 Anodes: High silicon, chromium iron, 2-3/16 inch by 24 inch with No. 8 AWG stranded copper lead wire having high molecular weight, polyethylene (HMW PE) insulation. Lead length 20 feet. Anodes prepackaged in 8 inch by 48 inch steel canister with coke breeze backfi11. Durichlor $\mathbf{5 1}$ Anode Company, Type TAB.

2.3.3 Test station, high impact plastic housing, 9 terminal removable plastic terminal board, removable green cover, 7-3/4 inches in diameter, 5 inches high, Street Fink CP Test Station, manufactured by Cott Manufacturing Company or an approved substitute.

2.3.4 Permanent Underground Reference Electrode: Saturated gelled coppercopper sulfate with cotton bag and backfill mix, 30 year design life, 
EI Electrochemical Devices, Incorporated, EDI Model UL-CUG-LWO10 or an Page 166 approved substitute. Provide with 10 feet of No. 814 AWG or 7 arger ECT-525 HMW/PE insulated lead wire.

PART 3 - EXECUTION

3.1 PREPARATION

3.1.1 Field Measurements: Scale dimensions on the Drawings show desired and approximate location of equipment, actual locations, distances, and levels shall be governed by field conditions.

3.2 INSTALLATION

3.2.1 General

3.2.1.1 Perform work in accordance with NFPA 70, this specification, and Drawings.

3.2.1.2 Use appropriate calibrated special tools when installing devices for which special installation tools are recommended by manufacturer.

3.2.1.3 For excavation and backfill of soil, refer to Section 02225 .

3.2.2 Anodes: Install to depthof 7 -feet, \pm 6 inches. Install vertical anodes to depth of 7 feet ( \pm ) 6 inches and horizontal anodes to depth of 4 feet ( \pm ) 6 inches.

3.2.2.1 Use subsurface radar scanning machine to locate underground structures before augering. Hand auger holes for anodes that are located above or within 4 feet from underground tanks or structures. Power auger may be used for other anodes. Maximum auger size, 12 inches.

3.2.2.2 Lower anodes to bottom of holes by rope, and center within holes. Do not use lead wires to lower anodes. If temporary casings have been used, slowly withdraw casings while backfilling.

3.2.2.3 Backfill around anodes by sluicing with water.

3.2.2.4 Repair damaged anode lead wire insulation by encapsulation with epoxy resin using conductor splice kit.

3.2.2.5 Connect anode lead conductor to terminals in anode distribution box using compression type terminal lug.

3.2.3 Test Station: Install where shown on the Drawings. Stamp or engrave survey marker nameplate, using $3 / 16$ inch high (minimum) letters, TEST STATION T (numbers shown on the Drawings).

3.2.3.1 Identify each terminal in the test station with a nameplate. Engrave with the pipe designation or words "Reference Electrode." Character height $1 / 8$ inch. Secure nameplates to the terminal board by use of clear RTV silicone sealant.

3.2.3.2 Place the test station in the 6-inch PVC conduit and seal, as shown on the Drawings. 
3.2.3.3 A field sketch of each test station shall be made to show the configuration of new and existing pipes exposed by the excavation. This sketch shall also show the proposed connection location of pipe test conductors, the location of pipe bonding jumpers (if required by the Drawings) and the location of the reference electrode.

3.2.4 Permanent Underground Reference Electrode: (See paragraph 3.3.2.2 for testing before installation.)

3.2.4.1 Follow manufacturer's installation instructions. Do not allow the reference electrode to freeze.

3.2.4.2 Install reference electrode horizontally, 6 to 12 inches below the outer surface of pipe. For configuration of 2 parallel pipes, install in center of configuration, and not adjacent to or touching any pipelines. Construction Engineer will assist in positioning reference electrodes if required.

3.2.4.3 Bring lead wire to top of hole for termination in test station and install wire marker with words: REFERENCE ELECTRODE.

3.2.4.4 Repair damaged lead wire insulation using conductor splice kit.

3.2.4.5 Backfill in accordance with Section 02225 .

3.2.5 Pipe Test Conductors, Bonding Jumpers and Negative Return Cable

3.2.5.1 Existing pipes

a. Before work commences, ICF KH will verify usage of each pipe to which conductors are to be connected. If pipes are coated, cut window in coating large enough to accommodate exothermic weld mold. Wire brush each pipe and file to bright metal surface, free of oil and dirt. Make exothermic welds of conductors to metal pipe only in accordance with approved manufacturer's instructions, or use ground clamp connectors on nonprotected metal piping as directed by the Construction Engineer. If ground clamp connectors are used, coat connections using the same materials and installation methods as for exothermic welds. Install bonding jumpers across mechanical pipe joints (such as threaded couplings or bell and spigot connections) that have test conductors attached, with No. 4 AWG copper wire and exothermic weld. Extend bonds to a point 30 feet from the nearest anode.

b. Inspect exothermic welds in accordance with manufacturer's instructions. If weld fails, make another weld at least 12 inches from previous we Td attempt and inspect.

c. At pipe-conection, apply-ełeap-RFV-sificoneseatant-on-exposed copper wipe, wett material and bared pipe.-Orerlap sealant on coppep wire insulation, on any pipe coating-op-on-bared pipe-a-minimum-of I inch. Smoth-seatant by-hand. At pipe connection, apply liquid epoxy coating on exposed copper wire, weld material and bared pipe. overlap coating on any pipe coating or on bared pipe a minimum of 1 inch. Wrap exposed copper conductors with electrical splice insulating tape and plastic insulating tape.

d. Conductor size specified on the Drawings.

ITWRS \SPEC\W320C7.WP5 $\quad 16640-7$

$W-320-C 7$

As Built Rev 1 
e. Repair damaged pipe test conductor insulation with 2 hal $f-1$ apped 2536, Rev. 0 layers of electrical splice insulating tape and 2 half-lapped layers of Page 168 plastic insulating tape.

f. Make repairs of foam insulation on pipe with sprayed polyurethane as follows.

1) Install in accordance with manufacturer's recommended procedure.

2) Side-wall retainer may be used to assure uniform width and height of sprayed insulation. Obtain approval of retainer wall installation and materials from Construction Engineer.

3) Repair opening in flexible duct liner with plastic sheet material similar to existing.

g. Identify the end of each conductor using specified wiremarker with typewritten or imprinted pipe number to which conductor is connected. Label pipe test conductors connected to unidentifiable pipes with pipe size followed by words "UNKNOWN."

h. Use terminal lugs for conductor terminations in test station.

i. Backfill in accordance with Section 02225 .

\subsubsection{New pipes}

a. Wire brush each pipe conductor standoff bracket and file to bright metal surface, free of 0 il and dirt. Make exothermic weld of conductors to standoff bracket in accordance with approved manufacturer's instructions.

b. Inspect exothermic welds in accordance with manufacturer's instructions. If weld fails, make another weld at least 12 inches from previous weld attempt and inspect.

c. Apply elear RTV siticone-sealant on all exposed copper wipe, weld material and bared conductor standoff-bracket. Over7ap sealant on copper-wipe-insulation, on any pipe-coating op on bared stuface-a minimum of 1 -inch.-Smooth seatant by hand. Apply liquid epoxy coating on exposed copper wire, weld material and bared conductor standoff bracket. Overlap coating on any pipe coating or on bared surface a minimum of 1 inch. Wrap exposed copper conductors with electrical splice insulating tape and plastic insulating tape.

d. Conductor size specified on Drawings.

e. Repair damaged pipe test conductor insulation with 2 half-lapped layers of electrical splice insulating tape and 2 half-lapped layers of plastic insulating tape.

f. Identify the end of each conductor using specified wiremarker with typewritten or imprinted pipe number to which conductor is connected.

g. Use terminal lugs for conductor terminations in test station. 
h. Backfill in accordance with Section 02225 . 
3.2.6 Conductors: Install anode lead, and negative return cable as follows: Page 170

3.2.6.1 Place in trenches prepared in accordance with the Drawings.

3.2.6.2 Identify cables, using specified wiremarkers, at terminations except at inaccessible underground locations. Nomenclature shall be as shown on Drawings.

3.2.6.3 Terminate anode lead cables at anode distribution box. Use terminal lugs for conductor terminations. Terminate negative return cable as shown on the Drawings.

3.2.6.4 Repair damaged cable insulation by using conductor splice kit.

3.2.6.5 Cover cable ends with plastic electrical tape until ready for termination.

3.2.6.6 Cable marker: Install as noted on Drawings.

3.2.7 Rectifier: Attach to concrete pad with concrete expansion anchors as shown on the Drawings.

3.2.7.1 Terminate ac wiring on rectifier input terminals and dc wiring on rectifier output terminals.

3.2.7.2 Fill rectifier with specified oil to level shown on rectifier case.

$3.3 \quad$ FIELD QUALITY CONTROL

3.3.1 Continuity Testing

3.3.1.1 Furnish instruments and equipment required to conduct testing.

3.3.1.2 Test wiring for continuity, 1 ohm or less is acceptable. Record results.

\subsubsection{Exothermic Welds}

3.3.2.1 Document exothermic welds of conductors to new and existing pipe. Include following:

a. Pipe test conductor: Identification of pipe connected to and associated test station.

b. Bonding jumper: Identification of each pipe to which connected and general location.

c. Negative return cable: Identification of pipe to which connected.

d. Verification of a weld that is in compliance with manufacturer's installation and inspection requirements. 
a. Before functional test, conduct an accuracy test of $2 \mathrm{MC} \mathrm{Miller}$ Model RE-5 portable reference electrodes as follows:

1) Place end of 2 portable reference electrodes in a plastic bucket filled with tap water. Using a digital voltmeter, measure voltage between the electrodes and verify that value is less than $20 \mathrm{mV}$.

2) Place permanent reference electrodes being tested in a plastic bucket filled with tap water. Soak electrodes for at least 3 hours.

3) Place end of I portable reference electrode, that has been tested for accuracy in water, in the plastic bucket or touch end of portable reference electrode to outside bag of permanent reference electrode.

4) Using a digital voltmeter, measure voltage between the permanent reference electrode and the portable reference electrode. Verify that value is less than $50 \mathrm{mV}$. If difference is equal to or greater than $50 \mathrm{mV}$, discard and replace permanent reference electrode with another and repeat test.

5) Record voltage between permanent reference electrode and portable reference electrode on Data Sheet (Form KEH 2255) and submit completed form to Construction Engineer.

3.3.2.3 Perform Acceptance Test Procedure (ATP) WHC-SD-W320-ATP-002. 


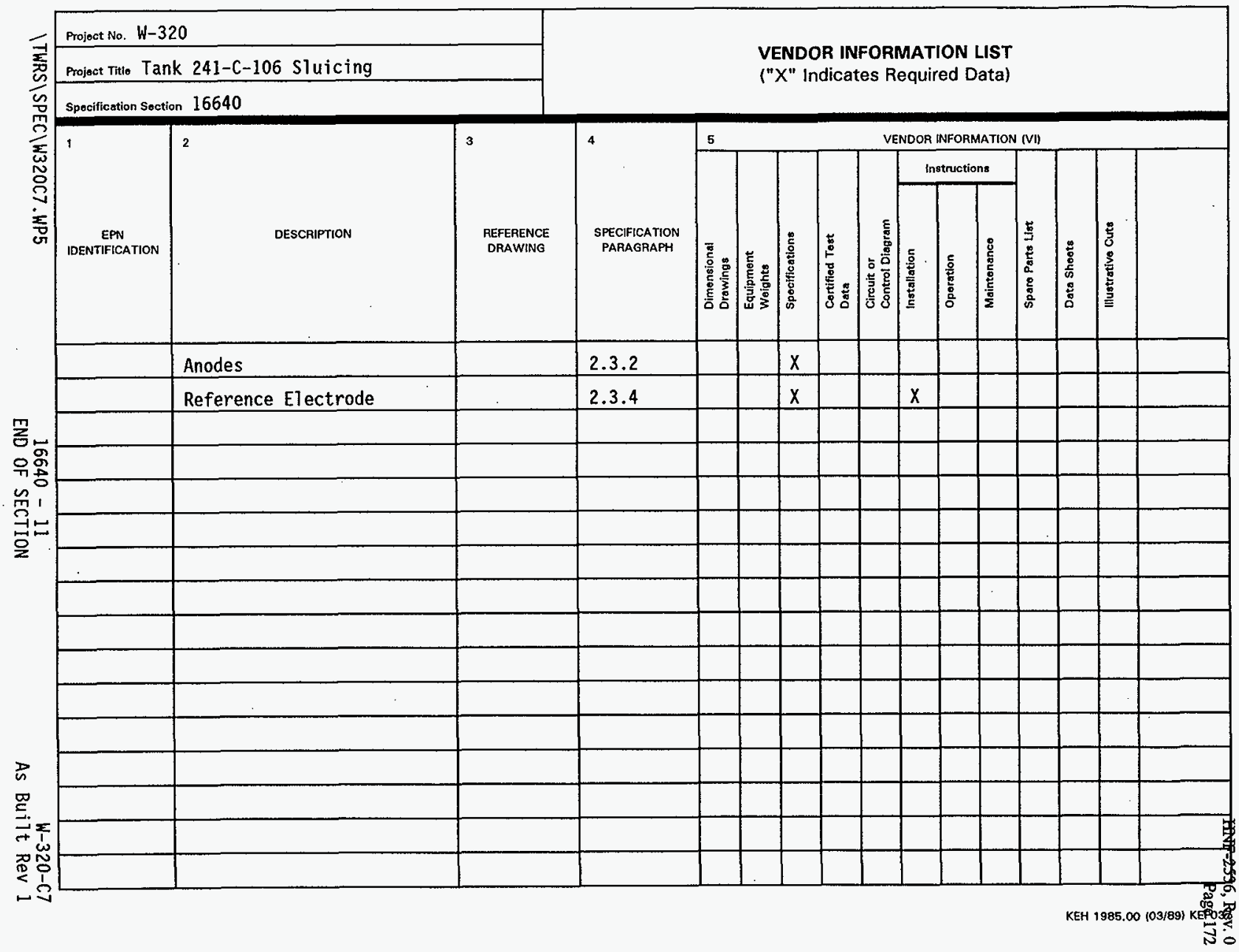




\section{DISTRIBUTION SHEET}

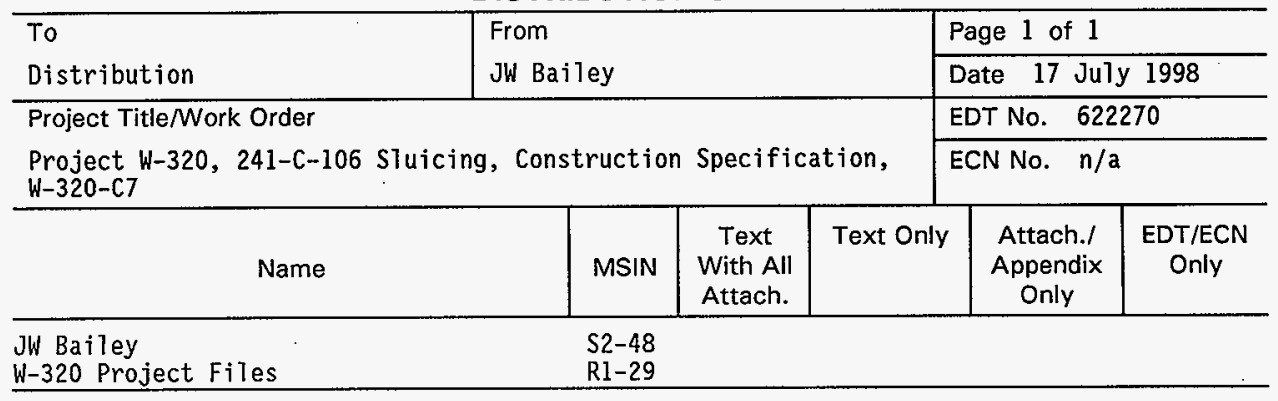

